\title{
Condition Monitoring Technology for Civil Works Lock Operating Machinery
}

Andrew Schimpf, L.D. Stephenson, and Ashok Kumar

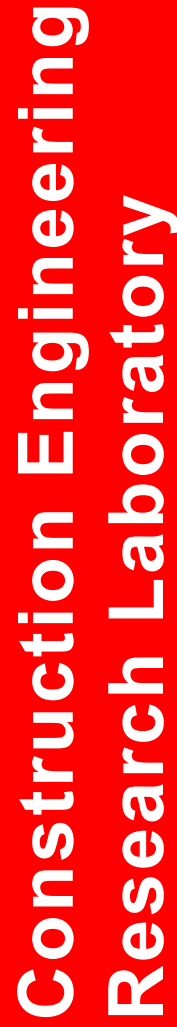





\section{Condition Monitoring Technology for Civil Works Lock Operating Machinery}

Andrew Schimpf

US Army Corps of Engineers

St. Louis District

St. Louis, MO 63103-2833

L.D. Stephenson and Ashok Kumar

Construction Engineering Research Laboratory

PO Box 9005

Champaign, IL 61826-9005

Final Report

Approved for public release; distribution is unlimited.

Prepared for US Army Corps of Engineers

Washington, DC 20314-1000 
ABSTRACT: This pilot project successfully demonstrated condition monitoring and predictive maintenance at Port Allen Lock by installation of programmable logic controllers (PLCs) and field sensors for lock operating machinery and structural components at one of the lock's gate leafs. The need to continue such research as a more complete condition monitoring program at Port Allen Lock, and then as a part of an overall computerized control system has also been demonstrated. This study achieved the following goals:

1. It was shown that a PLC control system can be used for high-speed collection of the data from instrumentation transducers used to monitor the condition of lock equipment. It was also shown that the funds used to provide such a condition monitoring system can overlap significantly with those used to upgrade the control system of a lock and dam. Thus, one project can actually help justify the other instead of competing for the same funds.

2. This project showed the accuracy and real-time qualities of the data collected by the PLC system.

3. The data collected can be used onsite for short-term purposes such as static warnings as well as being stored and trended for long-term prediction of maintenance based on the changes to operating machinery conditions.

4. The data can be exported in spreadsheet database form for use with other programs such as Microsoft ${ }^{\circledR}$ Excel. SQL Server and OPC data collection platforms are also compatible with this type of data acquisition making it flexible enough to use for virtually any application.

The project demonstrated on a small scale that the possibility of future cost savings might be attainable from such instrumentation if applied on a global scale.

DISCLAIMER: The contents of this report are not to be used for advertising, publication, or promotional purposes.

Citation of trade names does not constitute an official endorsement or approval of the use of such commercial products.

All product names and trademarks cited are the property of their respective owners. The findings of this report are not to be construed as an official Department of the Army position unless so designated by other authorized documents.

DESTROY THIS REPORT WHEN IT IS NO LONGER NEEDED. DO NOT RETURN IT TO THE ORIGINATOR. 


\section{Contents}

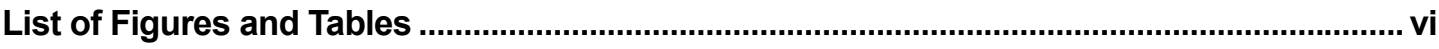

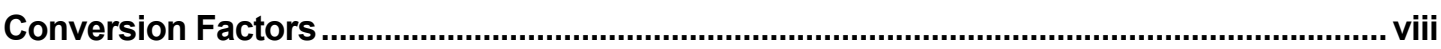

Preface

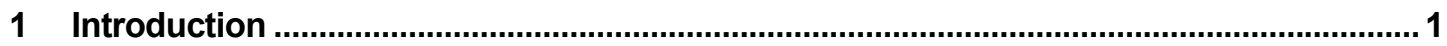

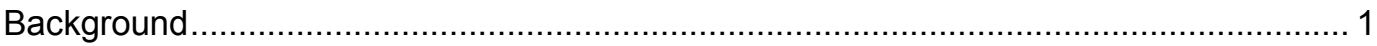

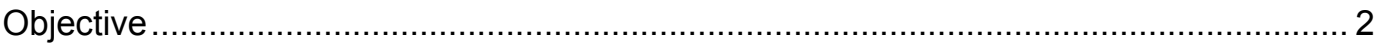

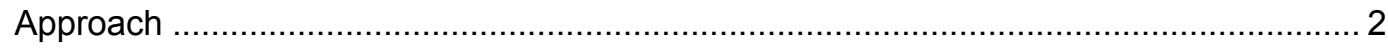

Scope

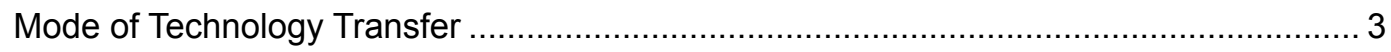

2 Operation, Maintenance, and Condition Monitoring...................................................... 4

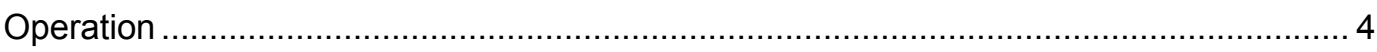

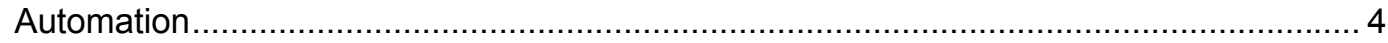

Lock

Dam

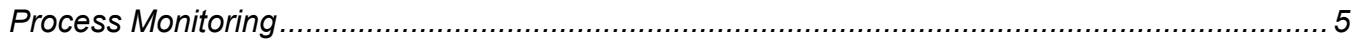

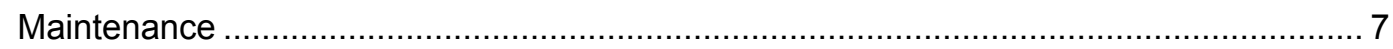

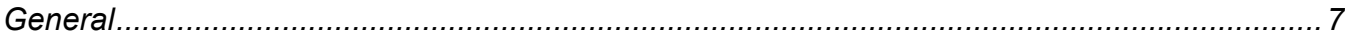

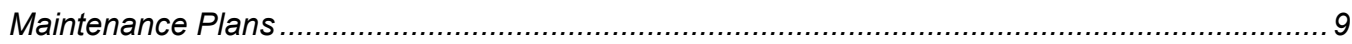

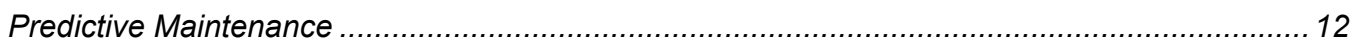

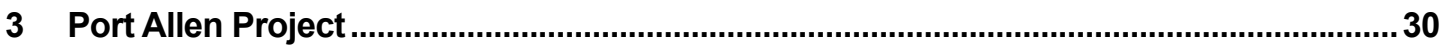

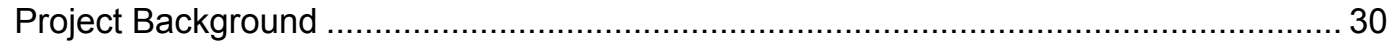

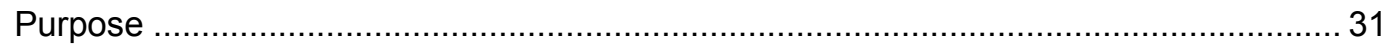

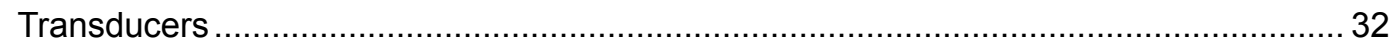

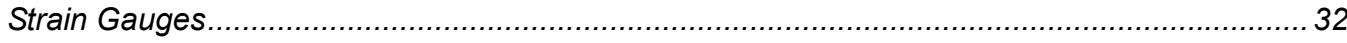

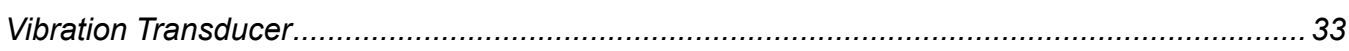

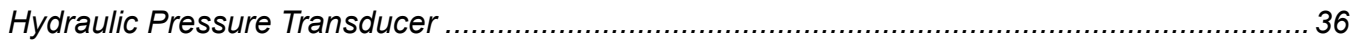

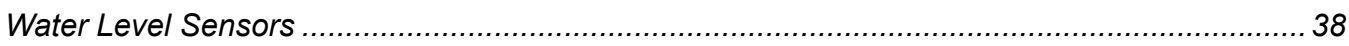

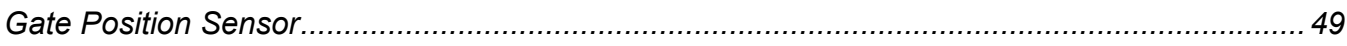

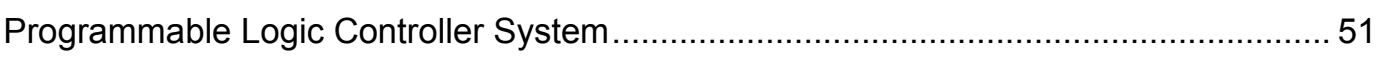

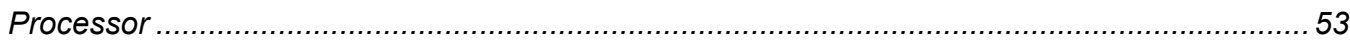

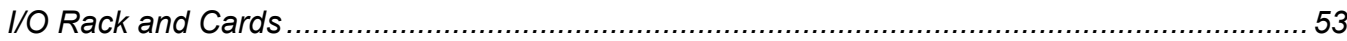




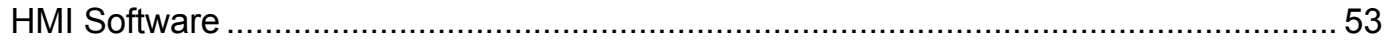

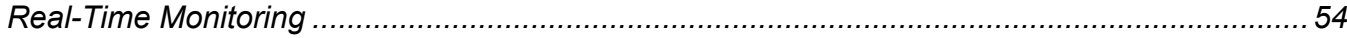

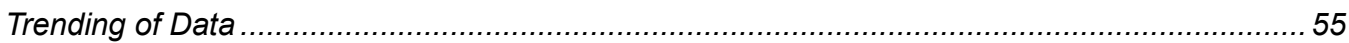

4 Conclusions and Recommendations

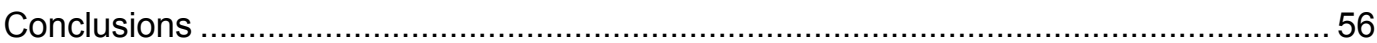

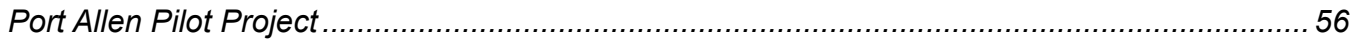

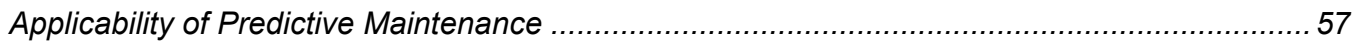

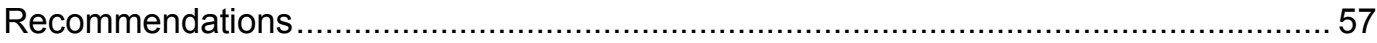

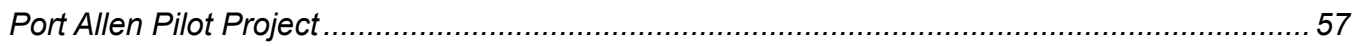

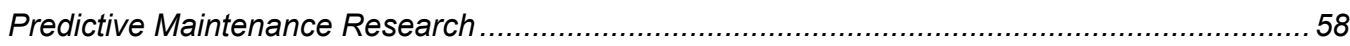

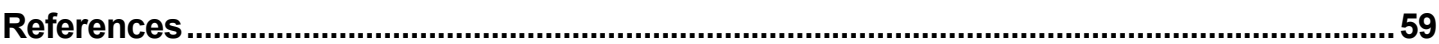

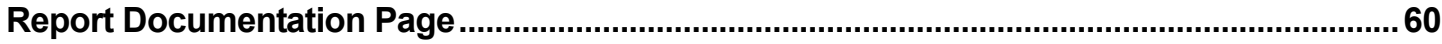




\section{List of Figures and Tables}

\section{Figures}

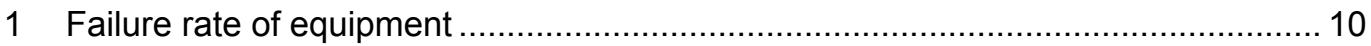

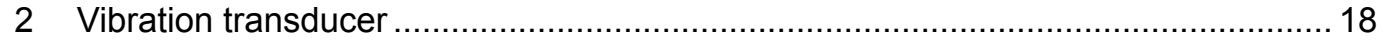

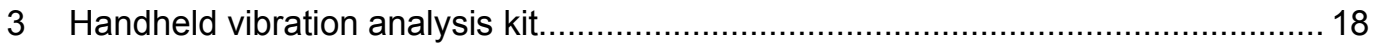

4 Time domain showing peak and RMS values of vibration amplitude ..................... 18

5 FFT produces the vibration frequency spectrum ................................................. 19

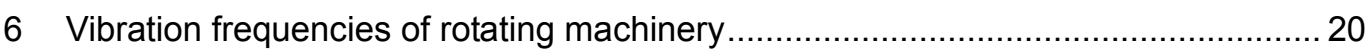

7 Long-term trending of the frequency spectrum can predict required

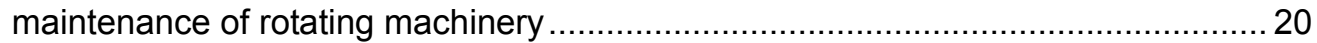

8 Motor contactor; presence of heat caused by current imbalance not evident to

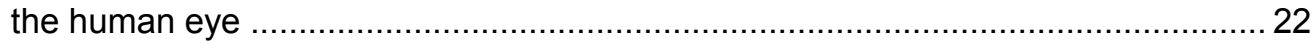

9 Infrared thermographic image of the same motor contactor shows a problem with excessive current in one phase ................................................................. 22

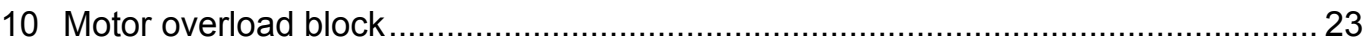

11 Thermographic picture showing overload on middle phase .................................... 23

12 Panelboard appears to be in proper operating condition.......................................... 24

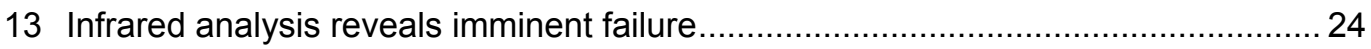

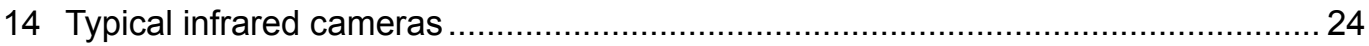

15 Vibrating wire strain gauge

16 Electric motor with built-in condition monitoring sensors .................................... 27

17 Map showing position and role of Port Allen Lock in the GIWW ............................. 31

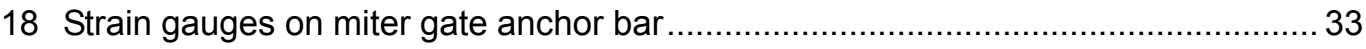

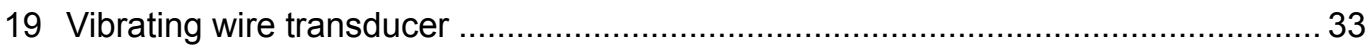

20 Port Allen operating screen showing the strain in the gate anchor .......................... 33

21 Vibration / accelerometer transducer on miter gate motor....................................... 34

22 Vibration / accelerometer transducer on miter gate pump ..................................... 34

23 Port Allen operating screen showing the vibration of the pump and motor .............. 36

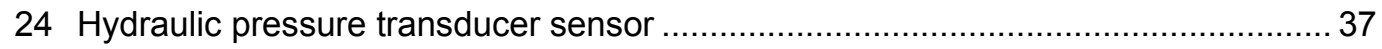

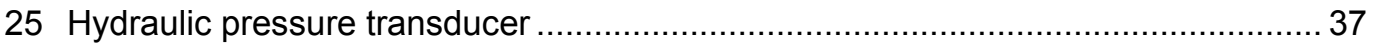

26 Port Allen machinery screen showing hydraulic pressure transducer signals .......... 39

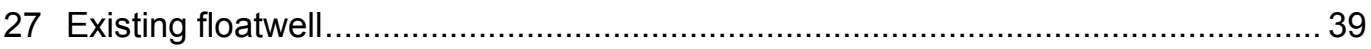


28 Existing river / canal gauge readout on control console no. 1 .............................. 40

29 Handar data collection platform at Port Allen Lock .............................................. 41

30 Screen capture showing weather data collection platform information..................... 41

31 Web browser screen of the PLC web server showing weather data ....................... 42

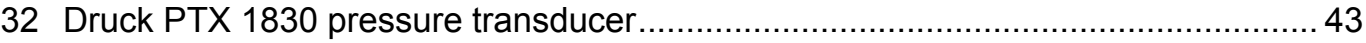

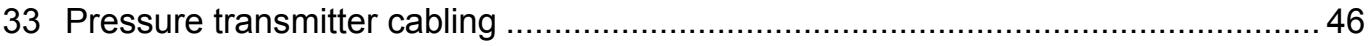

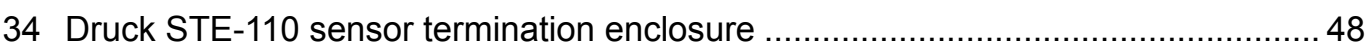

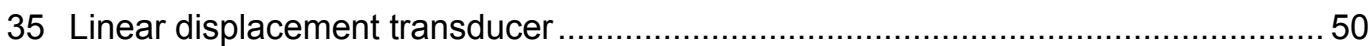

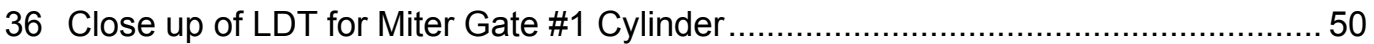

37 Port Allen operating screen showing the position of the miter gate ......................... 51

38 PLC block diagram designed for Port Allen ...................................................... 52

39 PLC enclosure in spreader room \#1 showing the I/O rack .....................................5 52

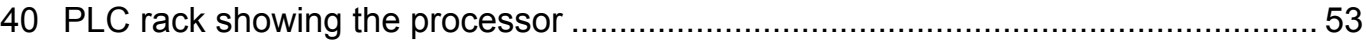

41 Screen capture of a chart showing various monitored parameters ......................... 55

\section{Tables}

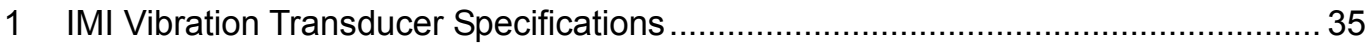

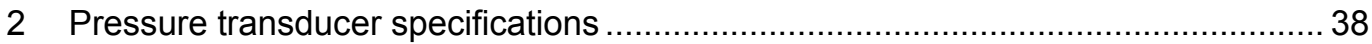

3 Specifications for the Druck Submersible Pressure Transducer .............................. 43

4 Druck STE-110 sensor termination enclosure specifications................................... 48 


\section{Conversion Factors}

Non-SI units of measurement used in this report can be converted to SI units as follows:

\begin{tabular}{|l|c|l|}
\hline Multiply & By & To Obtain \\
\hline degrees Fahrenheit & $(5 / 9) \times\left({ }^{\circ} \mathrm{F}-32\right)$ & degrees Celsius \\
\hline degrees Fahrenheit & $(5 / 9) \times\left({ }^{\circ} \mathrm{F}-32\right)+273.15$ & kelvins \\
\hline feet & 0.3048 & meters \\
\hline inches & 0.0254 & meters \\
\hline miles (U.S. statute) & 1.609347 & kilometers \\
\hline pounds (mass) & 0.4535924 & kilograms \\
\hline
\end{tabular}




\section{Preface}

The work described in this report was authorized by Headquarters, U.S. Army Corps of Engineers (HQUSACE) as part of the Innovations for Navigation Projects (INP) Research Program. This study was conducted under Work Unit 33125, "Lock Gate Operating Controls and Equipment" managed at the U.S. Army Engineer Research and Development Center (ERDC), Vicksburg, MS. Dr. Tony C. Liu was the INP Coordinator at the Directorate of Research and Development, HQUSACE. Don Dressler, HQUSACE, was the Research Area Coordinator, and the INP Program Monitor was Dan Casapulla, CEMP-ET. Dr. Stan Woodson, ERDC Geotechnical and Structures Laboratory (GSL), was the INP Program Manager.

The work was performed by the Materials and Structures Branch (CF-M) of the Facilities Division (CF), Construction Engineering Research Laboratory (CERL). Andrew Schimpf is an Electrical Engineer in the Electrical/Mechanical (E/M) Design Branch at the Corps of Engineers St. Louis District. The CERL Principal Investigator was Dr. Ashok Kumar. Special appreciation is due the St. Louis District E/M Design Branch and the Port Allen Lock operating and maintenance staff for their efforts on behalf of this work. The technical editor was Linda L. Wheatley, Information Technology Laboratory - Champaign. Martin Savoie is Chief, CF-M, and L. Michael Golish is Chief, CF. The Technical Director of the Facilities Acquisition and Revitalization business area is Dr. Paul Howdyshell. The Director of CERL is Dr. Alan W. Moore.

CERL is an element of the U.S. Army Engineer Research and Development Center (ERDC), U.S. Army Corps of Engineers. The Commander and Executive Director of ERDC is COL James R. Rowan, and the Director of ERDC is Dr. James R. Houston. 


\section{Introduction}

\section{Background}

The U.S. Army Corps of Engineers operates 278 locks in the United States, and lock operating machinery must be properly maintained to prevent lock closures or reduced efficiency. Unscheduled machinery maintenance can be very costly and disruptive. Lock and dam components are subject to failure resulting from excessive wear of components from routine use or from excessive loading, as may occur when large debris obstructs the proper movement of the gate. The excessive loads and wear may eventually result in irreparable damage to the machinery. Also, critical components used in gates are subject to fatigue and wear. In some cases, fatigue of these components can lead to eventual loss of a gate if the problem is not corrected.

In the Great Lakes and Ohio River Division, scheduled lock closures of 1-10 days have trended upward, from 10 closures in 1999 to 60 closures in 2002, and the backlog of maintenance is increasing. Other Corps Divisions likely observe this trend as well. Typically, dewatering can last 10-45 days and costs about $\$ 1.5$ million.

Condition monitoring and predictive maintenance technology can help reduce unscheduled maintenance, downtime, and associated costs. Condition monitoring is a system to enhance efficiency, safety, and reliability of lock operations. It uses programmable logic controllers (PLCs) and personal computers (PCs) that provide real-time condition indicators of the lock machinery.

Predictive maintenance involves condition monitoring of equipment, and a methodology for the performance of maintenance only when there is objective evidence of need, as part of an overall maintenance effort to prevent unscheduled downtime from failure and predict the opportune time for maintenance. Currently, periodic inspections are conducted to allow for detailed observations of equipment and critical structural steel components of gates. A condition monitoring system for lock gates should also include fatigue monitoring of fracturecritical components, such as lock gate anchor bars, in addition to monitoring the electrical and mechanical parameters of the operating machinery. 
These advanced technologies may find their most useful application at single locks, where no auxiliary locks are available for lock traffic during unscheduled closures. There is a need to develop a low-cost condition monitoring and predictive maintenance system and evaluate its long-term cost benefits.

\section{Objective}

The objective of this work was to develop and implement condition monitoring and predictive maintenance technology as a pilot project at a Corps of Engineers lock, including remote monitoring and display capabilities.

\section{Approach}

The Port Allen Lock near Baton Rouge, LA, in the New Orleans District, was selected as a pilot project to demonstrate the capabilities of condition monitoring and predictive maintenance technology. This navigation and flood control project is at the Mississippi River entrance to the Morgan City Canal portion of the Gulf Intracoastal Waterway (GIWW). Port Allen Lock completes around 8,000 lockages annually and is considered extremely vital to the navigation interests in this country as well as to local flood protection. As part of this research, the following condition monitoring type sensors were installed on the number one (North River End) miter gate at Port Allen Lock: four vibrating wire strain gauges, four hydraulic pressure transducers, two vibration sensors, a gate position transducer, river, chamber and canal water level sensors, and temperature, humidity, wind speed, wind direction, and rainfall gauges. The data from these devices are collected by a standard PLC system and displayed locally via a $\mathrm{Hu}$ man/Machine Interface (HMI) software package. The data are also stored and trended for long-term comparison as the operating signature curve of the gate changes. All data are date and time stamped for comparison purposes. The project demonstrates the collection and accuracy of the data and its applicability in the protection and maintenance of the gate and its machinery. While no specific abnormalities were found in the gate machinery, a good operating curve has been established for the parameters measured, and future problems will be found early enough to schedule maintenance with minimal disturbance to navigation.

Gauges were mounted on the primary and secondary anchor bars to measure the strain in the gate anchoring system as the gate is moved through its cycles. The hydraulic pressure transducers were placed at the main system pump, the pilot pressure line, and the rod and cap end of the operating cylinder. The vibration 
transducers were mounted one each on the motor and the hydraulic pump. These parameters are trended with the movement of the gate (from the gate position transducer) and the changing of the water levels and temperature conditions.

\section{Scope}

This report is the result of considerable research, study, experimentation, and fieldwork on the potential applications of condition monitoring and predictive maintenance at Corps of Engineers locks. Due to the limited nature in which the technology has been applied at Port Allen Lock, the findings of this report cannot be considered as 100 percent complete; however, the research has demonstrated that a global approach to the concept of condition monitoring can have significant savings in maintenance and down time at Corps projects.

\section{Mode of Technology Transfer}

It is recommended that the results of this investigation be incorporated in Corps of Engineers guidance, Engineer Manual (EM)-1110-2-2610, "Gate Operating Equipment for Navigation Locks and Spillways." 


\section{Operation, Maintenance, and Condition Monitoring}

\section{Operation}

The operation of a Corps of Engineers lock and dam falls directly under the responsibility of the onsite lockmaster. In executing a project's mission, however, everyone connected with it has a responsibility to improve the safety and increase the efficiency of the project. The background included in this chapter will discuss the maintenance of projects and some ideas for improving the efficiency of how maintenance is performed on them. One means for improvement is the use of predictive maintenance and the electronic monitoring of equipment condition in real time. The operation of the project is also a parameter that is suited for condition monitoring and will be discussed herein. In all cases, projects should be operated within the guidelines provided in the project operations and maintenance (O\&M) manual. This manual should be continually updated to reflect all changes in operating procedures at the project including those resulting from or made safer by automation.

\section{Automation}

Automation of a lock and dam project can range from the simple manual startauto stop of a single gate to the complete lockage and recording of a vessel log without operator intervention. The appropriate level of automation for a project is a judgment made by all involved with the project. As a minimum, new and electrically rehabbed projects should be operated with a PLC control system and HMI computer interface as discussed in Chapter 4 of EM-1110-2-2610. The possibilities of automation as discussed herein will be logical additions to such a system as the operating personnel become confident with a new way of operating. The major objection to automation at locks and dams is the removal of personnel from the process. While it is true that the PLC can never be programmed to monitor everything as well as a trained and alert eye, it can be programmed to continually monitor the process in great detail, and learn from its mistakes. And failures do occur at locks where operators are watching the equipment. 


\section{Lock}

Most locks are good candidates for automatic operation. Time-tested safeguards can be put in place to allow a single operator to perform multiple duties, even maintenance duties, while the PLC takes over control of the lock(s) once a lockage cycle and direction is initiated. This is very successful at locks in Europe and can be used here as well. Careful documentation of the cause and surrounding circumstances of a failure and/or accident is important in order to prevent its reoccurrence. This is already happening at some Corps locks that have PLC control systems. When a problem occurs, revisions are made to the PLC program to prevent the problem from happening again and to create an alarm condition to alert operators of impending failures. Rather than retraining the operators, lock maintenance personnel are "retraining" the PLC. This documentation is important when new systems are programmed. If this is happening already, why not program the PLC with the responsibility from the beginning? The Corps of Engineers has maintained that human operators are necessary in the control room for safety. The use of PLCs is now being explored, however, to assist in relieving the operators from "watching" for the symptoms of impending problems, thus enhancing safety, efficiency, and reliability.

\section{Dam}

A PLC can be programmed with the information or operating criteria required for automatic pool control and regulation. Pool, tailwater, rainfall forecasts, lock approach outdraft conditions, flow, and other parameters can be programmed as algorithms in the PLC to automate the function of the dam gates. Again, this automation can free lock operators to perform maintenance-type duties or to observe the lock operation for enhanced safety. It can also maximize the operational efficiency of multiple dams on a river system.

\section{Process Monitoring}

To improve the effectiveness of the project, the process of locking a boat and operating a dam must be examined for inherent inefficiencies. The PLC is an excellent tool for monitoring such parameters, and it never forgets to log movement of equipment, or accurately record gate operating times and other parameters. Inefficiencies will become evident when such data are closely monitored.

\section{Approach times}

The time it takes for a vessel to approach the lock may seem to be based entirely upon the vessel operator, but the truth may be that the operation of the lock and 
dam has much to do with the length of time required for this process. Circumstances such as traffic light signaling, traffic queuing, outdraft, operation of the dam, inefficiencies in direction change, operation of adjacent locks, pleasure craft, and visibility may all cause a potential delay to traffic. Only careful monitoring of the process, along with these and other circumstances surrounding it, will present useful data to operations management. These data can be used to improve the operation of the project. The amount of improvement will vary by project, but the information gathered will be useful knowledge to have and much of it will come for a one-time set up cost of programming the PLC to monitor particular portions of project operations.

\section{Gate movement}

At most locks that use a PLC for operational control, the system initiates gate movement only after being issued operator commands (through pushbuttons or HMI). Inefficiencies can exist due to delays in the times the operator gives these commands. The PLC can be programmed to automate the process and remove these delays. There are few situations that can occur during the process for which the PLC cannot be programmed to provide safe and efficient operation. These infrequent procedures require manual intervention, which should always be an override to an automated process.

\section{Filling and emptying}

Like gate movement, at most locks the filling and emptying of the lock chamber is a process in which the PLC must wait for the judgment of the operator. In most cases the operator is basing his/her decision on parameters that the PLC is already monitoring (i.e., gate and valve interlocks, water levels). There are a number of different reasons for which the filling and emptying process of a lock chamber must be varied at different projects. These include: high lift, pleasure craft, set-over lockages, empty barge cuts, discharge velocity, over filling/emptying, and open-river conditions. These conditions can be programmed into the PLC to automate the process for enhanced efficiency, and for safety in filling and emptying the lock chamber.

\section{Ice and debris removal}

During cold weather, operators often must stop the procedure of locking river traffic in order to remove ice and debris from gate recesses. There is often no documented procedure for doing this. Each operator uses their own methods, and different site conditions may require different procedures. Monitoring the conditions present while different operations are used to pass or remove ice from 
behind gates may, with analysis of the data, reveal the most efficient way of performing this operation for the various conditions that can occur when ice is present.

\section{Maintenance}

This portion of the background information provides guidelines and ideas for design and operation engineers in an effort to use technology to control the increasing cost of maintaining lock and dam projects. Not all of these concepts are necessarily appropriate or immediately applicable to all locks. With dwindling O\&M budgets and aging projects, however, new ideas and practices must be adopted to reduce the cost and increase the efficiency of maintenance practices at Corps of Engineers projects. Design engineers should take every opportunity to "design out" maintenance on a project, regardless of its size. Many of the ideas presented herein are relatively inexpensive to include in a project if they are incorporated early in the design process. At times the concepts discussed in this report may appear to be in a rough design format. The intent is to guide and inspire a designer as they do research and engineering for their specific project, not to become a design document.

\section{General}

It is estimated that, on average, production plants using mechanical/electrical machinery in their process spend anywhere from 15-40 percent of their operating budgets on the maintenance of this equipment. Recent surveys of maintenance management effectiveness indicate that roughly one-third of this expenditure is wasted (Mobley 1990). The primary cause for the waste is lack of factual, real-time data justifying the actual need for maintenance or repair of machinery, equipment, and systems. The average annual cost to maintain a major Corps of Engineers lock and dam project is roughly \$500,000 (Melvin Price Locks and Dam, St. Louis District, Fiscal Year 2000 [FY00]). Considering that many smaller locks have similar machinery and maintenance staffs and perform similar preventive maintenance on regular schedules, it can be assumed that this cost is not too far from the national average. The estimate for the 278 Corps of Engineers-operated locks in the United States would then indicate that the organization spends more than $\$ 100,000,000$ nationwide performing direct maintenance on the mechanical/electrical equipment and machinery at the projects. Because a profit margin is not considered for Corps projects, closure time (lost production) is not included in the overall cost of maintenance. In private industry, this is a large portion of the cost of maintenance. It can be assumed that 
navigation interests lose considerable money due to unscheduled downtime for maintenance and repair (M\&R) of Corps lock equipment.

Traditionally, the Corps of Engineers has treated maintenance as a necessary evil. Years ago there was probably little that could be done to reduce the cost of maintenance at these facilities. With the rapidly growing electronics field, however, the technology now exists to monitor in real time the condition of various pieces of equipment, the failure of which highly impacts the operational efficiency of a project. Combine this technology with the development of meaningful software databases and advanced Computerized Maintenance Management Systems (CMMS), and it is possible that lock maintenance costs can be improved. If significant funds can be saved using technology and engineering, and the efficiency and safety of lock and dam projects can be improved, this area should be investigated. Design engineers will be asked to take the lead in this endeavor by developing a fundamental knowledge of these concepts and addressing the individual needs of lock and dam applications.

Industry management surveys indicate that average productivity of maintenance personnel is between 25 and 35 percent, meaning that the average maintenance craftsman spends less than 4 hours (per 8-hr shift) producing a product (or service) that contributes to the efficiency of the project. Analysis of the industry surveys and reference to the following bulleted list indicate that this loss of productive time is fairly typical of many projects. These conditions may also occur at Corps lock and dam projects:

- Multiple trips to suppliers for materials

- Return trips for the proper tools to do the job

- Trips to the job site to see what is required

- Parts not in stock; wait for delivery from vendor

- Incomplete planning and communication, proper elements not represented

- Poor craft coordination

- Waiting for drawings from engineering

- Looking for supervisor to get instructions or answers to questions

- Waiting for the next work assignment for the next job

- Insufficient quantity and/or wrong type of workers scheduled for job

- Waiting for equipment to be shut down

- Being pulled off job because of unscheduled emergency work in other areas of the project.

On the average, $2 \mathrm{hr}$ of truly productive time is lost whenever a craftsman is taken off a job unexpectedly because of emergency higher priority work in an- 
other part of the project. No matter how small or large a maintenance crew, an effective maintenance control plan can help perform the work more efficiently.

\section{Maintenance Plans}

There are four types of maintenance plans considered for this discussion: Failure Directed, Time-Directed, Reliability/Performance-Directed, and ConditionDirected maintenance. The major electrical and mechanical components of a lock and dam can be categorized under these types of maintenance programs. Throughout the following discussions, the analogy of an automobile is used to illustrate certain concepts, because most people can easily relate to the care and maintenance of an automobile.

\section{Failure-directed maintenance}

Many of our projects have equipment that is maintained on a failure-directed basis. A component is simply replaced when it fails. For these components, spare parts must be kept in inventory. The headlight on a car, for example, does not easily lend itself to preventive/predictive maintenance. Because there are two, if not four, headlights on a car, the failure of one light does not render the car inoperable. Also the headlights are only required for nighttime operation. In addition, the "downtime" required to replace a headlight is minimal. Therefore, failure-directed maintenance is probably a reasonable approach for the headlights on most cars. Some lock and dam components lend themselves to this type of maintenance. A good maintenance program would limit components on the failure-directed maintenance plan to those that, like the automobile headlight, fail without warning, do not lend themselves to condition monitoring, have relatively low material and labor cost to repair or replace, 20and have long shelf life with low inventory costs to maintain adequate spares. Failure-directed maintenance items also should have relatively low consequence in regard to the capacity or safe operation of the project.

On the surface, a failure-directed maintenance program seems to be the least expensive because it is, in effect, a no maintenance program. It is actually the most expensive. The high costs of a spare parts inventory, overtime for unscheduled repairs, long downtime, and low production outweigh the savings from not doing preventive maintenance. In addition, it leads to a vicious reactionary cycle of unplanned M\&R costs, making it difficult to sufficiently fund that project and others. Analysis of maintenance costs performed by independent studies indicates that a repair made in this fashion costs about three times that of the same repair or maintenance performed in a scheduled preventive mode. This 
estimate does not consider downtime costs to the navigation interests, because the Corps only tracks direct costs to repair the failure.

\section{Time-directed maintenance (preventive maintenance)}

The most common plan used in private industrial plants today is time-directed preventive maintenance. Under such a plan, each piece of equipment receives maintenance regularly regardless of its condition or use. The maintenance interval is usually dictated by published manufacturer information or by experience on the project under the assumed use. The equivalent illustration using the maintenance of an automobile would be to change the oil in a car every 2 months on a regular plan. Again, there are some items of equipment at a lock and dam for which this type of maintenance is suited, while other equipment would be maintained much too often under such a plan, resulting in excessive cost. In general, this type of plan should be limited to equipment that fails without warning, has relatively high material and labor cost to repair or replace, and may or may not have high consequence in regard to the capacity or safe operation of the project. Equipment that fails without warning is very difficult to monitor using condition monitoring as described later in this chapter. The statistical life of normal equipment generally shows high probability of failure immediately following installation (due to improper installation) followed by a relatively low failure rate and then high probability of failure again near the end of its mean time between failure (MTBF) cycle. This results in the traditional "bathtub" curve as shown in Figure 1.

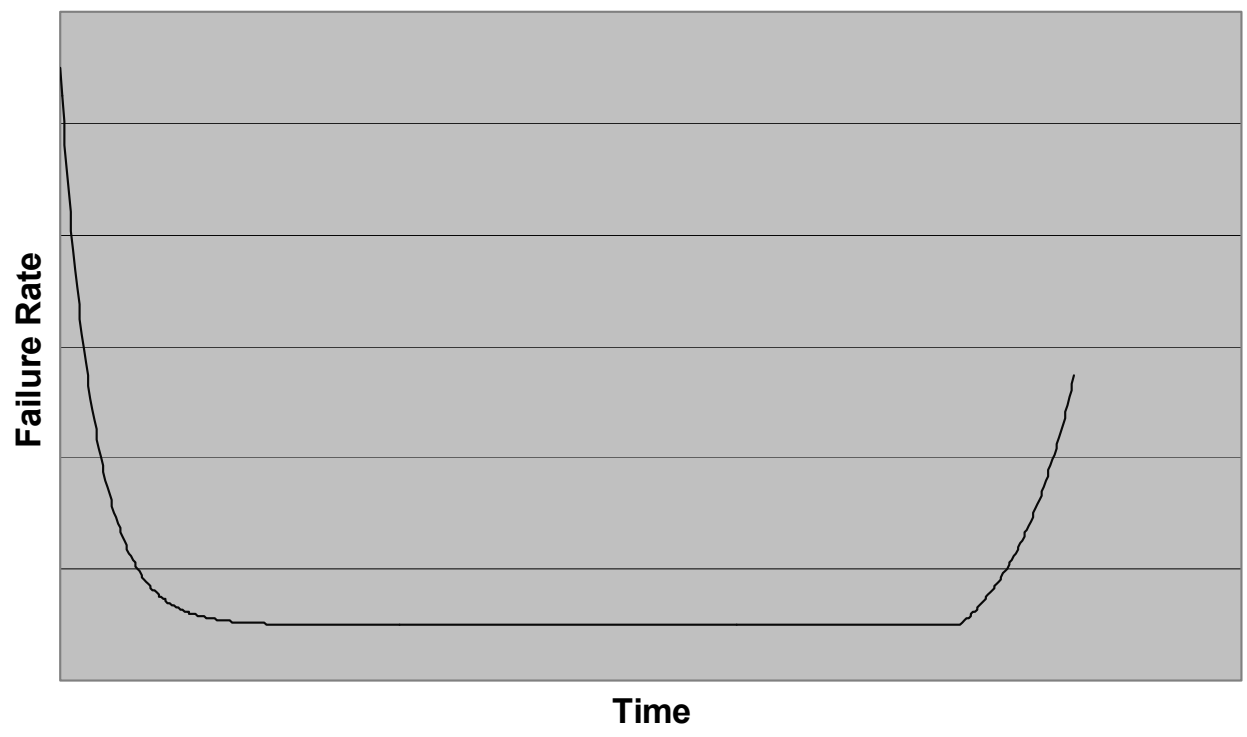

Figure 1. Failure rate of equipment. 
A motor, for example, may have a published maintenance cycle of 4,000 hours of operation at rated load. Because most Corps projects do not track the hours of operation of a particular motor, it is simply said that this cycle is about a year of operation and required maintenance on the motor is planned annually. First, the published maintenance cycle is based on continuous running at rated load. Most of the motors do not run continuously and do not run at rated load. In some cases, the motors run at substantially less than rated load. Unseen problems with machinery can cause motors to run at substantially higher loading, thus increasing the urgency for maintenance. Second, the likelihood of failure a short time after installation is not accounted for in a time-directed preventive maintenance scheme. Because of these reasons, time-directed maintenance ultimately leads to unscheduled repairs and/or replacement, and the expensive reactive cycle just discussed often occurs.

\section{Reliability/performance-directed maintenance}

Some maintenance plans are a combination of time- and reliability/performancedirected. A reliability/performance-directed maintenance plan requires equipment to be maintained on intervals based on past performance data, often supplied by a manufacturer or a plant's own experience. If the oil is changed in a car every 3,000 miles, it is being maintained on a performance-directed plan. The 3,000 miles is based on manufacturer information about the typical breakdown of motor oil when used in a particular type of engine. This form of preventive maintenance is higher than time-directed. Since the relative condition of the equipment is not considered, however, excessive maintenance cost could occur. There may be times, for reasons not readily apparent, when equipment needs to be maintained more frequently than the published MTBF, or even on an immediate basis, to avoid failure.

Using the example of the motor from the previous subsection, it would make more sense to maintain the motor based on the actual hours of its operation. Modern PLC systems make this type of "hours of operation" recording very easy to do. However, the starting and braking torque currents, the actual running load current, and the bearing wear are not as easy to track and will have the greatest affect on the life and maintenance requirements of the motor. Consider also that every motor is inherently constructed a little differently and can be ex-

pected to behave differently under various conditions. Equipment suited for a performance-directed maintenance plan should fail without warning, have relatively high material and labor cost to repair or replace, have varying operating conditions or mean use (making it difficult to maintain in a time-directed basis), and have high consequence in regard to the capacity or safe operation of the project. 


\section{Condition-directed maintenance (predictive maintenance)}

The highest order of preventive maintenance, called predictive maintenance, uses the concept of condition monitoring to predict and schedule the maintenance based upon the actual condition of the equipment. New automobiles that have sensors built in to the motor oil pan to detect the breakdown of oil viscosity are an example of this type of plan. The idea is that, if the car is used only on weekends, it does not need its oil changed every 2 months. This offers considerable unit savings over time-directed plans. In addition, if the car is only driven on the highway and the driver is very cautious and accelerates slowly and uses the best possible motor oil, the car may not need its oil changed every 3,000 miles either. In this plan, the oil would be changed only when it is absolutely necessary. This plan may also occasionally require an oil change at more frequent intervals if driving habits so dictate. This will prolong the life of the vehicle and would not happen under any of the previous plan types. To add such condition monitoring sensors to an existing vehicle would be relatively expensive and likely not worth the cost unless a large fleet of automobiles is maintained and improvements in high maintenance costs are desired. However, to design such a condition monitoring device into a vehicle during the engineering stage is very low cost and would easily pay for itself. This type of planning could be applied to maintenance of equipment on lock and dam projects. In some cases, resources are wasted because of time-directed maintenance practices. In other cases, failures occur that might have been predictable and hence avoidable with the right type of condition monitoring procedure.

\section{Predictive Maintenance}

Following automation of process, predictive maintenance is the next step toward a state-of-the-art O\&M program for management of a lock and dam facility. In much the same way that time- and performance-directed maintenance are forms of preventive maintenance, predictive maintenance can also be used under different terms. A common perception of predictive maintenance is that it is the use of vibration analysis, infrared surveys, and other condition monitoring equipment to trend the condition of machinery to detect developing problems and avoid costly repairs. While this is the basic concept behind such a program, predictive maintenance is a process for improving productivity, product quality, and overall efficiency of the project process. It is a "state-of-mind" process that must be supported at all levels of plant operation, including upper management, design engineering, construction engineering, and hired labor. Every person on the job must be trained to think in ways that support the program. All of the sensors and electronics in the world cannot replace what a well-trained set of eyes, ears, and hands can detect about project operating equipment and processes. The electronics are intended to supplement the human monitoring 
The electronics are intended to supplement the human monitoring process, not replace it entirely. Predictive maintenance can replace a number of lower grade jobs with fewer, more diversified, more responsible, higher graded positions. The goal is to work smarter, not harder.

Predictive maintenance is preventive maintenance driven by the condition, trended in real-time, of the machines and operating equipment, rather than the scheduling of maintenance based on industry MTBF averages. A good predictive maintenance program uses mechanical/electrical condition parameters of the equipment as well as subsystem efficiencies, overall plant efficiency, operator perception, electronic and human sensors, and any number of other monitoring factors to determine the most cost-effective means of maintaining, repairing, or replacing the equipment. A plan like this cannot eliminate all of the failuredirected or preventive maintenance at Corps projects, but it can help control the unscheduled M\&R cycles that incur the most cost to the project, including that of lock downtime.

Predictive maintenance is not an excuse to buy expensive monitoring equipment and data acquisition hardware and software. Nor is it intended to create work for personnel to measure, collect, monitor, and review data collected from machinery, equipment, and systems within the project. Instead it is a process to avoid costly unexpected failure of critical parts of the process such as gate operating machinery or electrical switchgear. Despite the fact that studies indicate predictive maintenance is a proven concept, many plans implemented will fail to show positive results. The reasons can vary by project, but ultimately they will point to a general lack of understanding from management as well as poor upfront planning. Before forming a predictive maintenance program, the system designer should meet with project maintenance and management personnel to establish the system's needs as well as project goals that are anticipated by the adoption of such a system. These should include the following general goals as well as some project-specific target improvements:

- Eliminate unnecessary maintenance

- Reduce rework costs

- Reduce lost production caused by failures

- Reduce spare parts inventory

- Increase process efficiency

- Improve product quality

- Extend the operating life of plant systems

- Increase production capacity

- Reduce overall maintenance costs

- Increase overall profits 
- In addition to allowing preventive maintenance, predictive maintenance trending can also be used to find root causes of chronic maintenance problems and problems with equipment start-up.

Since a truly successful predictive maintenance program must be supported, as well as accepted, at all levels of the organization, it is important that all personnel, from maintenance to management to funding, be represented during the development of the process. It may even require a drastic change to the organization's attitude toward maintenance and maintenance personnel qualifications. Most significant changes in process are difficult to initiate. Often the organization resists funding a new concept. While this discussion may not completely justify the funding outlay to all interested parties, it can offer suggestions on how to get started. The following process can be used to implement a successful predictive maintenance program for a lock and dam project.

\section{Equipment identification}

The project maintenance management team must first identify every piece of equipment that, either by itself or in combination with other components, can halt or impede the production process (locking navigation traffic, regulating pools for purpose of navigation) or create unsafe project conditions. It is important to note that predictive maintenance is not limited to mechanical/electrical equipment. Structural features, such as strain gauges, can be included on the list making use of the wide range of condition monitoring possible with today's sensor and electronics technology. This project uses strain gauges on the miter gate anchorages to record stresses in the gate anchoring system. The list should break down equipment into individual parts that can be repaired separately and/or have varying consequences on the operation of the project. For example, the list should break out the individual input/output (I/O) cards on a PLC system because they can be replaced independently and their failure, depending on their relative position in the system, could have varying impacts on the overall system. A motor or gear reducer, however, should be treated as one piece of equipment because repairing any part of it generally requires removing the entire unit from operation. The list will be used to determine which items should be maintained under what type of plan, and what items should be addressed first when putting together a new facility maintenance plan.

\section{Criticality ranking (failure index)}

A failure index should be determined for each piece of equipment based on the relative criticality of that component in the mission of the project. Each project 
will have a different ranking system for its components. A possible ranking system for a lock and dam project might be:

Lock is closed/loss of pool control. Failure of these components renders the navigational lock inoperable or causes the gates on the dam to be inoperable resulting in loss of pool control. These two consequences are considered the worst and leave the project unable to perform its two basic functions. Production is stopped.

Safety interlocks will not function. If the lock is operated through an emergency fail-safe system and true interlocks or limit switches are not used, the safety and capacity of the project are severely crippled. Production is low; safety is very low. Often extra personnel will be required to operate the lock when it is in this condition. A simple limit switch failure can cause this problem.

No operation through PLC. If the PLC system (normal operating system) is down, the lock may still function, but at reduced capacity and safety. Loss of the PLC often requires more operators because personnel must monitor equipment that is normally monitored by the PLC. Production is low; safety is low.

Reduced capacity. If failure of the component reduces the capacity of the lock, but not the safety, it is considered less critical. Production, however, may still be affected. An example of this might be a component that renders a culvert valve inoperable. Provided the valve can be closed, or bulkheaded, many locks can operate safely with one less culvert valve. However, filling and emptying times are increased. Production is lowered; safety is unaffected (Obviously, safety would be affected at some projects where filling and emptying with one valve can strain mooring lines.)

No operation from central control tower. Failures of the control network, or of the building systems, may render the central control room inoperable. Because the closed-circuit television system is located here, the capacity of the lock may be slightly reduced and the safety may also be reduced due to a lack of visibility. Additional operators may be needed. Production and safety are moderately reduced.

Automatic mode not operable. If a component's failure leads to loss of the automatic locking system, and yet the rest of the control system is fully operable, the capacity of the lock may be reduced as equipment is operated manually, but safety is not affected. Production is moderately reduced; safety is normal. 
Maintenance required. This level of consequence does not immediately affect the operation of the lock or dam, nor does it create immediate unsafe operating conditions. For example, failure of a shop air compressor requires maintenance but does not immediately close the lock or risk loss of pool. Production and safety are normal.

Different projects will have different ranges for failure index listings of equipment. Some components, which are parts of a system or subsystem, may not fit neatly into one of these categories. In some instances, the worst reasonable case should be assumed and, in others, an engineering judgment must be made based on relevant past experience. Effects and consequences of equipment failure should be accurate and realistic. Overstating these will skew the apparent results and/or savings (or lack thereof) achieved by predictive maintenance. It is vital to know the exact role of each component in the reliability and safety of the overall system. The objective of a predictive maintenance program is to improve the reliability and decrease the maintenance costs of the entire system.

\section{Preventive maintenance}

For each component or piece of equipment on the list developed earlier in Equipment identification, carefully document the manufacturer's recommended periodic preventive maintenance. Supplement this information with historical maintenance records of the routine maintenance performed on this and like equipment during the project (or similar project) history. The relative condition of the equipment at the time of maintenance could also be important information. Analysis of these data will help determine what type of condition monitoring can be used to predict failures. It will also determine in part what conditions to look for when determining the need for maintenance or replacement.

\section{Condition monitoring}

Thus far the steps taken under Predictive Maintenance have been similar to the steps necessary for any type of maintenance program. Condition monitoring is really the technique that defines predictive maintenance and separates it from lower forms of maintenance programs. Therefore, it is critical to have quality real-time information derived from a project's condition monitoring equipment. What type, or combination of condition monitoring types, is correct for a lock and dam project? The answer to this question can vary from project to project. Regardless of how the information is derived, whether it be trended and stored electronically, or simply observed by alert maintenance personnel, accurate indication of the real-time condition of the equipment is the single most important 
part of a predictive maintenance system. Following are the more common types of condition monitoring systems.

Vibration monitoring. The most commonly used and understood method of condition monitoring is the use of vibration transducers and handheld sensors to measure and record the vibration in mechanical equipment. This includes installing instrumentation on gears, shafts, bearings, pillow blocks, pinions, pumps, and hydraulic equipment to measure imbalance, misalignment, gearmeshing frequency, and mechanical rub. A machine's condition is directly related to its level of vibration. As vibration increases or becomes excessive, mechanical trouble is the reason. Through the use of a carefully conducted vibration monitoring program, small increases in vibration can be recognized long before a defective component actually fails. A well-implemented monitoring program makes it possible to detect impending problems, analyze its causes, and take appropriate corrective action. Monitoring can be performed by a permanently mounted vibration transducer such as the one shown in Figure 2, or by a handheld unit as shown in Figure 3.

Vibration monitoring starts with analyzing the frequency data derived from the transducer. Every machine or group of machine elements moves in ways that produce repetitive vibration at precisely defined frequencies. The output of the transducer is passed through a filter to reject frequencies that are considered noise (i.e., extremely high and extremely low frequency signals). Keep in mind that the purpose of this monitoring is to predict maintenance based upon longterm trends of the frequency signal. Viewing the filtered signal on an oscilloscope will show the changes in amplitude of the vibration with time (see Figure 4). The valuable information that can be derived from this observation is the peak and root mean square of the amplitude signal. These two values are the basic fundamental parameters of vibration analysis and can be derived from either type of transducer shown in Figures 2 and 3. 


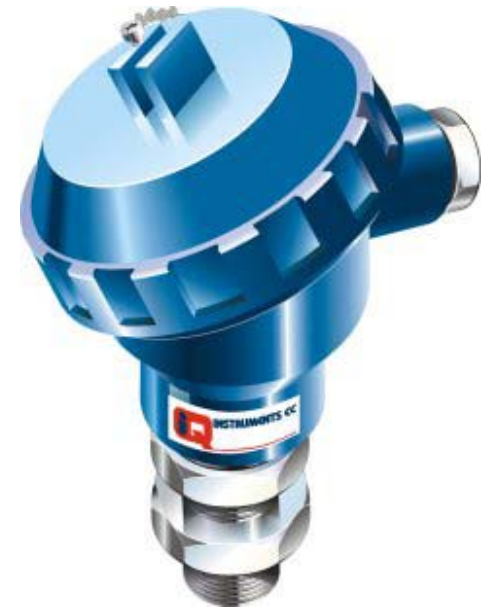

Figure 2. Vibration transducer.

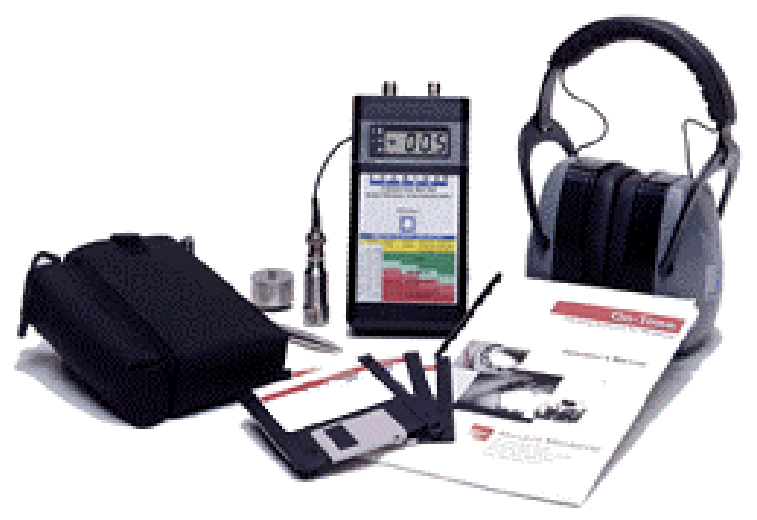

Figure 3. Handheld vibration analysis kit.

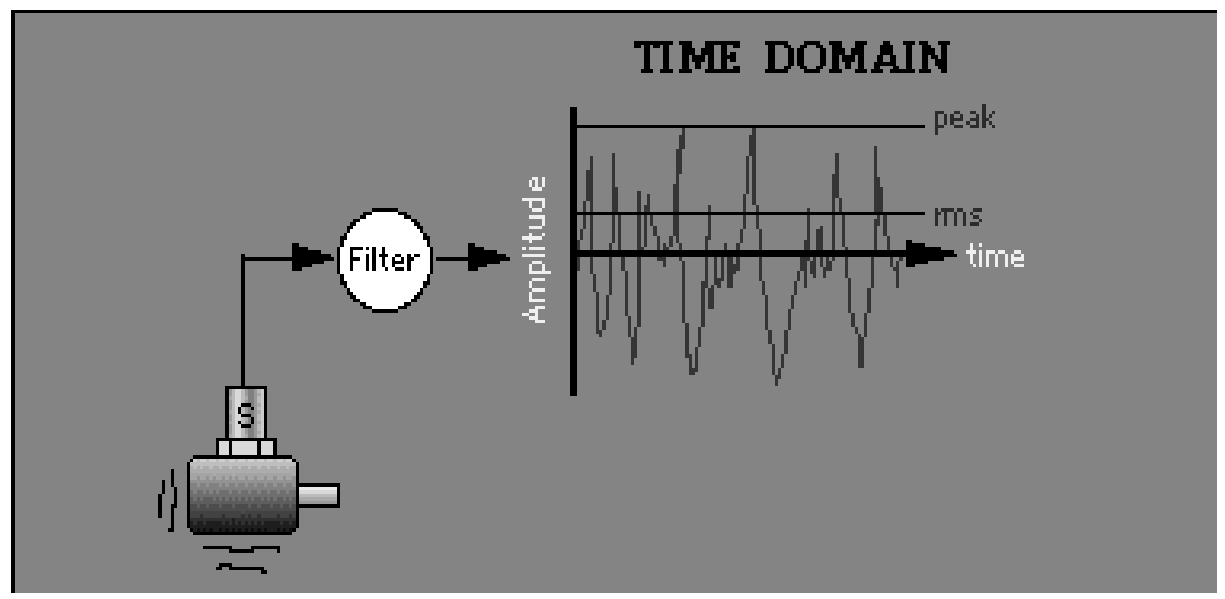

Figure 4. Time domain showing peak and RMS values of vibration amplitude.

Digitizing the signal, a function performed by the plant CMMS software, or simply with the software included with most handheld vibration meters, will allow a tabular definition of the amplitude values. With this tabular definition, an equation can now be derived to mathematically describe the vibration of the machinery at the point where the measurement is taken. A mathematical function known as the Fast Fourier Transform (FFT) will convert the signal to a frequency-based domain. This graph is called the frequency spectrum of the machinery vibration (see Figure 5). This vibration spectrum allows us to see the vibration caused by coupling inaccuracies, gear mesh, bearing faults, and many other sources. 


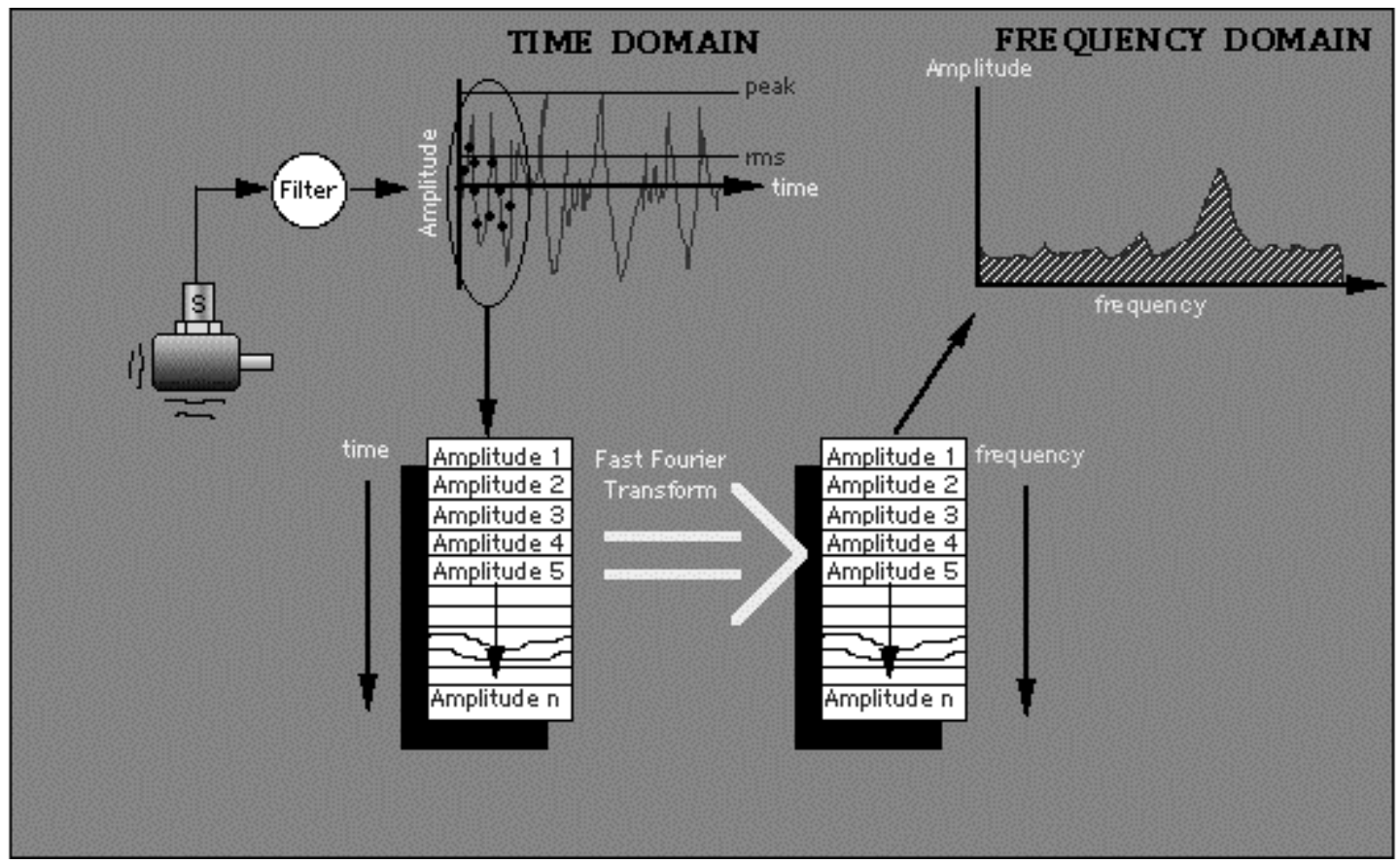

Figure 5. FFT produces the vibration frequency spectrum.

Because lock and dam machinery is of complex design, numerous peak amplitudes can occur in the vibration graph, and a single transducer can track several vibration frequencies. These vibration frequencies can be determined from the geometry of the machine elements and located on a plot that shows how much vibration there is at any given frequency of the vibration spectrum (Figure 6).

The best way of determining true machine condition is to develop an operating "signature curve" benchmark of the vibration spectrum. Through the use of long-term trending and data comparison of the vibration spectrum, patterns of wear and degradation can be determined long before they become a catastrophic failure. Using special signal processing techniques and statistical analyses, it is possible to monitor the progress of any developing machine fault that results in increasing vibration. Once determination is made of the maximum amount of vibration to allow a fault to generate before the machine is repaired, we can trend the amount of vibration caused by a particular fault can be trended and a prediction made for how much time is left before the repair should be done (see Figure 7). 


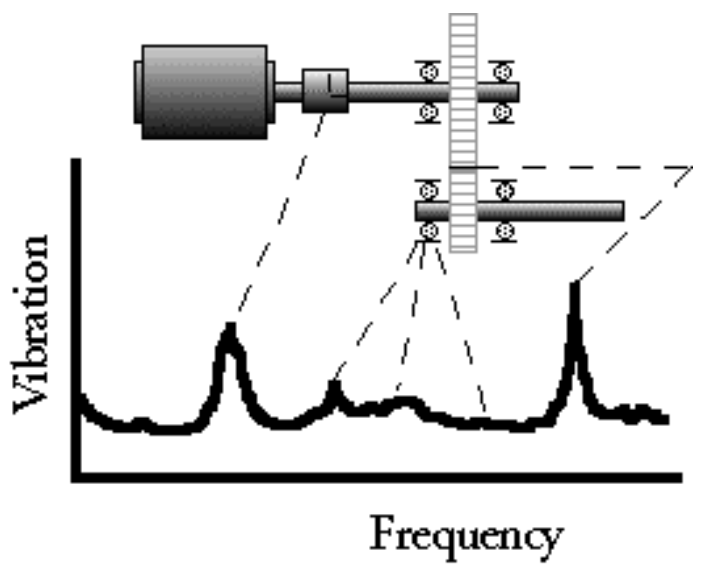

Figure 6. Vibration frequencies of rotating machinery.
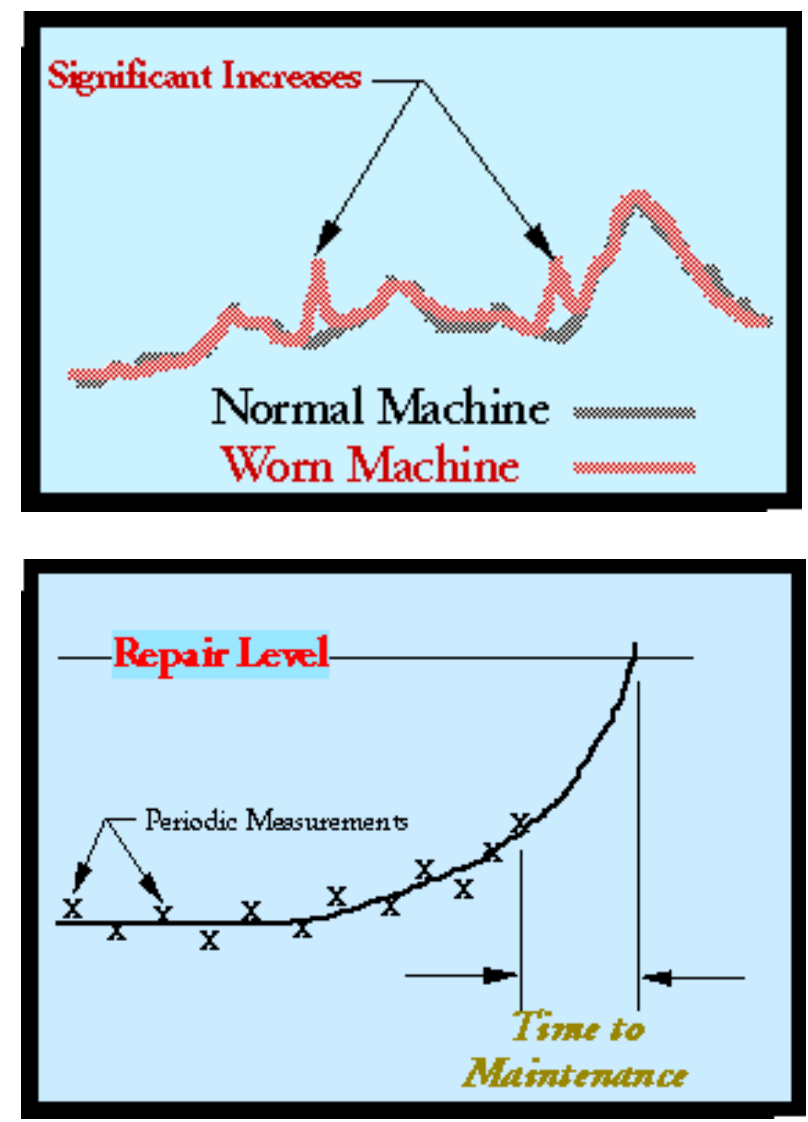

Figure 7. Long-term trending of the frequency spectrum can predict required maintenance of rotating machinery.

While this may seem like a lot of sophisticated mathematical analysis, the truth is it is rather simple to do and an advanced degree in statistics is not necessary. Most modern PLC control systems, even low-end systems, can handle far more $\mathrm{I} / \mathrm{O}$ than is actually needed to operate and monitor the lock equipment status. Combine this with powerful, relatively inexpensive HMI packages that can provide considerable trending, and the biggest part of the material cost for such vi- 
bration monitoring equipment is covered. Some HMI packages make it relatively easy to develop a signature vibration curve for a given set of machinery components. Only the transducers and the programming labor remain, and the cost of these items is likely far less than the unscheduled maintenance caused by failure of a single machine. This, of course, does not include the cost of unexpected downtime to commercial navigation interests.

Thermography. Infrared thermography is a nondestructive testing technique that is a valuable tool in a multitude of application areas. As the name implies, infrared thermography is a technique that produces a visible graph or thermographic image of heat energy radiated from objects. Thermography uses a portion of the infrared band of the electromagnetic spectrum between approximately 1 and 14 microns. This bandwidth is usually associated with infrared radiated energy produced by object temperature. Electronic instruments used in infrared thermography utilize a lens system to focus the invisible energy radiated from the first 1/1000 of an inch of an object's surface onto the infrared sensitive detector. The various energy levels are measured by the detector and then transformed into a visible image, with each energy level represented by a different color or gray-scale level. This image is viewed by an observer on a Liquid Crystal Diode (LCD) or Cathode Ray Tube (CRT) display. The image can be stored digitally, or on video, for review, analysis, and reporting at a later date. All infrared systems, from the simple to the complicated, are sensitive to infrared radiated energy only. They do not actually measure temperature. They are useful in applications where a variation in temperature, reflection, surface condition, or material may cause a difference in the radiated energy level as detected by the infrared camera.

When an electrical device is operating outside its normal capacity (overload condition), there will be an increased amount of heat present. This may not be discernable with the human senses, but a thermographic infrared camera such as that shown later in Figure 14 can detect the presence of excessive heat before an electrical failure occurs. Figures 8 through 13 demonstrate the results that can be obtained from a simple point-of-use thermographic infrared camera. As with the vibration analysis, prevention of a single failure of a large motor, contactor, or panelboard will pay for the cost of instituting a thermography testing procedure as part of the overall project predictive maintenance program. Fault clearing devices may not reveal the problem in time to perform preventive maintenance. Often a circuit can be "hot" due to malfunctioning load and/or current imbalance, but when a protective device trips, the problem has already escalated to a failure. 
Meggering insulation. The integrity of electrical insulation is what keeps electrical equipment operational. Electrical equipment insulation degrades over time. Exposure to elevated temperatures and contaminants has a direct impact on how long certain types of insulation can last before breaking down. The most important variable in monitoring insulation quality is resistance. It is the measuring, recording, and interpretation of the resistance value over a period of time, that becomes a valuable tool in predictive diagnostics.

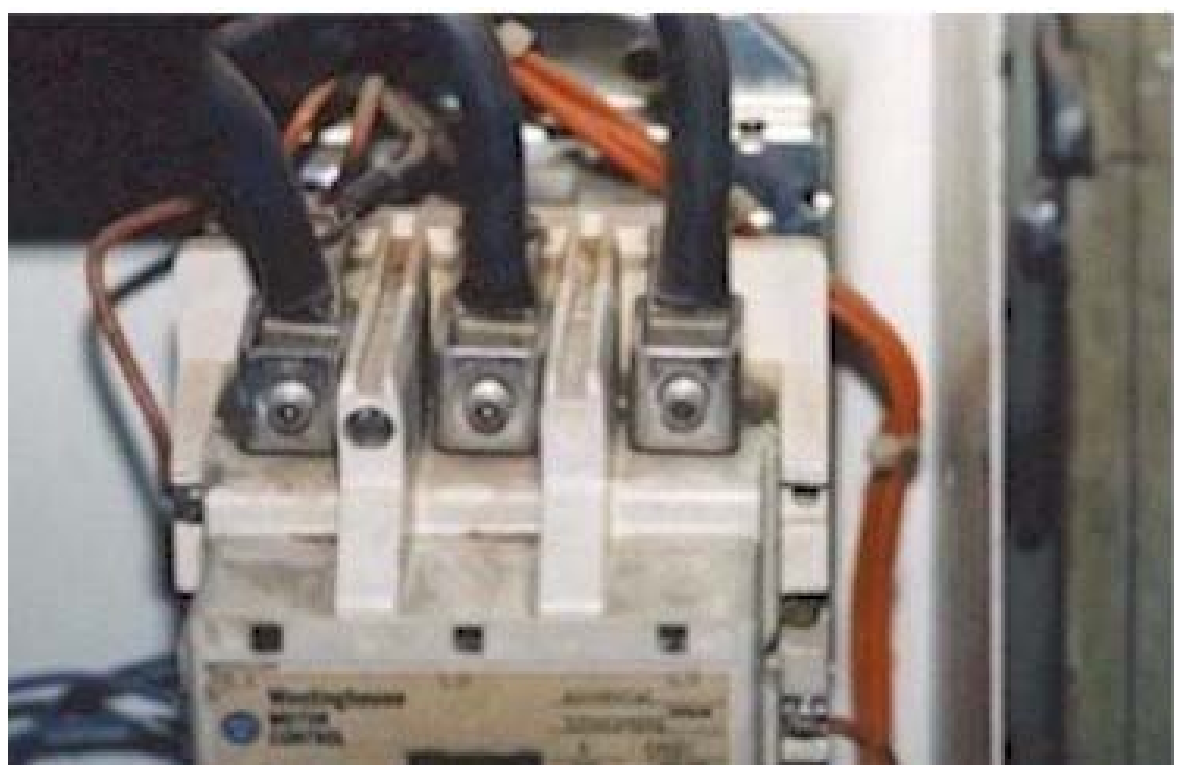

Figure 8. Motor contactor; presence of heat caused by current imbalance not evident to the human eye.

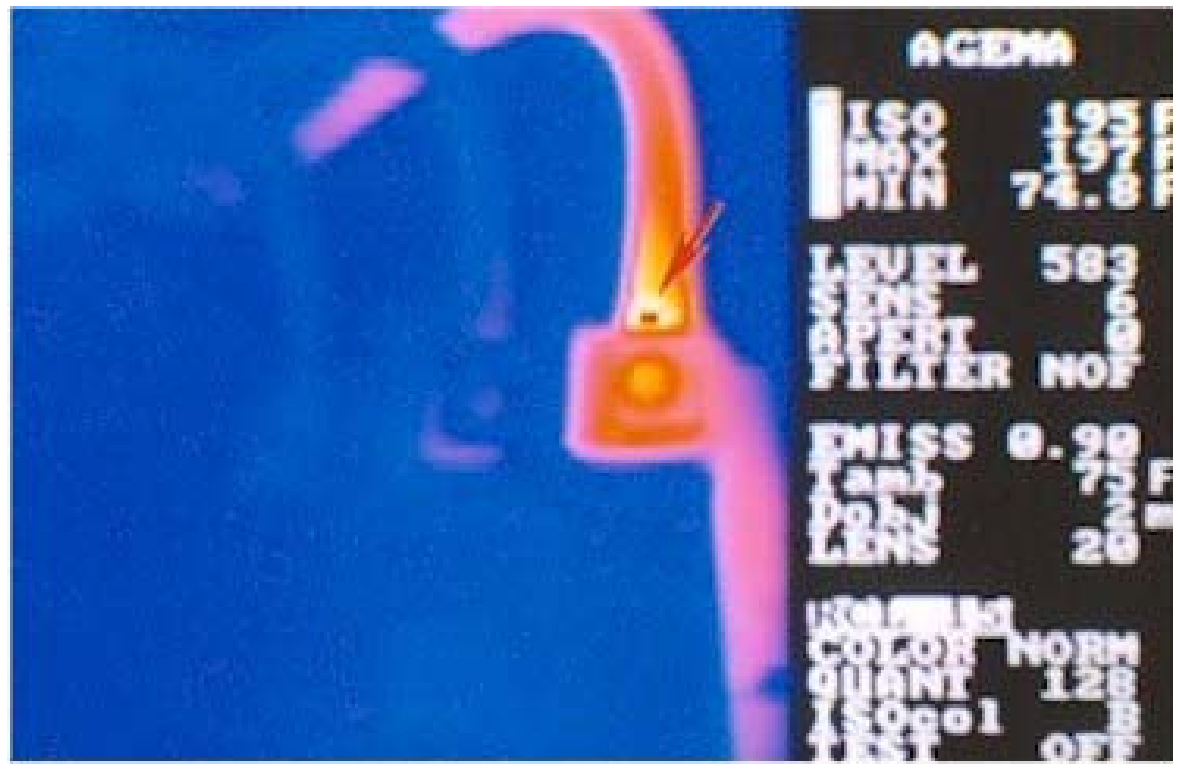

Figure 9. Infrared thermographic image of the same motor contactor shows a problem with excessive current in one phase. 


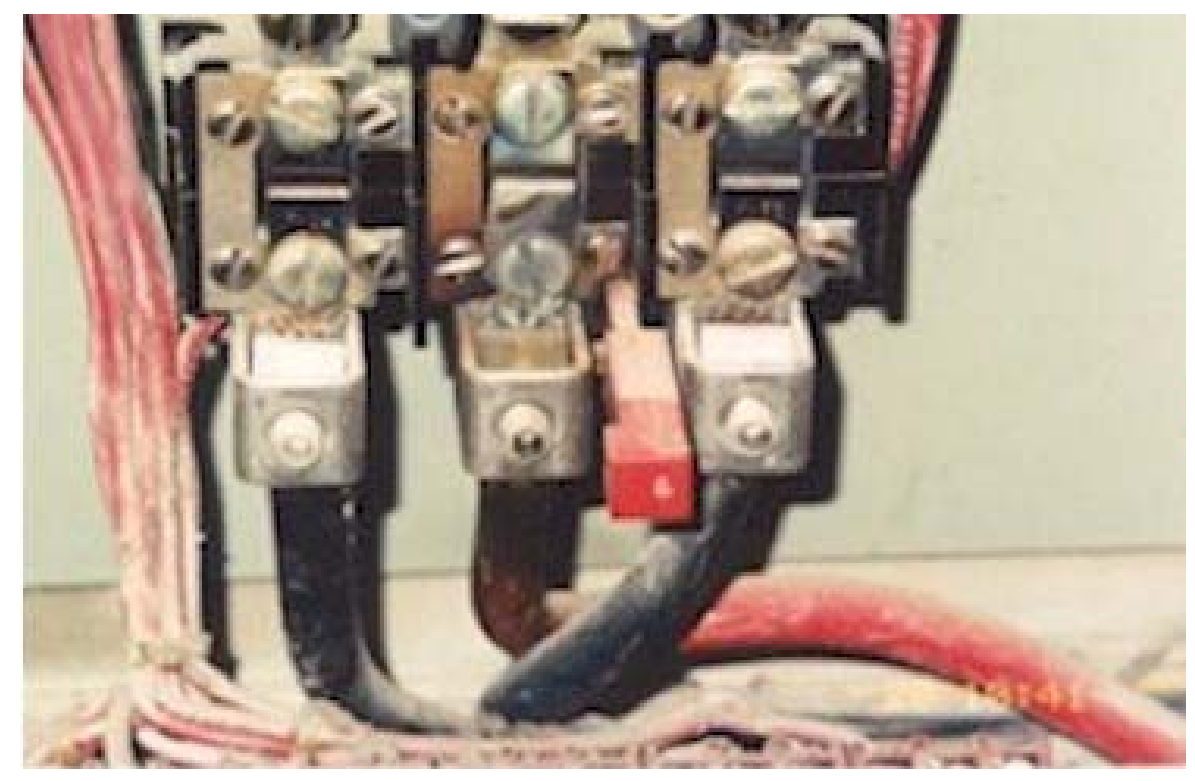

Figure 10. Motor overload block.

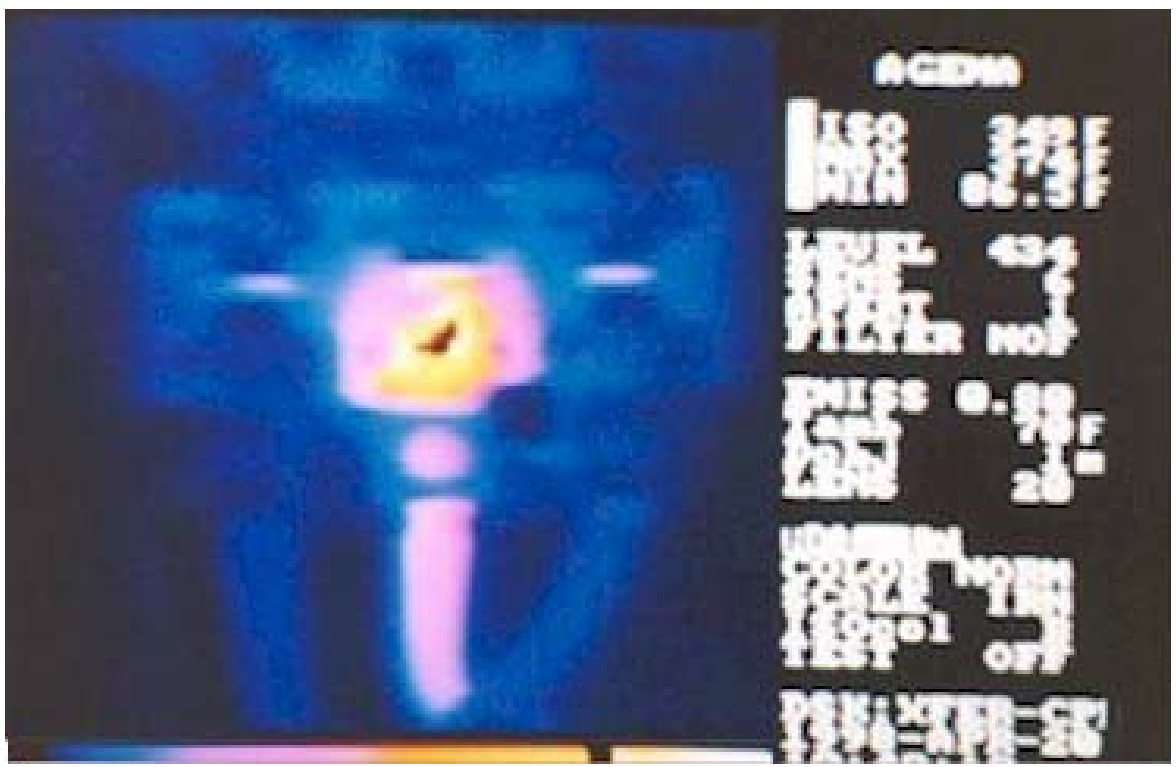

Figure 11. Thermographic picture showing overload on middle phase. 


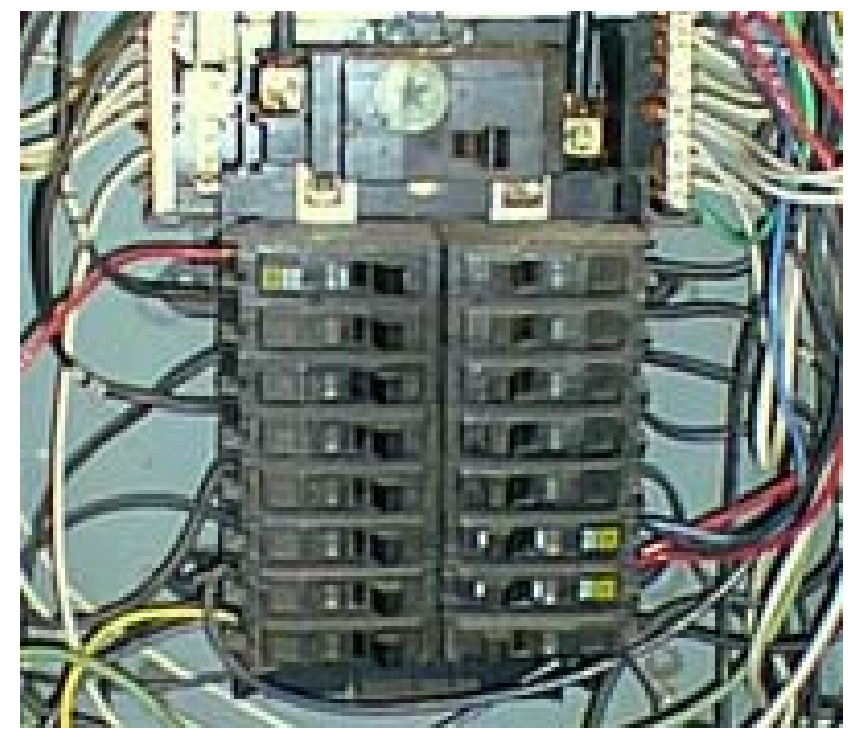

Figure 12. Panelboard appears to be in proper operating condition.

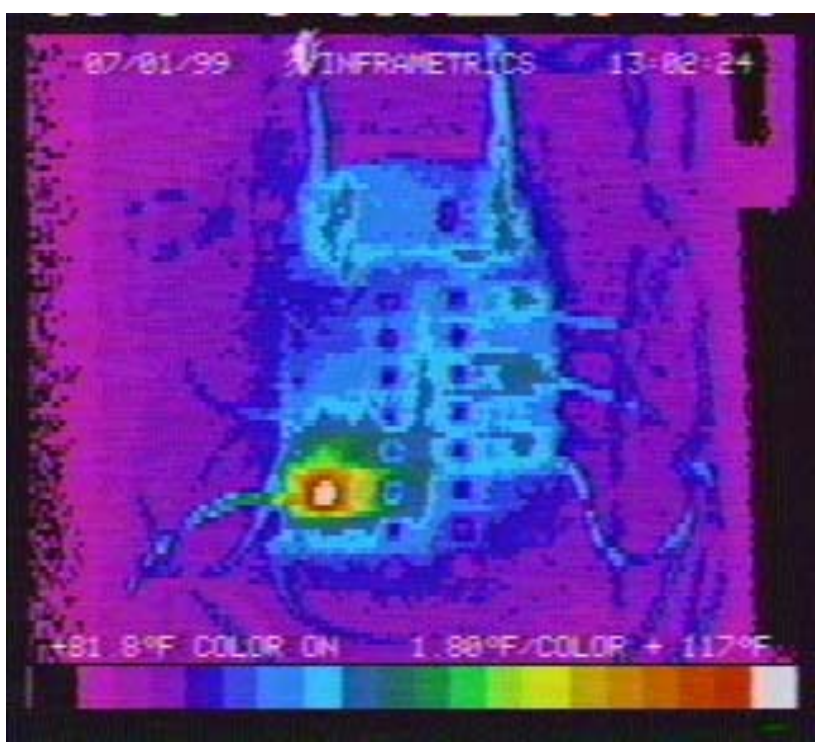

Figure 13. Infrared analysis reveals imminent failure.
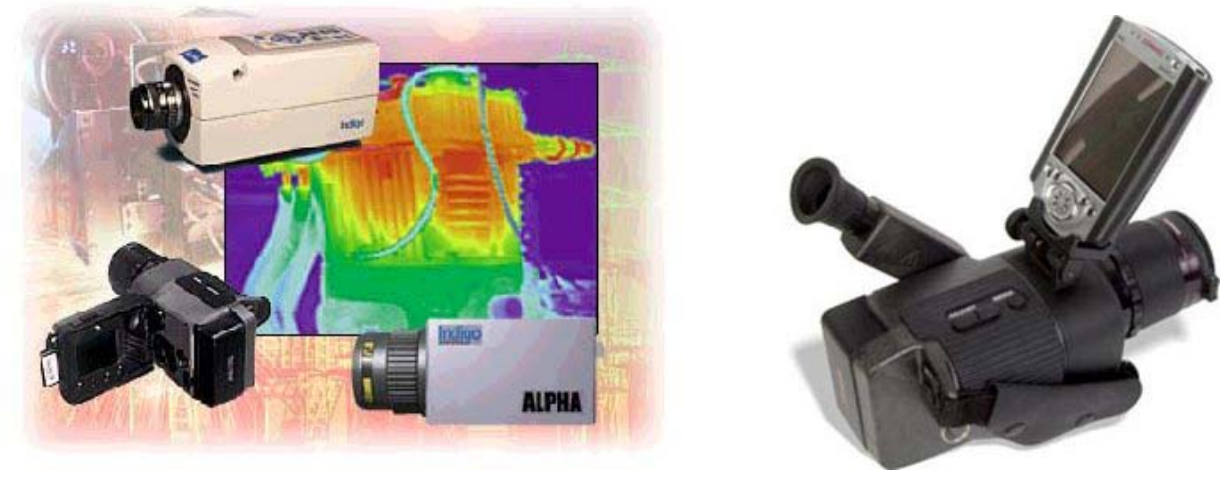

Figure 14. Typical infrared cameras. 
Structural strain. The use of vibrating wire strain gauge technology for measuring the stresses in structural members is perhaps the most useful form of condition monitoring of Corps of Engineers lock and dam projects. The ability to continuously monitor the stresses in the miter gate strut arms, diagonals, and anchorages, the culvert valve trunion anchorages, struts, and bell cranks, the tainter gate struts, trunions, and girders, and numerous other structural members is a huge tool in the prevention of failures at Corps projects. The large majority of extended and costly closures are caused by structural failures. Often these failures are preceded by significant changes in the stresses of structural members, as well as changes in the operational condition of the mechanical machinery. Continuous monitoring of the stresses in these structural members as equipment is operated establishes a baseline operating curve that can be used by the PLC or higher order HMI software for continuous comparisons to ensure that the operating conditions do not fall outside acceptable limits. Figure 15 shows a typical vibrating wire strain gauge transducer similar to that used on this pilot project.

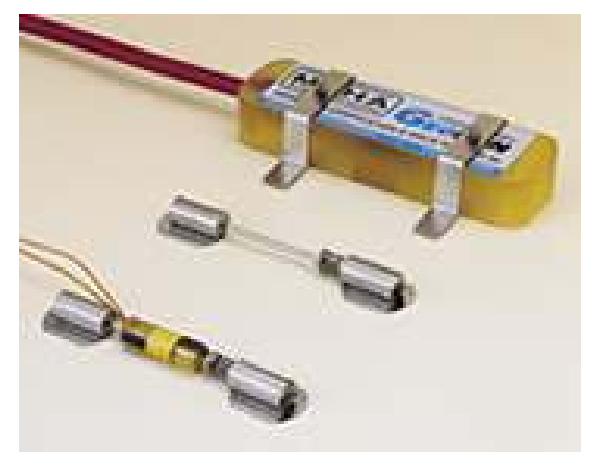

Figure 15. Vibrating wire strain gauge.

Hydraulic pressures. The operating pressure of hydraulic-operated machinery is directly related to the load under which that machinery is subjected. Interferences in the operation of a miter gate, for example, will cause the system operating pressure to be higher. This is a very simple and precise way to determine if the conditions under which the equipment is operating have changed. The change could be due to impending structural failure, impending mechanical failure, changing conditions such as siltation or failure of electrical equipment.

Electrical operating conditions. With today's technology and the availability of electrical equipment with built-in condition monitoring capabilities and high speed communications, it is a good idea to include electrical parameters in any condition monitoring effort. Such conditions include voltage, current, power factor, inrush, breaker and relay status, switchgear temperature, and others. Failures of mechanical and/or structural equipment are often predictable by looking at the electrical operating parameters, as the changed condition that causes the failure will often first result in higher operating currents or different electrical operating parameters. 
Normal operating conditions. Other parameters that are observed normally during operation of the project should also be considered as parameters to be monitored for predictive maintenance purposes. Often the data are already collected by a PLC but are only being used for display for operator judgment. Such process parameters include water levels, gate position, valve position, temperature, humidity, rainfall, etc.

Tribology. Tribology is a general term that refers to the operating analysis of the bearing lubrication support structure of machinery. There are several tribology methods that are used by a predictive maintenance program including lubricating oil analysis and wear particle analysis.

Lubricating oil analysis is a testing technique that determines the condition of lubricating oils used in mechanical equipment. It is used to predict the condition of the operating machinery by providing an accurate quantitative breakdown of individual chemical components, both additives and contaminants, contained in the oil sample. Comparison of successive samples for traces of metal can provide an early warning of wear pattern and eminent failure of oil-lubricated machinery. The cost of this type of analysis is relatively low with the use of automated solid-state systems. The benefits derived are quality control, reduction of lube oil inventory, and determining the most cost-effective interval for changing oil. True benefits of this type of predictive maintenance are only possible if representative oil samples are taken on a regular basis.

Wear particle analysis is the study of the particles taken when drawing samples of lubricating oils. As discussed, lubricating oil analysis determined the condition of the oil; analysis of the particle contained within can predict the relative condition of the machinery. The particle shapes, size, composition, and quantity are analyzed in making an accurate prediction of the actual condition of the mechanical equipment. Conditions for which the testing looks are rubbing wear, cutting wear, rolling fatigue, and rolling and sliding wear.

Motors and drives. Traditionally, the only precautionary condition monitoring done to machinery motors at Corps of Engineers locks is the periodic meggering of the stator and rotor windings. This is a good practice and provides early indication of a number of potential problems with motors. However, meggering is often done only once a year. Results are compared to the manufacturer's tolerances and trends are not identified. Figure 16 shows a modern alternating current (AC) drive motor with factory-installed condition monitoring equipment. While a motor like this may be an expensive retrofit of a functioning motor, its cost during a major upgrade or construction of a new project will pay for itself in the downtime it saves. 

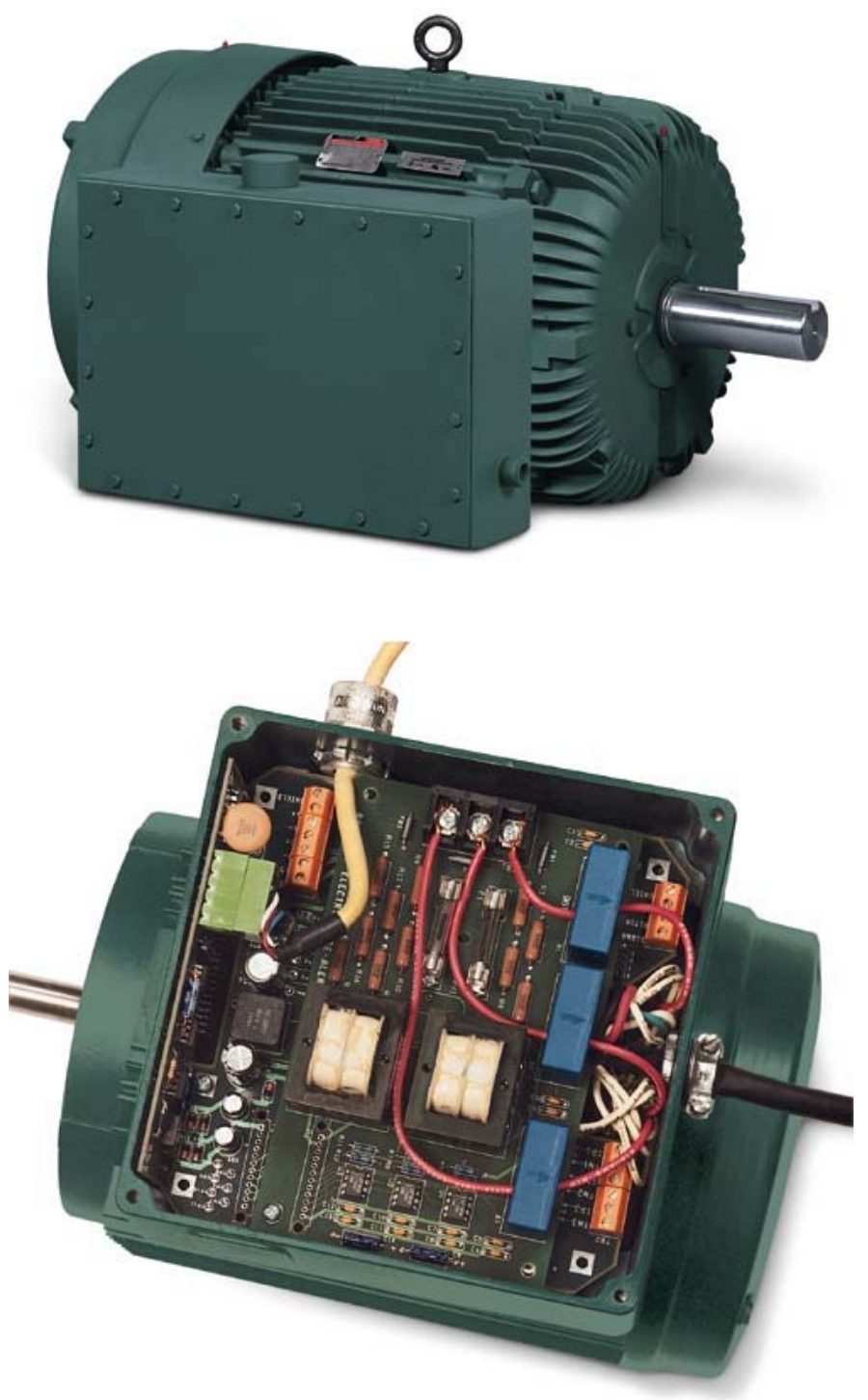

Figure 16. Electric motor with built-in condition monitoring sensors.

The devices shown in Figure 16 monitor all three stator winding temperatures, bearing temperatures, vibration, current during each phase, voltages, power factor, and frequency. Power condition signature analysis provides comprehensive diagnostic information about winding, rotor, and bearing conditions and can detect broken or loose rotors, bars, slip frequency side bands, poles, and other problems with the motor. Usually, if motor problems are detected early enough, they can be scheduled for servicing and repair with other scheduled downtime, which is on average 3 to 5 times cheaper than responding in an unscheduled manner to a failure. In addition to the built-in condition monitoring equipment, the motors are equipped with communications packages that allow the information to be trended in real-time by the PLC/HMI control system. The data can be configured for alarms as needed by the user. 
Modern variable speed drives are becoming more common on projects today. The drives' inherent fine speed and load control, coupled with truly reliable technology, make them ideal in situations where smooth acceleration and deceleration contribute to prolonging the life of machinery and structural equipment. At locks and dams this technology is replacing dual-winding and wound rotor motor technology. All variable speed drives on the market today are equipped with condition monitoring technology. As users, project personnel do not always take advantage of the information available with modern solid-state controllers. When the specifications are done, the designer often does not know what system will be furnished and, therefore, which condition monitoring information is available. If they are available, data should be recorded and trended to help search for long-term changes in the operating parameters of the equipment. What seems like relatively trivial information, needed only by the drive, may be useful for other purposes. Changes in the signature dynamic braking currents, for example, may be indicative of changes in the motor conditions or changes in the loading or condition of the machinery.

Process parameters. Locks and dams are built to pass traffic and regulate pool levels to allow navigation. These are the basic product of the process. The subprocesses that contribute to this product should, as part of a good conditionbased predictive maintenance program, be monitored for efficiency and compared with an acceptable baseline for efficiency of the system. Processes such as gate open and close, filling and emptying, and pool fluctuation should be recorded to see if there are any gradual changes in the times that these processes take. This could be indicative of machinery or equipment problems starting to develop. If machinery is sitting idle for relatively long periods of time during lockages, perhaps there is a problem with operator efficiency or other circumstances contributing to the delays. Events such as overfilling, overemptying, skewing, machinery overtravel, overloads, traffic signal failure, overpressure, circumstances surrounding accidents, and other malfunctions or abnormal operating conditions should all be recorded for analysis of trends that indicate correctable problems. The safety, efficiency, and reliability of the lock and dam are essential to the economic benefits of the inland waterway users and are, therefore, important factors to monitor.

Visual inspection. Electronic monitoring, data acquisition, and trending are intended to supplement, not replace, the presence of qualified maintenance personnel. Through the human senses of sight, touch, hearing, and smell, project maintenance personnel can detect many problems with the operation of machinery. They cannot, however, maintain constant 24-hr surveillance of all of the equipment as can a monitoring device connected to a PLC. In addition, when a slight change of operating pattern, whether visual or audible, has persisted for a 
time, human senses eventually become accustomed to the change, and further deviation from the original benchmark operating pattern becomes undetectable. A PLC never forgets the original operating conditions and continually compares the current conditions to both the original and those recorded more recently. In one case the system is looking for absolute changes in the condition of the equipment, and in the other it is looking at the trends. Both are important in determining the condition of the equipment and the need for maintenance or replacement.

Alert and alarm limits. All of the condition monitoring equipment discussed here produces some kind of electrical signal. In most cases it is recommended that a PLC or PC be used to condition the signal and convert it into a meaningful real-time parameter in engineering units that describe the condition of the equipment monitored. This should be accomplished as part of the programming effort. Alarm limits can be programmed to alert operators and maintenance personnel of problems with the equipment.

Generally, these alarms will be of two different types, Static (threshold) and Dynamic (trending). Static alarms are tripped when a monitored parameter reaches a predetermined limit, such as hydraulic fluid reaching a certain pressure. Dynamic alarms are tripped when trending data shows inconsistent conditions or conditions that change in an irregular pattern even though they are within the threshold limits. Both trend patterns are important. Most maintenance personnel and management see the reason for static alarm trips: if the pressure is too high, the pump should be shut off. However, this type of alarm may be indicative of a fault or failure that has already occurred, which usually requires unscheduled maintenance with the necessary downtime to repair the problem. Dynamic alarms that detect changes in the operating signature of the equipment, or multiple pieces of equipment, can alert maintenance personnel to a problem before failure has occurred. Pressures that fluctuate or change abruptly in a manner that is outside the signature curve, even though they are within acceptable tolerances, may point to an impending problem that can be scheduled for service under normal maintenance. Often these alarms can be compared with real-time vibration and motor monitoring data to help locate an impending fault. A motor that normally operates at 30 percent of full load, for example, suddenly begins to operate at 80 percent of full load. This change will not trip breakers or cause overloads, but is a sign of significant change in the operating condition and probably points to impending mechanical or structural failure. 


\section{Port Allen Project}

\section{Project Background}

Port Allen Lock is on the GIWW between Morgan City, TX, and Port Allen, LA, approximately 1/10 mile from the Mississippi River Entrance to the Canal at Baton Rouge, LA (Figure 17). The lock is $84 \mathrm{ft}$ wide by $1,200 \mathrm{ft}$ long with maximum lift of $32 \mathrm{ft}$ at river stage 40.0. The project has miter gates and reverse tainter valves at both ends of the lock and averages around 8,000 lockages annually. Port Allen Lock is considered critical to navigation interests on the GIWW and to flood control interests. The project was selected for this research project for the following reasons:

- The project serves a critical role in the inland waterway system

- The project does a sufficient number of lockages to provide good real-time data about the conditions of the machinery as the project is operated

- Prior to this work, Port Allen did not have a PLC system

- Port Allen was part of a previously designed control system upgrade, including plans for a complete PLC operating system that could be used in this project

- The project O\&M staff has a reputation for supporting such innovative technology and providing the resources and field experience for installing the equipment. 


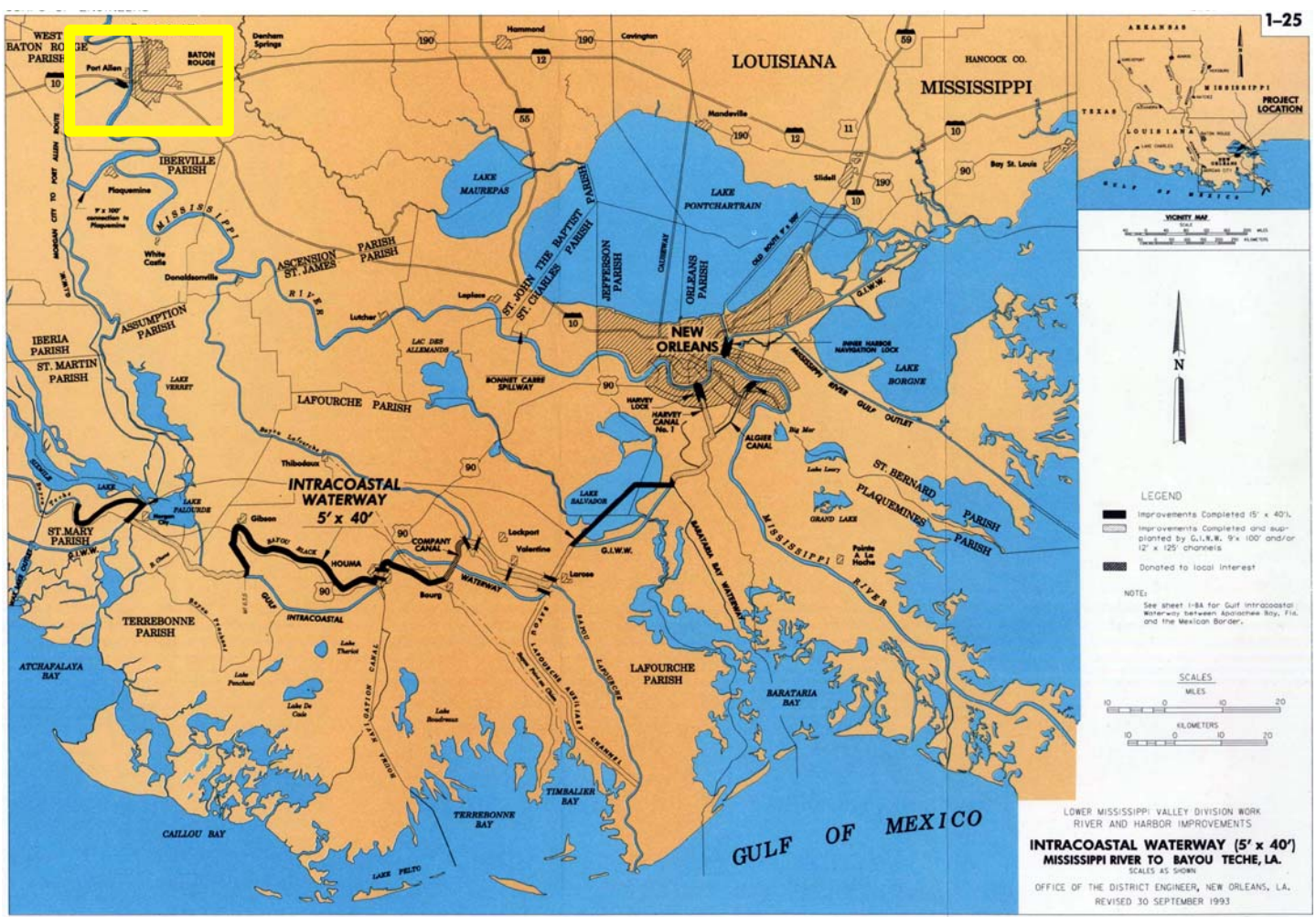

Figure 17. Map showing position and role of Port Allen Lock (upper left) in the GIWW.

\section{Purpose}

This research project has the following purposes:

- To show that a PLC control system can be used for high speed collection of the data from instrumentation transducers used to monitor the condition of lock equipment

- To show the accuracy and real-time qualities of the data

- To show that the data can be used onsite for short-term purposes such as static warnings as well as stored and trended for long-term prediction of maintenance based on the changes to operating machinery conditions.

- To show that these data can be formatted for use with projects and programs

- To show how future cost savings may be attainable from such instrumentation

- To show how this type of system need not compete with control system upgrade funding, but rather how one system can be used to help justify the other. 


\section{Transducers}

At the heart of any condition monitoring project are the devices that actually collect the data from the lock equipment. The transducers installed around the project provide the PLC with real-time high-speed data about the condition of various parameters. While there are literally hundreds of different transducers available, each with a specific purpose, time and funding constraints led to the selection of the following transducers for this demonstration project.

\section{Strain Gauges}

Four vibrating wire strain gauges were installed on the number one miter gate to monitor the stresses in the anchorage system. The primary and secondary anchorage bars on the miter gate were instrumented with Geokon VK-4100 vibrating wire strain gauges (Geokon, Inc., Lebanon, NH). The transducers are epoxy fastened to the anchor bars as shown in Figures 18 and 19. Permanent installation of such a system would normally require that these transducers be spot welded to the gate anchor bars. The strain gauges consist of a vibrating wire transducer, which is epoxy-fastened to the anchorage bar, and a molded coil housing clamped over the transducer.

The vibrating wires, when "plucked" by the electro-magnetic coil, resonate at a frequency dependent on the tension in the wire. Because the ends of the vibrating wire are rigidly bonded to the steel in the anchor bar, the frequency output is dependant on the stresses in the steel member. In this case, because a continuous readout of the strain is required, a Geokon 8020 single-coil Auto Resonator is used to pluck the vibrating wire and read the corresponding frequency output. The auto resonator is located in the PLC cabinet in spreader room no. 1. The output of the auto resonator is a high-frequency pulse that is read by a highspeed counter card in the PLC rack. The unique aspect in this application of strain gauges (which are used readily throughout the Corps) is the use of the auto resonator and the PLC to continually collect data from the strain gauges. The frequency output of the strain gauges is a pulse count equivalent to the micro strains seen in the units. Because it can be assumed these anchor bars are under some stress prior to the installation of the strain gauges and because this is only a demonstration project, it was decided to call the existing strain on the gates zero (0). Therefore, the PLC offsets the signal from the strain gauges to read 0 upon initial installation. The resulting strain is displayed on the operating screen as shown in Figure 20. 


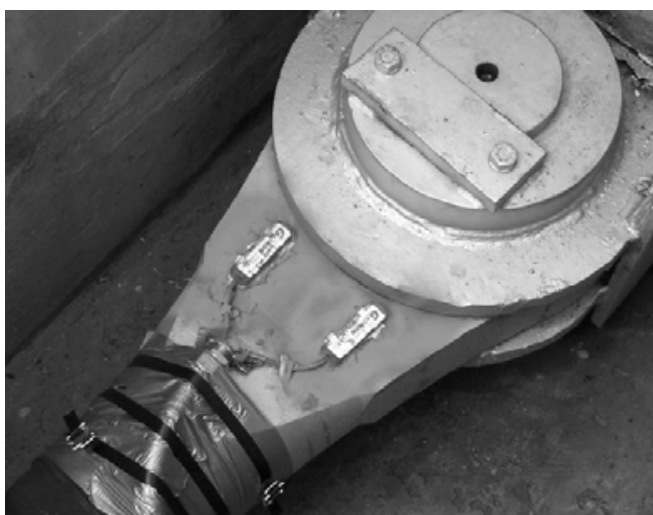

Figure 18. Strain gauges on miter gate anchor bar.

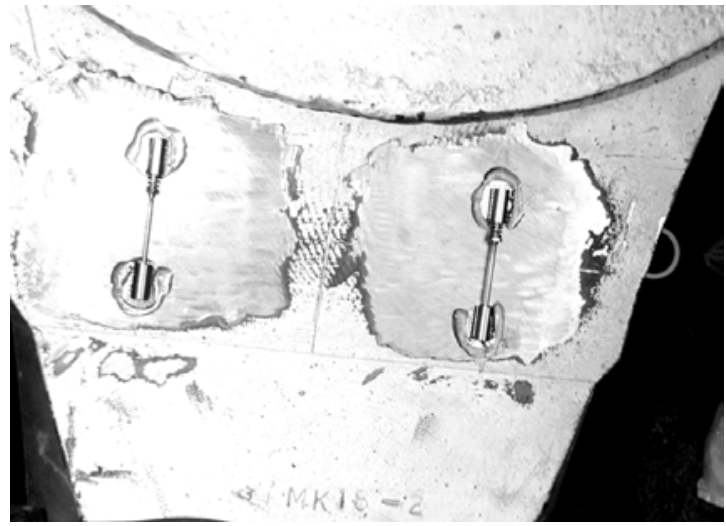

Figure 19. Vibrating wire transducer.

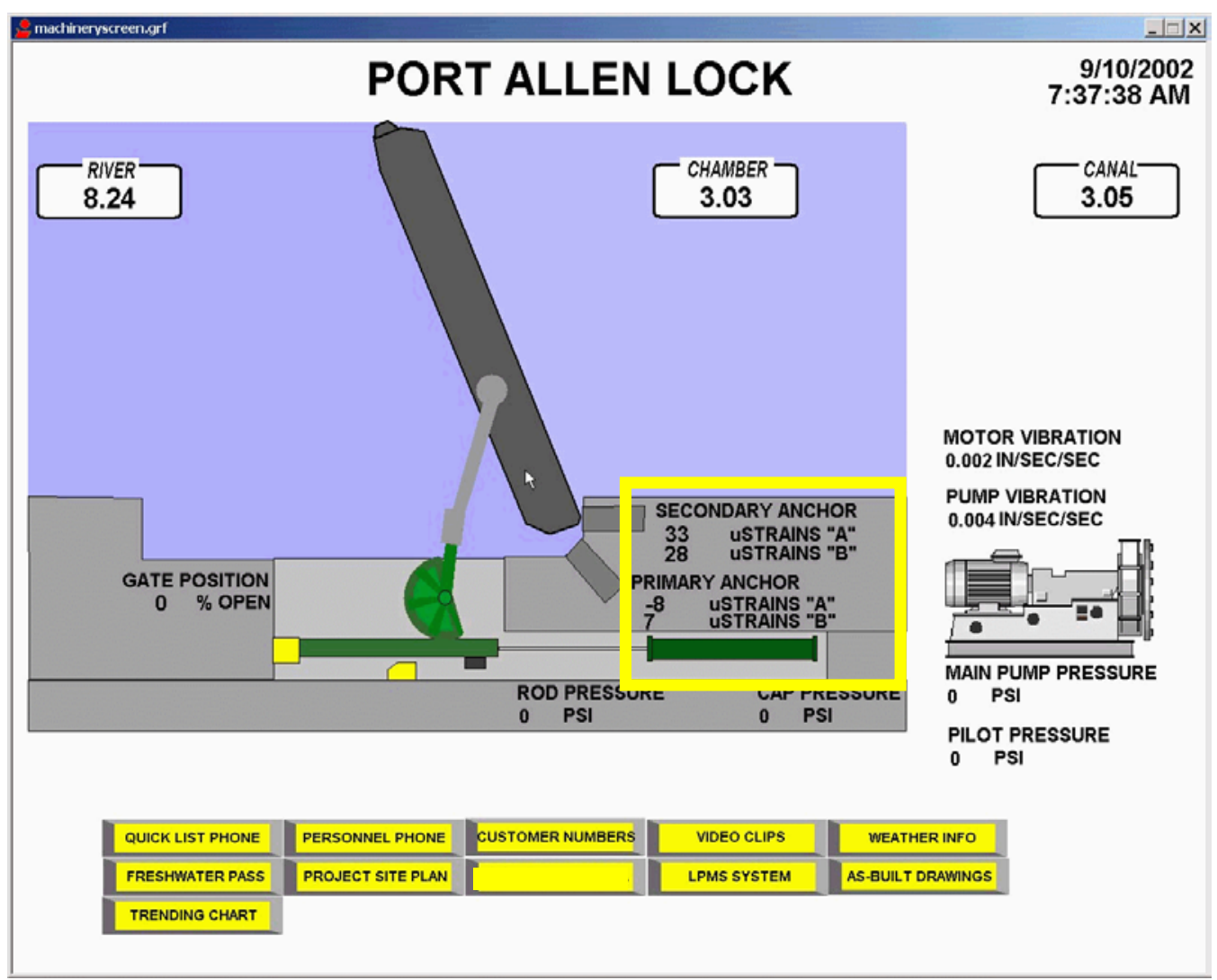

Figure 20. Port Allen operating screen showing the strain in the gate anchor.

\section{Vibration Transducer}

Two vibration transducers were installed, one each on the hydraulic pump and pump motor to monitor the vibration of each piece of equipment as the gate is moved. The transducers are Industrial Monitoring and Instrumentation (IMI) vibration transducer accelerometers. The transducer is epoxy-fastened to the motor housing as shown in Figure 21. An identical unit is on the hydraulic pump housing as shown in Figure 22. 


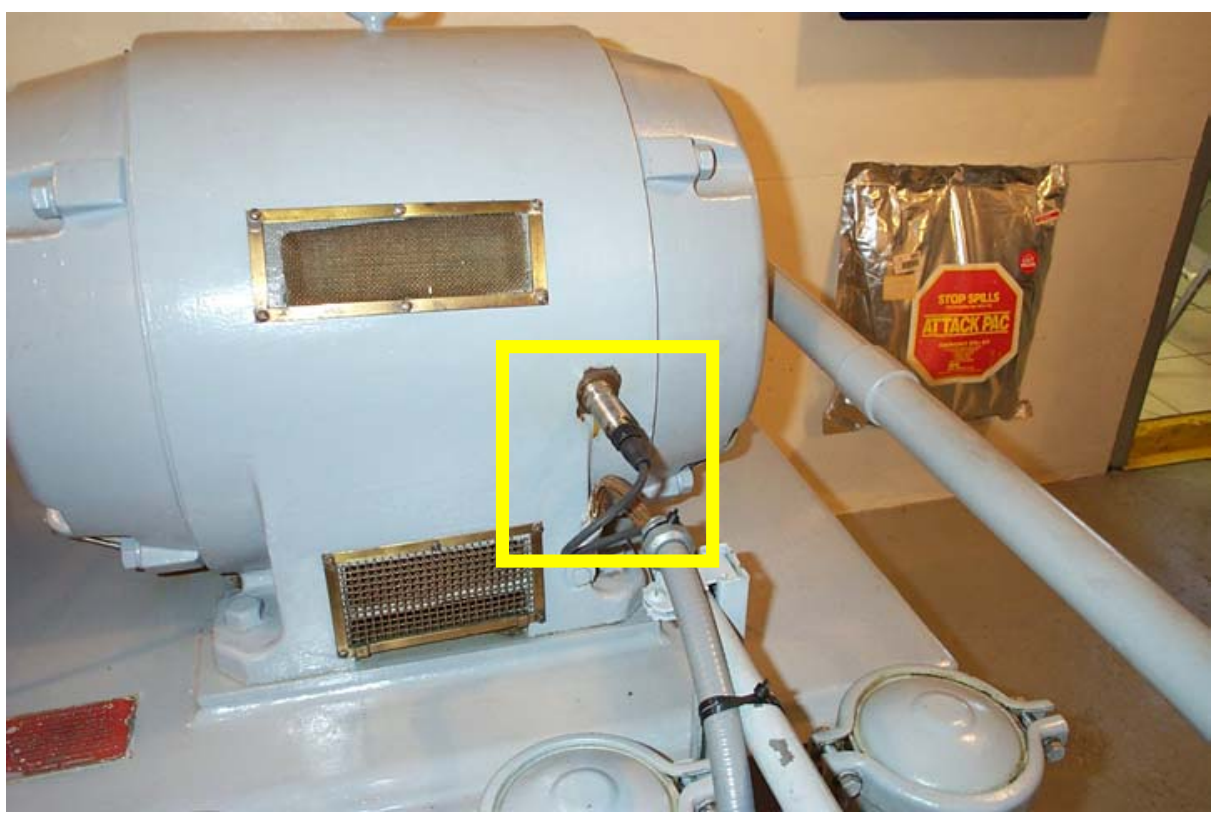

Figure 21. Vibration / accelerometer transducer on miter gate motor.

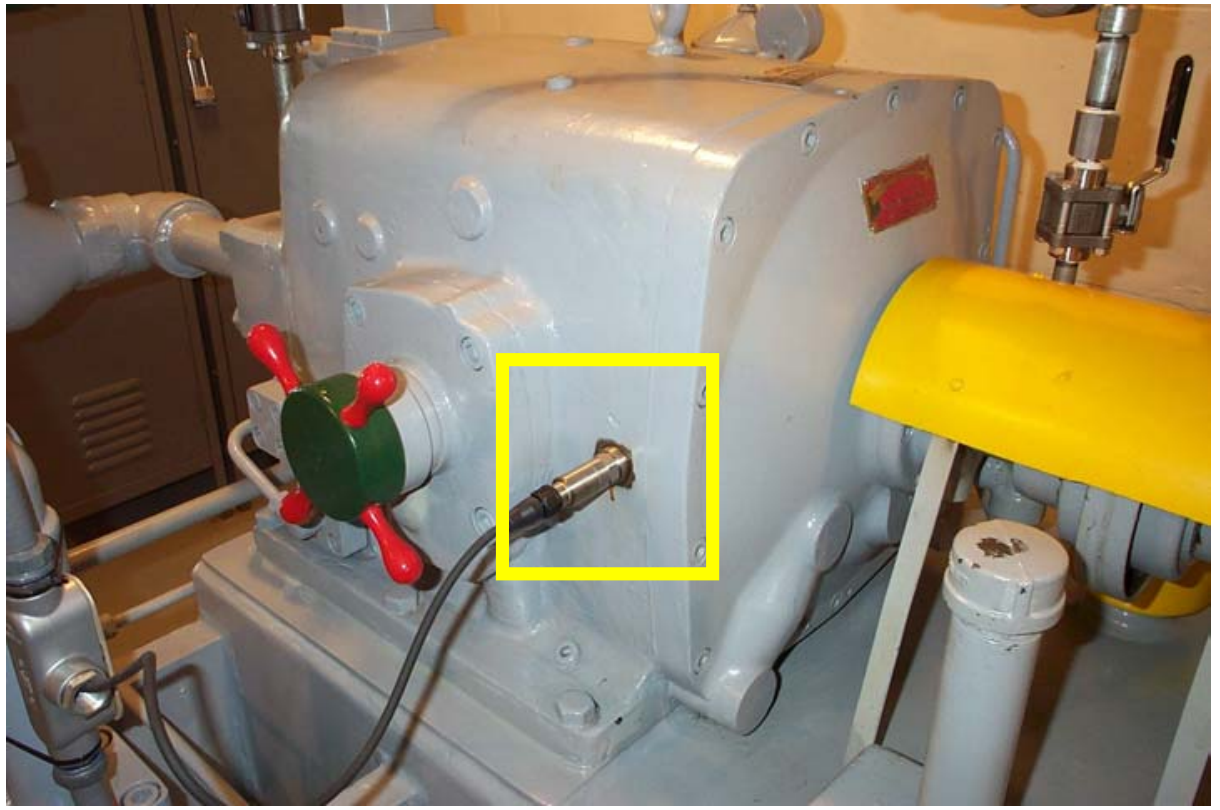

Figure 22. Vibration / accelerometer transducer on miter gate pump.

The transducers produce a 4-20 mA signal, which varies proportionately with the rms acceleration or peak velocity component of the input vibration, which in this case is the motor or pump housing. The engineering units are inches/second/ second. Table 1 shows the specifications of the units installed at Port Allen Lock. 
Table 1. IMI vibration transducer specifications.

\begin{tabular}{|c|c|c|}
\hline Dynamic Performance & English & SI \\
\hline Current Output & $4-20 \mathrm{~mA}$ & $4-20 \mathrm{~mA}$ \\
\hline Measurement Range & $0-1.0 \mathrm{in} . / \mathrm{sec} \mathrm{pk}$ & $0-25.4 \mathrm{~mm} / \mathrm{sec} \mathrm{pk}$ \\
\hline Resolution & $0.005 \mathrm{in} . / \mathrm{sec} \mathrm{pk}$ & $0.13 \mathrm{~mm} / \mathrm{sec} \mathrm{pk}$ \\
\hline Frequency Range: $( \pm 10 \%)$ & $180-60 \mathrm{kcpm}$ & $3-1000 \mathrm{~Hz}$ \\
\hline Amplitude Linearity & $\pm 1 \%$ & $\pm 1 \%$ \\
\hline \multicolumn{3}{|l|}{ Environmental } \\
\hline Temperature Range & -40 to $+185^{\circ} \mathrm{F}$ & -40 to $+85^{\circ} \mathrm{C}$ \\
\hline \multicolumn{3}{|l|}{ Electrical } \\
\hline Settling Time & $<60 \mathrm{sec}$ & $<60 \mathrm{sec}$ \\
\hline Supply Voltage Required & 15 to 30 VDC & 15 to 30 VDC \\
\hline Maximum Load Resistance & $50(\mathrm{Vs}-15)$ ohm & 50 (Vs-15) ohm \\
\hline Electrical Case Isolation & $>10^{8}$ ohms & $>10^{8}$ ohms \\
\hline \multicolumn{3}{|l|}{ Mechanical } \\
\hline Size (hex $x$ height) & $7 / 8 \times 2.48$ in. & $22.2 \times 55.7 \mathrm{~mm}$ \\
\hline Weight & $3.2 \mathrm{oz}$ & $90 \mathrm{gm}$ \\
\hline Mounting Thread & 1/4-28 UNF-2B & 1/4-28 UNF-2B \\
\hline Mounting Torque & 2 to $5 \mathrm{ft}-\mathrm{lb}$ & 2.7 to $6.8 \mathrm{~N}-\mathrm{m}$ \\
\hline Sensing Element & Ceramic/Shear & Ceramic/Shear \\
\hline Case Material & Stainless Steel & Stainless Steel \\
\hline Sealing (Welded) & Hermetic & Hermetic \\
\hline Electrical Connector, 2-pin (top) & MIL-C-5015 & MIL-C-5015 \\
\hline \multicolumn{3}{|l|}{ Supplied Accessories } \\
\hline \multicolumn{3}{|l|}{ Model 081A40 Mounting Stud (1) } \\
\hline \multicolumn{3}{|c|}{ Calibration: Current output at $0,10,100$, and $1000 \mathrm{~Hz}$} \\
\hline \multicolumn{3}{|c|}{ Optional Versions (Indicate using prefix letter shown) } \\
\hline M - Metric installation via supplie & $1 \mathrm{~A} 61$ stud, $1 / 4-28$ to & $6 \times 1.0$ \\
\hline
\end{tabular}

The PLC reads this signal and displays the value on the screen, programmed into the proper engineering units. See the IMI 640 Series bulletin for additional information on the transducer. The resulting vibration is displayed on the operating screen as shown in Figure 23. 


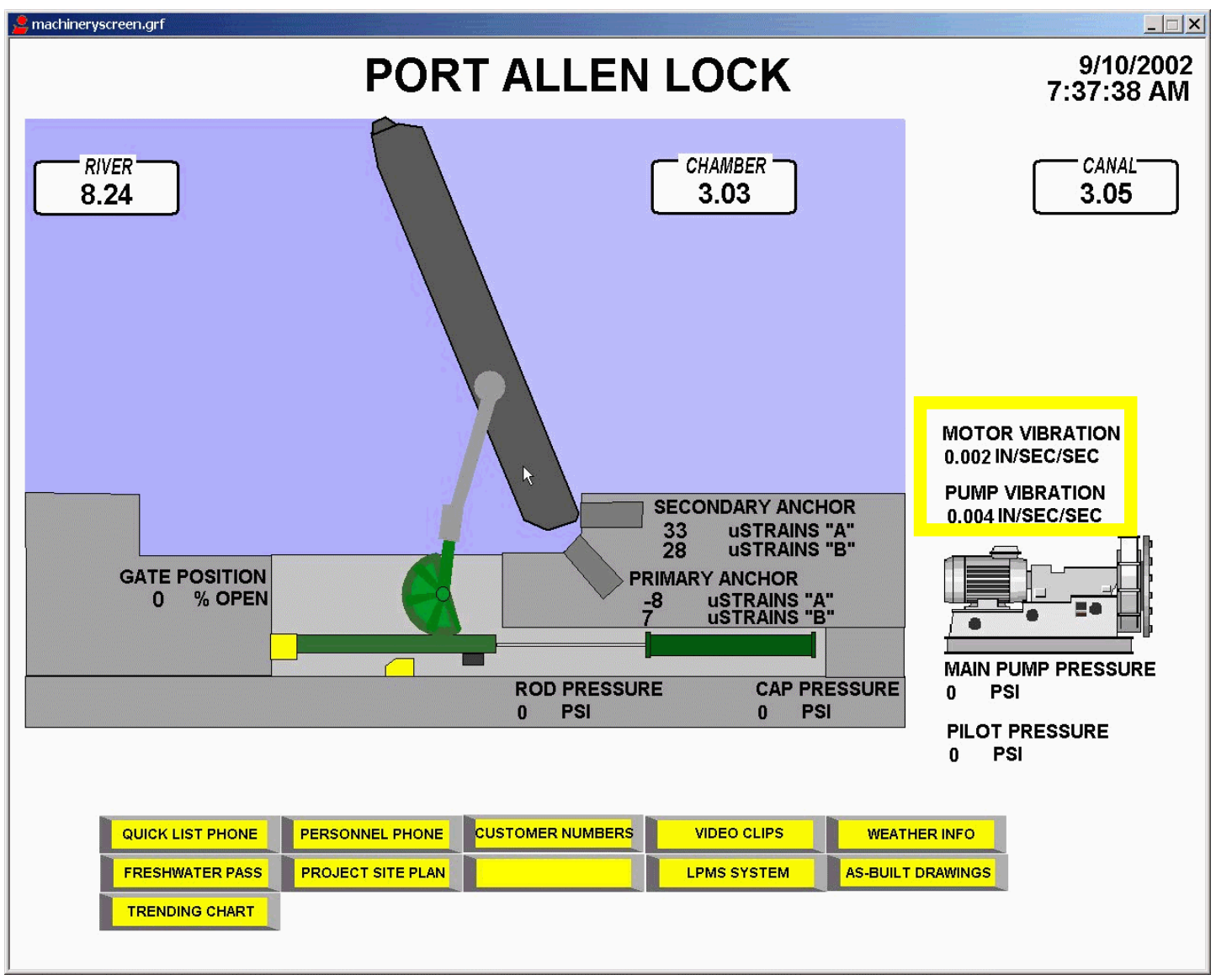

Figure 23. Port Allen operating screen showing the vibration of the pump and motor.

\section{Hydraulic Pressure Transducer}

The project included the installation of four hydraulic pressure transducers: one located on the main system pump, one on the pilot pressure line, one on the cylinder rod end, and one on the cylinder cap end. The pressure transducers (Setra Systems, Inc., Boxborough, MA) are capacitive in nature meaning they are designed adaptations of a simple, durable, and fundamentally stable device - the electrical capacitor. A compact housing contains two closely spaced, parallel, electrically isolated metallic surfaces, one of which is essentially a diaphragm capable of slight flexing under applied pressure. The diaphragm is constructed of a low-hysteresis material, 17-4 PH SS. These firmly secured surfaces (or plates) are mounted so that a slight mechanical flexing of the assembly, caused by a minute change in applied pressure, alters the gap between them creating, in effect, a variable capacitor. The resulting change in capacitance is detected and converted by an Application Specific Integrated Circuit (ASIC) to a proportional high-level analog signal. The result is a 4-20 mA signal, which varies proportionately with the pressure in the hydraulic line. See Figures 24 and 25. See Table 2 for pressure transducer specifications. 


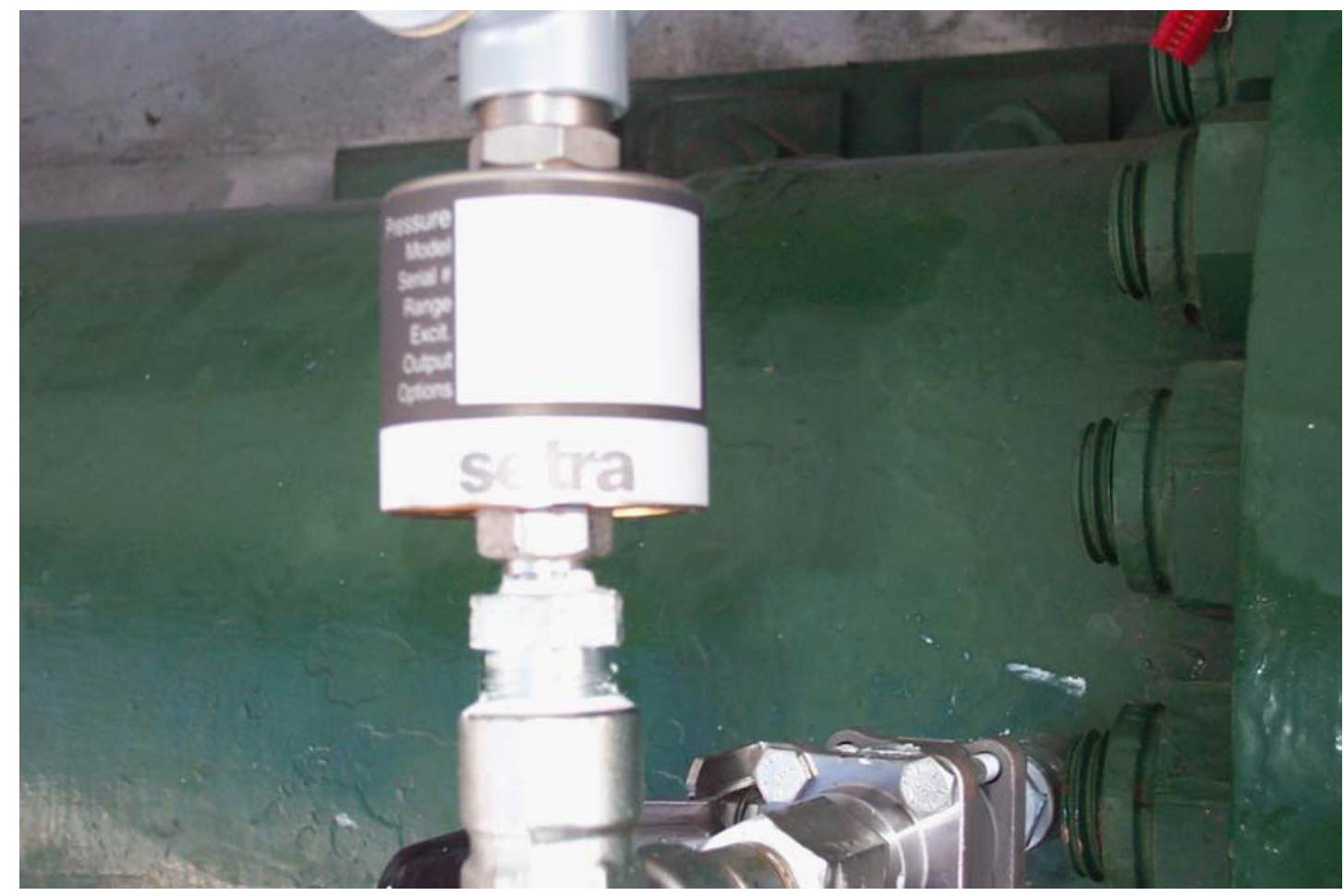

Figure 24. Hydraulic pressure transducer sensor.

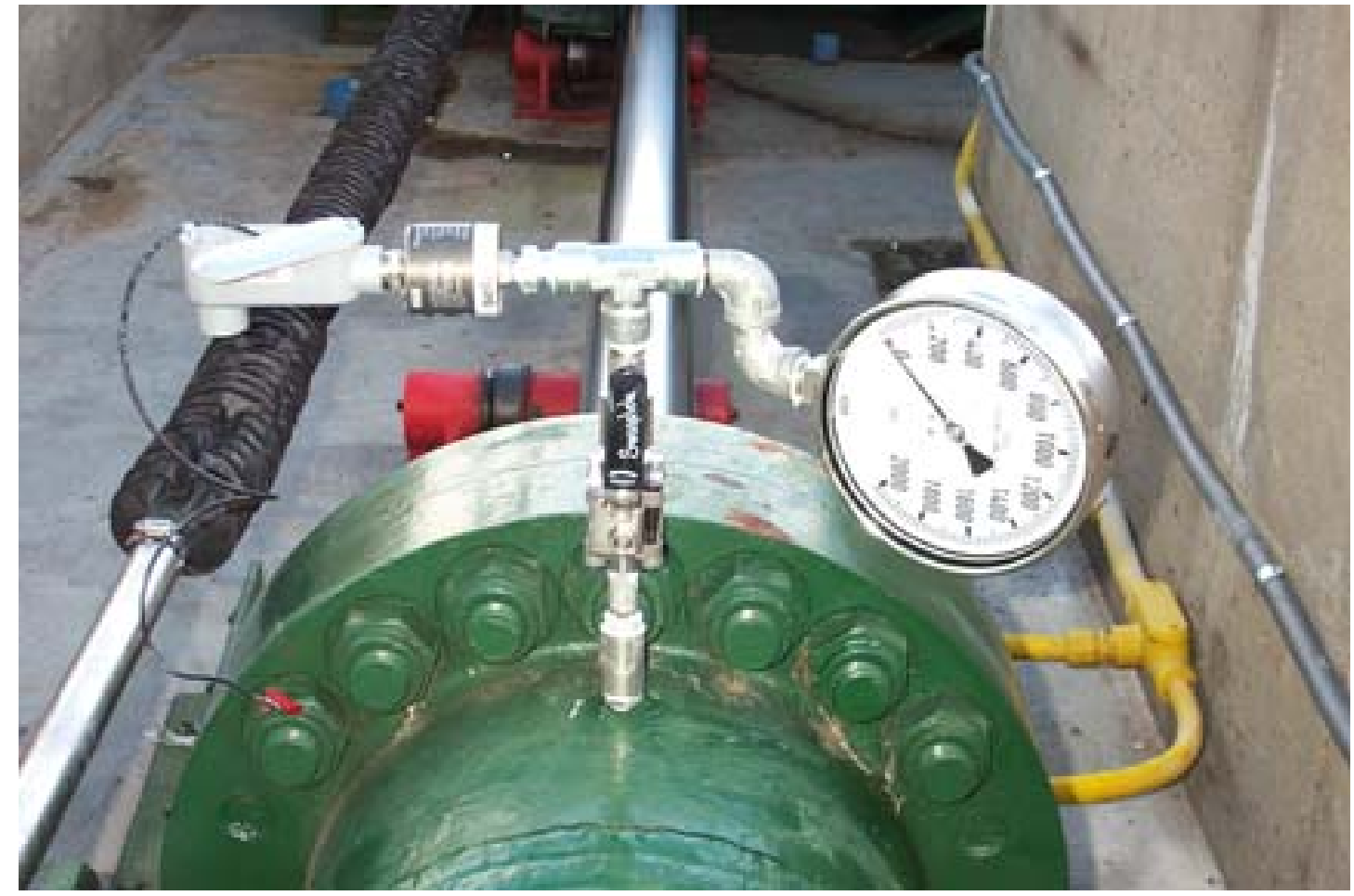

Figure 25. Hydraulic pressure transducer. 
Table 2. Pressure transducer specifications.

\begin{tabular}{|l|l|l|}
\hline Full Scale Pressure Output & $\begin{array}{l}\text { Model 206/207 (Voltage): } \\
5.1 \mathrm{VDC}\end{array}$ & $\begin{array}{l}\text { Model C206/C207 (Current): } \\
20 \mathrm{~mA}\end{array}$ \\
\hline Zero Pressure Output & $0.1 \mathrm{VDC}$ & $4 \mathrm{~mA}$ \\
\hline $\begin{array}{l}\text { Accuracy } \\
\text { (RSS Method) }\end{array}$ & $\pm 0.13 \%$ Full Scale \\
\hline Type of Pressure & Gauge \\
\hline Pressure Ranges & 0 to $25,50,100,250,500,1000,3000,5000,10000 \mathrm{psig}$ \\
& $1.6,4.0,6.0,10,16,25,40,60,100,160,250,400,700$, bar \\
$($ Model 206 only)
\end{tabular}

Monitoring of the pressure in the hydraulic lines is critical because any obstruction or mechanical/structural binding of the gates will almost certainly result in varying pressures in the hydraulic cylinder lines. Siltation, for example, which can lead to gate failure, will cause gradual increases in the hydraulic pressures of the lines. These increases, which would otherwise go unnoticed, may be within equipment tolerance, yet they are signs of impending failure. Structural damage to the gate is costly and time consuming to repair. Early indication of abnormal (i.e., different than baseline) conditions is critical in predicting early M\&R and avoiding unscheduled closures and costly repairs. The machinery screen shown in Figure 26 indicates the hydraulic pressures at Port Allen.

\section{Water Level Sensors}

Port Allen Lock previously had a water level system as part of a data collection platform manufactured by Handar (Vaisala/Handar, Woburn, MA). The old system consisted of two floats, one in the river and one in the canal, and a display on the existing control console in the no. 1 control house. See Figures 27 and 28. 


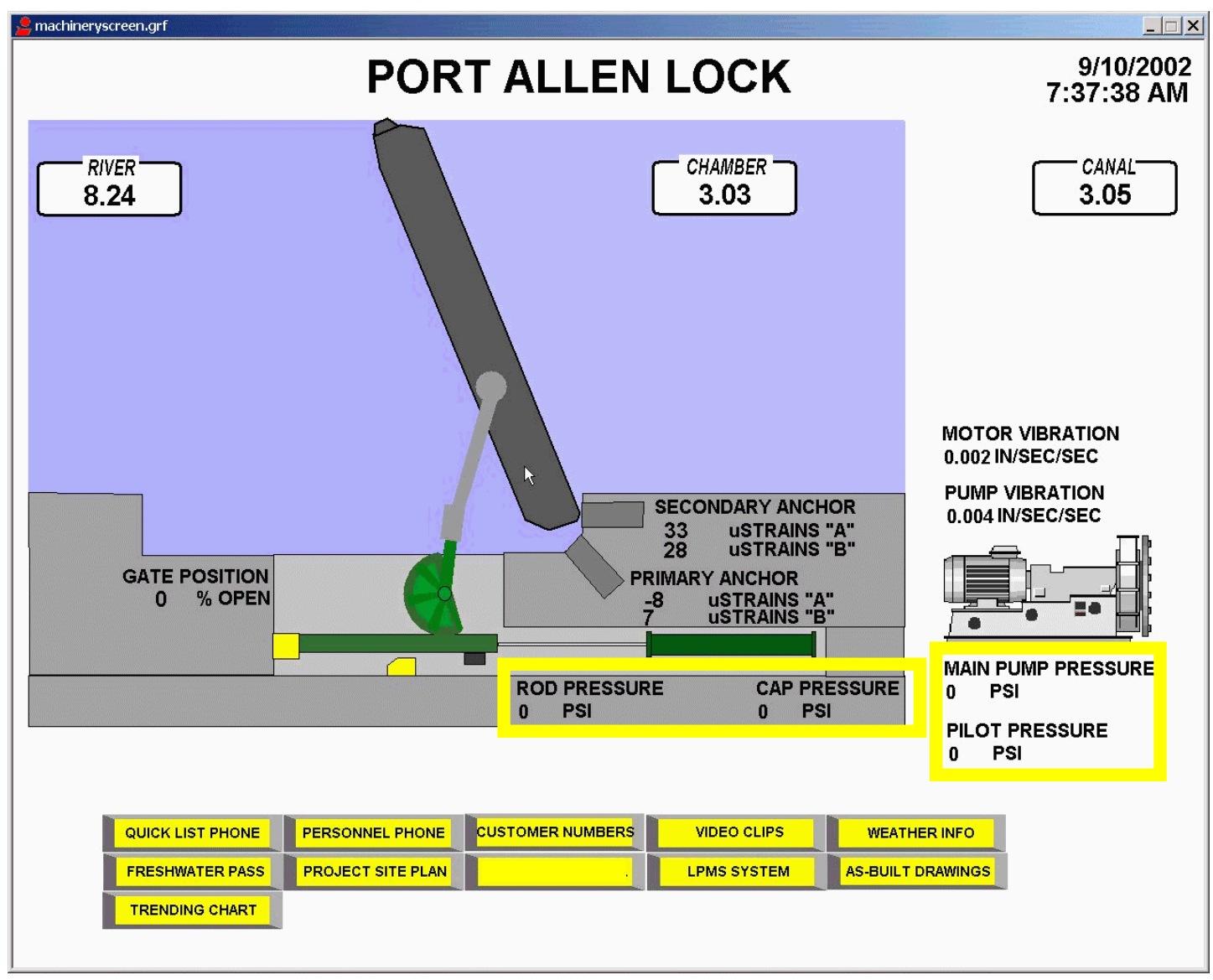

Figure 26. Port Allen machinery screen showing hydraulic pressure transducer signals.

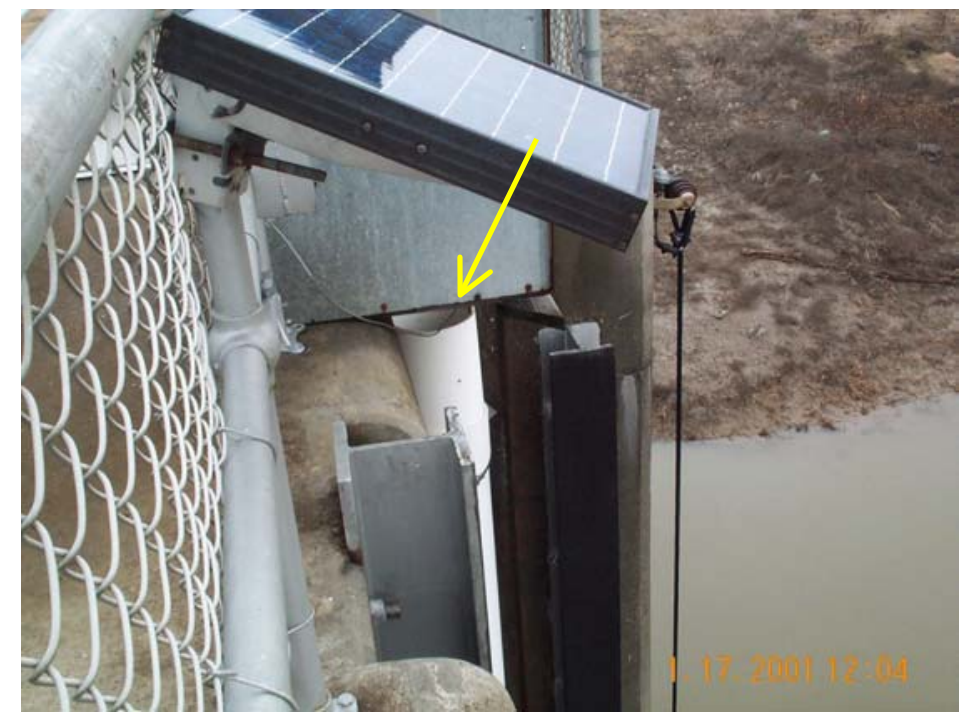

Figure 27. Existing floatwell. 


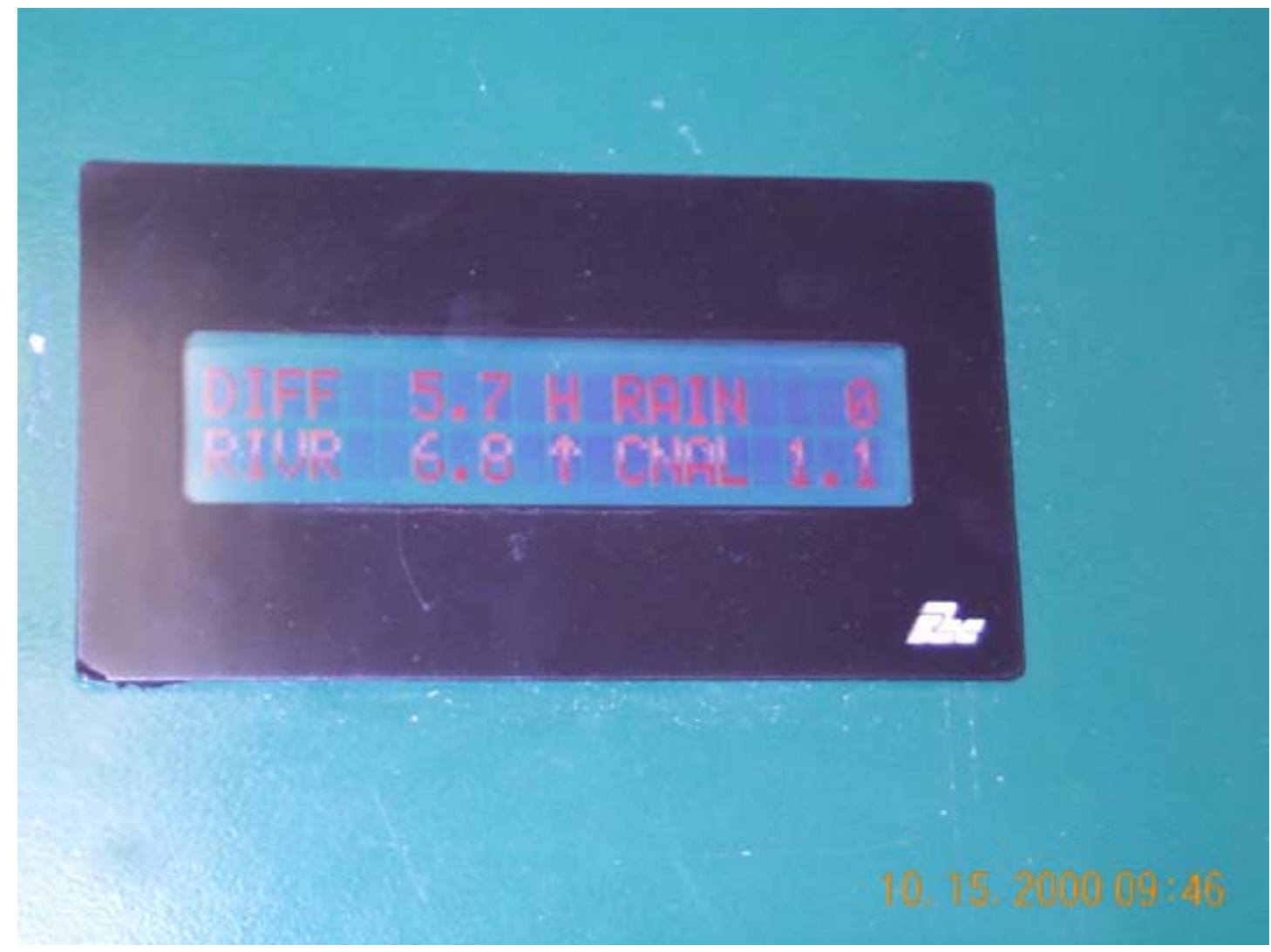

Figure 28. Existing river / canal gauge readout on control console no. 1.

The data collection platform shown in Figure 29 also collected rainfall data. Lock personnel had previously purchased a new wind speed/temperature transducer sending unit and the necessary firmware upgrades, but had no way of displaying the new signal because the display in the console (Figure 28) was limited to just the river, canal, and hourly rainfall stages with the time and date. Because the Handar unit shown in Figure 29 had a direct digital serial RS-422 output, the PLC, through the use of a serial input card, was able to directly read the message from the unit. This message contained the relative weather data in addition to the river and canal stages. The PLC was programmed to write the data into separate registers for displaying and trending by the HMI. This demonstration project allowed the lock operating personnel to use the PLC and HMI software to view all of the data on an operating screen. The demonstration then allowed the data concerning the river and canal stages to be trended as part of the condition monitoring project. The other information from the data collection platform is displayed on the operating screen but is also trended to see what effects it may have on the condition of the gate machinery. Figure 30 is a screen capture showing the relative weather data. 


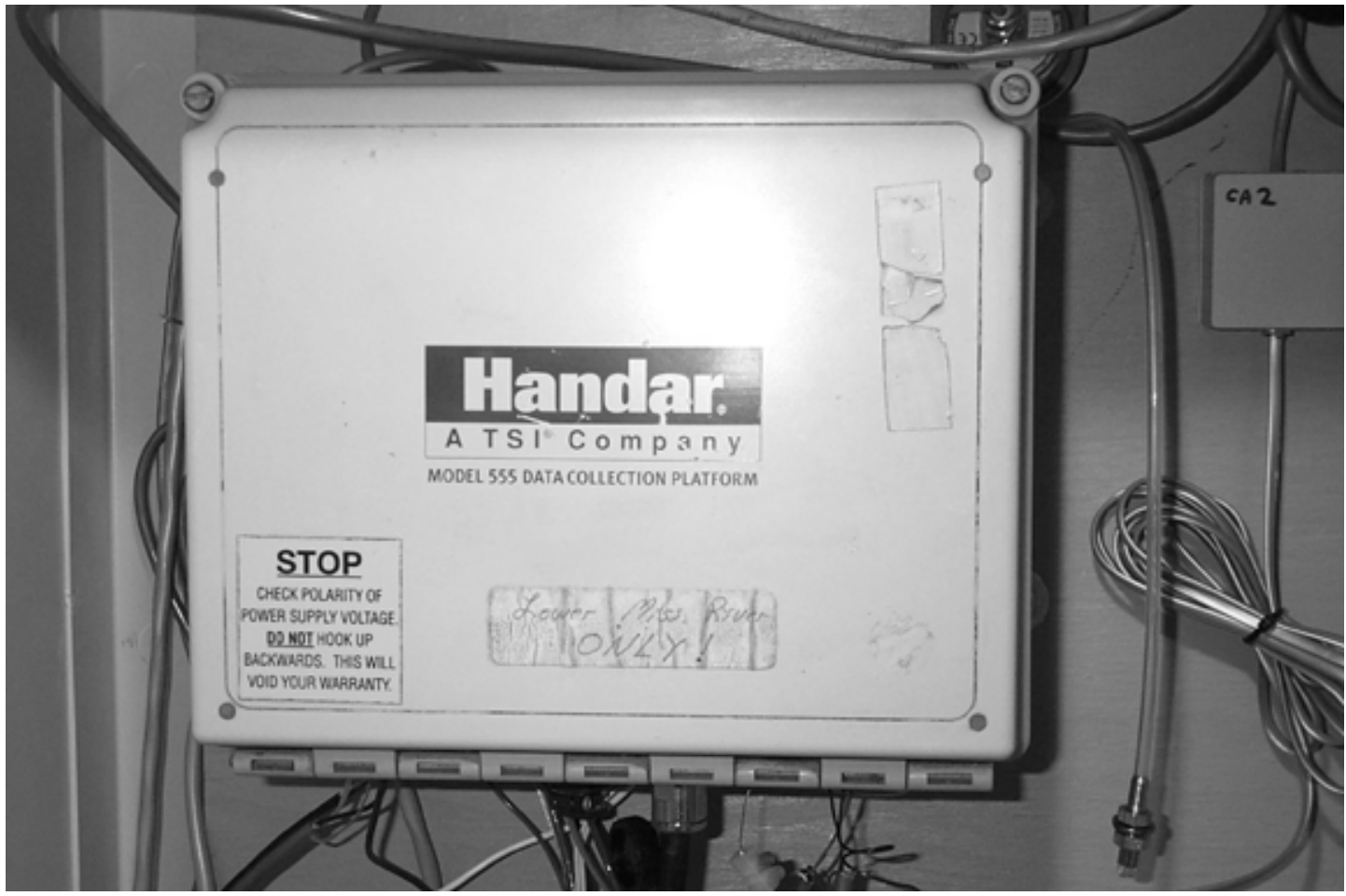

Figure 29. Handar data collection platform at Port Allen Lock.

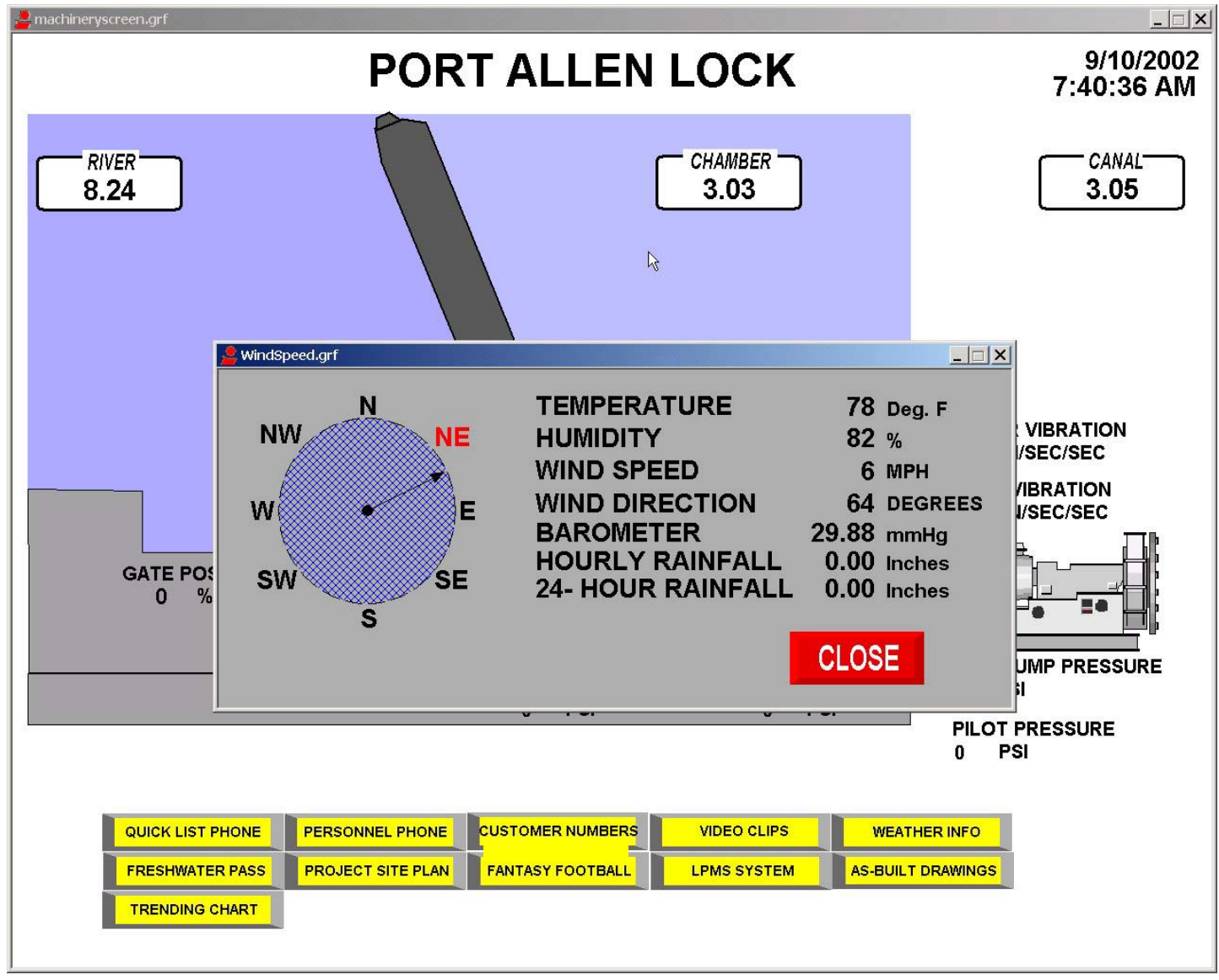

Figure 30. Screen capture showing weather data collection platform information. 
The PLC system chosen for this demo project, Modicon's Quantum Q534-14, has a built-in web server as part of the processor I/O rack Ethernet interface card. The web server is limited in space and has limited graphical applications (when compared to the HMI software Intellution iFix), but it has the ability to allow certain read-only data to be displayed using nothing more than Microsoft ${ }^{\mathbb{}}{ }^{\prime} \mathrm{S}$ standard Internet Explorer (IE) package. This option allows anyone within the Corps of Engineers firewall protection to see the data. Arrangements are being made to automatically publish the data on the New Orleans District website so local public interests can view it also. Figure 31 is a screen capture of the IE version of the PLC web server. This technology proved very useful during a recent hurricane (Lily) when real-time weather data were needed on a continual basis at the District office as decisions on hurricane alert status had to be made.

Because the chamber elevation is critical in assessing the stresses on the gates, the pressure on the hydraulic system, and the vibration of the motor and pump, a submersible pressure transducer was installed in a ladder recess in the lock chamber. Figure 32 shows the Druck PTX 1830 (Druck Inc., New Fairfield, CT) selected for this experiment. The corresponding Druck STE-110 Sensor Termination Enclosure was also installed in an area safe from submergence. Although not currently installed on the locks, an optional lightning arrester (also made by Druck) mounts in the STE-110 enclosure.

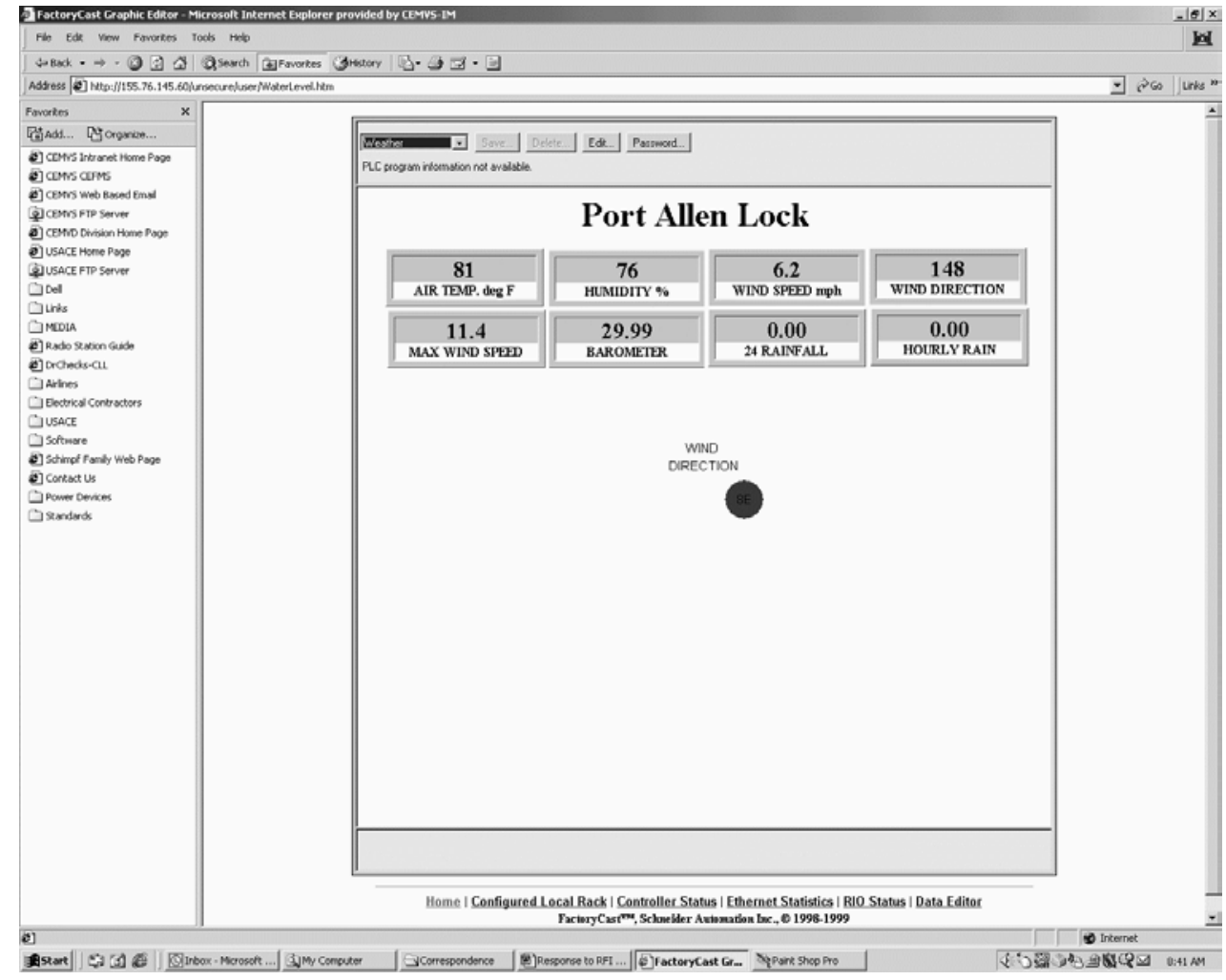

Figure 31. Web browser screen of the PLC web server showing weather data. 


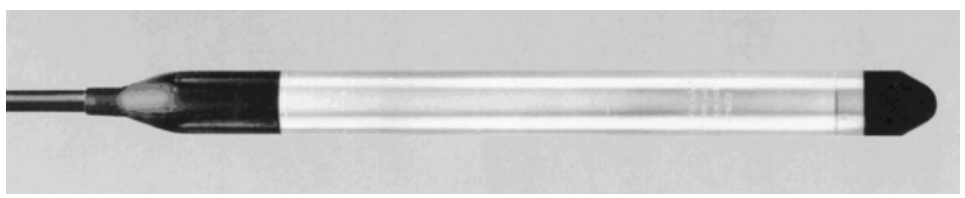

Figure 32. Druck PTX 1830 pressure transducer.

The PTX 1830 series of submersible pressure transmitters offers accuracy and versatility in the measurement of liquid levels. They feature a 4-20 mA output signal, which permits the use of an extremely long cable. The all titanium construction of the transmitters ensures long-term and reliable measurements of water depth. They also incorporate an advanced, silicon piezoresistive pressure sensor, which provides resistance to shock and vibration. A polyurethane cable is molded to the transmitter body to provide a high integrity, waterproof assembly. The cable is strengthened with Kevlar to prevent any measurable elongation when the cable is lowered into the lock chamber. The PTX 1830 has been designed for applications where space is very restricted. With a body diameter of only 0.7 in., it provides an important installation advantage in small diameter standpipes. In this demonstration, the unit was installed behind a ladder in a recess on the north lock wall in a 2-in. polyvinyl chloride (PVC) pipe. The PTX 1830 is available in vented and sealed gauge pressure ranges from 0 to 5 psi through 0 to 900 psi as shown in Table 3. For this project, a vented 20-psi unit was selected. The purpose of the vent is to provide a reference to atmospheric pressure to allow stability in the signal when atmospheric pressure conditions change as opposed to a change in water levels. The 20-psi rating was chosen because of the maximum fluctuation of chamber level.

Table 3. Specifications for the Druck Submersible Pressure Transducer.

\begin{tabular}{|c|c|}
\hline Operating pressure ranges & 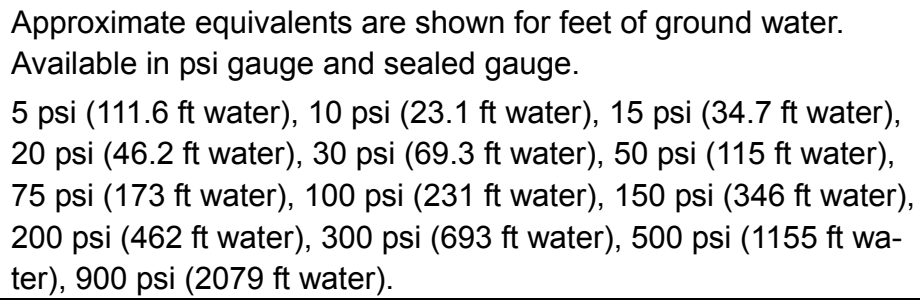 \\
\hline Overpressure & $\begin{array}{l}\text { The rated pressure can be exceeded by the following multiples } \\
\text { causing negligible calibration change: } \\
3 \times \text { for } 5 \text { psi range } \\
2 \times \text { for all other ranges }\end{array}$ \\
\hline Pressure media & $\begin{array}{l}\text { Fluids compatible with glass, silicon, titanium, and the polyure- } \\
\text { thane cable. }\end{array}$ \\
\hline Transduction principle & Integrated silicon strain gauge bridge. \\
\hline
\end{tabular}




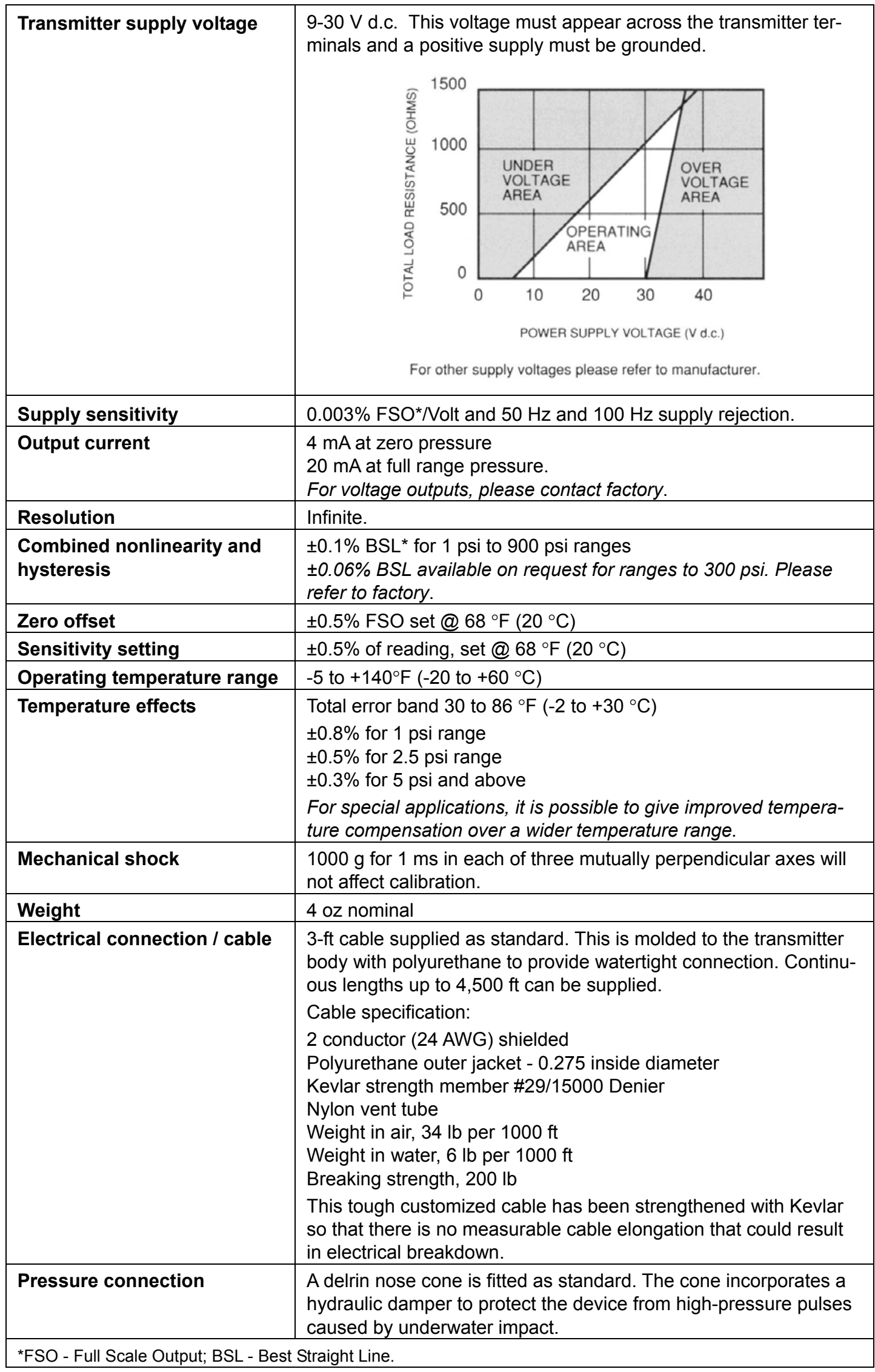


Excitation voltage. Most Druck transmitters work fine on 24 Volts Direct Current (VDC) nominal power; 10 to 30 VDC should be adequate for most applications. A 24 VDC power supply was supplied as part of the I/O rack assembly.

Installation. Before installing a depth/level pressure sensor, it is advisable to review certain criteria to ensure success. The following pre-installation guidelines were followed for this project:

1. Check to see that the proper range has been specified.

2. Select the proper accuracy. For best accuracy it is important that the optimum full scale be specified. To do this it is important to know how accurate the results of the output must be. In this case, because we were looking for accuracy of $0.01 \mathrm{ft}$, the transducer had to have an accuracy of $0.02 \%$ Full Scale (FS). Because the transducer is limited to 0.06 percent accuracy, or $0.027 \mathrm{ft}$, the corresponding output cannot be considered as totally accurate to 0.01 of a foot. The accuracy does, however, far exceed $0.1 \mathrm{ft}$.

3. Make sure that sufficient cable has been specified and provided to achieve the required depth. Normal practice recommends that the length of cable is equal to the depth below the measuring point at which the sensor will be located plus any lengths of cable necessary to reach the termination point. Because vented cable is relatively expensive, a terminal box is normally located close to the transmitter on the outside face of the lockwall where it is not subject to submergence. This allows a less expensive cable without a vent tube to be used for the distance from the terminal box to the PLC I/O rack. Refer to Figure 33 for typical cabling.

4. It is mandatory that a desiccant be used to prevent moisture from condensing and entering through the cable or vent tube. It is important to dry the air that can contain water vapor before allowing it to breathe into the sensor. The cable vent, as well as conductors, is a source of moisture ingress. The Druck STE-110 removes moisture from the air that can breathe through the vent or cable core. 


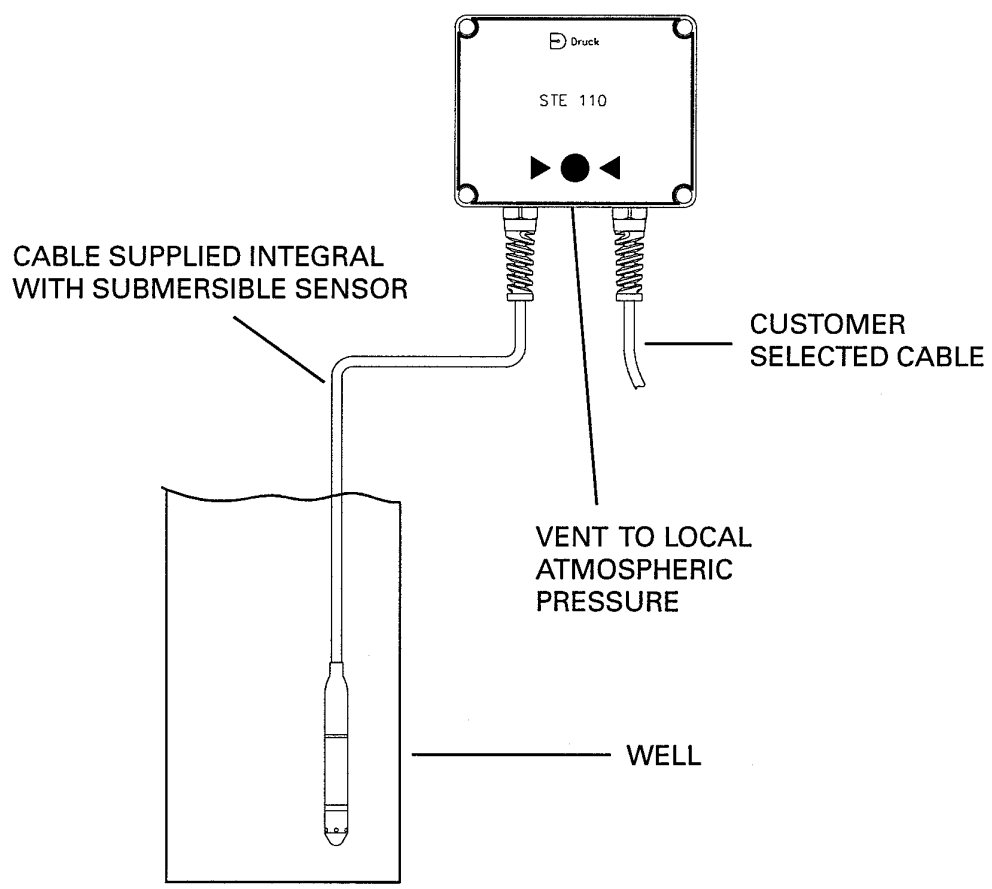

Figure 33. Pressure transmitter cabling.

One of the most important aspects of the water level sensing system is knowing how to calibrate the pressure transmitters. The Druck model currently used comes in several pressure ranges. Before calibrating the transmitter, or ordering a new one, it is important to understand which pressure ranges are appropriate for the application. The first step is to determine the depth to be measured. At Port Allen Lock, the minimum normal canal level is $2.0 \mathrm{ft}$ on the sill gauge, and the maximum normal river stage is $40.0 \mathrm{ft}$. The difference is $38.0 \mathrm{ft}$. The following formula is used to determine the pressure range required:

$$
P=\frac{L}{C_{f} S_{g}}
$$

where $\mathrm{P}=$ Pressure in psig; $\mathrm{L}=$ Level in feet; $\mathrm{C}_{\mathrm{f}}=$ Conversion Factor of Pressure in psi to feet; $S_{g}=$ Specific Gravity of the fluid being measured.

In the case here, $\mathrm{L}=38.0 \mathrm{ft}, \mathrm{C}_{\mathrm{f}}=2.307323 \mathrm{ft} / \mathrm{psi} @ 50{ }^{\circ} \mathrm{F}, \mathrm{S}_{\mathrm{g}}=1.000882046 @$ $50^{\circ} \mathrm{F}$, so that the pressure is:

$$
P=\frac{38.0 \mathrm{ft}}{(2.307323 \mathrm{ft} / \mathrm{psi}) \times(1.000882046)}=16.5 \mathrm{psi}
$$


The nearest standard pressure range for the Druck transmitters greater than this value is 20 psi. Therefore, the 20 -psi model was selected for this demonstration.

Once the transmitters are installed and connected to a PLC analog input module, the scale factor and offset need to be determined for use in the PLC programming logic. Using simple math, the water level is calculated as follows:

$$
L=I \times \text { scale } \div 10000+\text { offset }
$$

where $\mathrm{L}=$ the water level in feet; $\mathrm{I}=$ the raw value in the analog input module; scale is the scaling factor to be determined; offset is the offset in feet to be determined.

There are two ways to determine the scale factor. The first one is to use the transmitter operating pressure range to calculate the scale factor. Since the Modicon analog input modules have a raw input range from 640 to 32676, the scale is simply the operating range (46.2 ft for the 20 psi PTX 1830 model) divided by the analog input card range. The second method of determining the scale factor serves as a check on the previous method and requires the level transmitter to be lowered to two different levels and the analog input value noted at each level. The scale and offset are then calculated as follows:

$$
\text { scale }=\frac{L_{2}-L_{1}}{I_{2}-I_{1}} \quad \text { offset }=\text { reference level }-L_{2}
$$

where $\mathrm{L}_{1}=$ length of cable (in feet) at upper level; $\mathrm{L}_{2}=$ length of cable (in feet) at lower level (where transmitter will be permanently positioned); $\mathrm{I}_{1}=$ analog input value at upper level; $\mathrm{I}_{2}=$ analog input value at lower level; reference level = known elevation such as top of lock wall

The Druck STE-110 Sensor Termination Enclosure (Figure 34) is a compact and rugged enclosure providing simple field termination for vented gauge pressure transducers and transmitters. An integral microfilter assembly permits barometric reference while providing an effective barrier against ingress of dust. A field-replaceable DRI-CAN desiccant module is attached to the internal face of the enclosure. This module attracts water vapor, condenses it, and retains it through surface absorption and capillary condensation. The module is easily accessible once the cover is removed, and no tools are required for its replacement. A moisture status indicator, which is clearly visible externally, alerts the user when replacement of the desiccant module is necessary. 


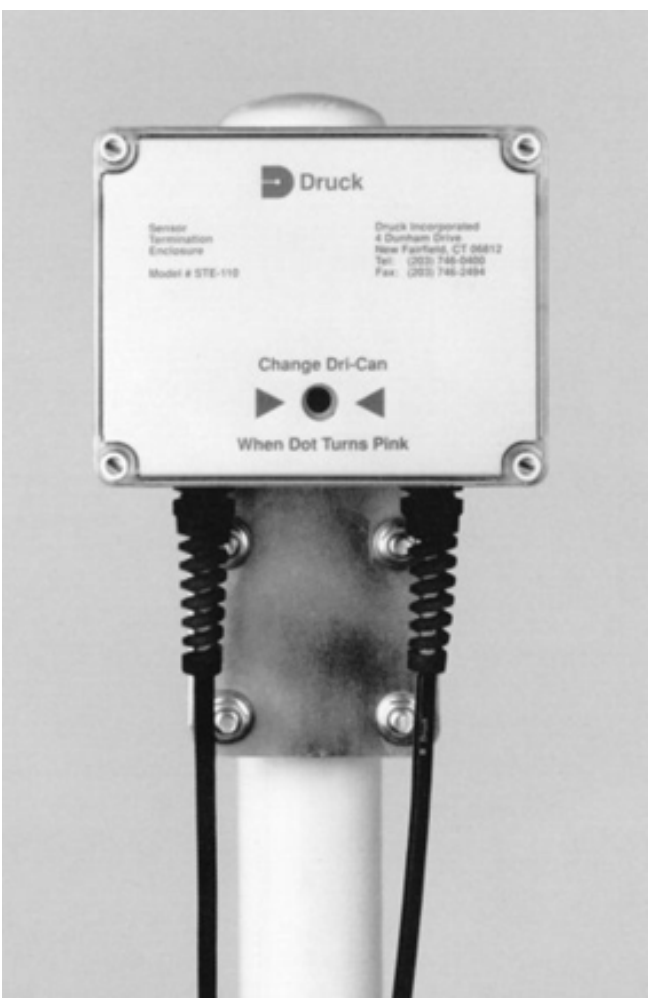

Figure 34. Druck STE-110 sensor termination enclosure.

The NEMA 4X enclosure is custom designed for outdoor installation and protects against corrosion, windblown dust and rain, splashing, and hose-directed water. The STE-110 is manufactured from PVC/polycarbonate, which results in a lightweight and highly impact resistant construction. See Table 4 for enclosure details.

Table 4. Druck STE-110 sensor termination enclosure specifications.

\begin{tabular}{|l|l|}
\hline Enclosure Environmental Rating & NEMA 4X \\
\hline Enclosure Material & $\begin{array}{l}\text { PVC base and clear halogen-free, self-extinguishing polycar- } \\
\text { bonate cover }\end{array}$ \\
\hline Color & Self-colored light gray \\
\hline Terminal Strip & 7 DIN STD terminals accepting 24 AWG to 12 AWG wires. \\
\hline Cable Glands & $\begin{array}{l}\text { Located at base of enclosure. Accept cable diameters of } 0.23 \\
\text { to } 0.39 \text { in. }\end{array}$ \\
\hline Desiccant Module & $\begin{array}{l}\text { Status colors: Blue - dry; pink - saturated. Heating the } \\
\text { DRI-CAN in a vented oven at } 300^{\circ} \mathrm{F} \text { for approximately } 3 \mathrm{hr} \text {, } \\
\text { or until the blue color returns, will restore the silicon gel ab- } \\
\text { sorbent capabilities of the module. }\end{array}$ \\
\hline Micro Filter & $\begin{array}{l}\text { Located at the base of enclosure } \\
\text { Material: Gore-Tex }\end{array}$ \\
\hline Weight & 2 Ib (nominal). \\
\hline Option & $\begin{array}{l}\text { (A) 2-in. pipe mounting kit. Manufactured from zinc-plated } \\
\text { mild steel. }\end{array}$ \\
\hline
\end{tabular}




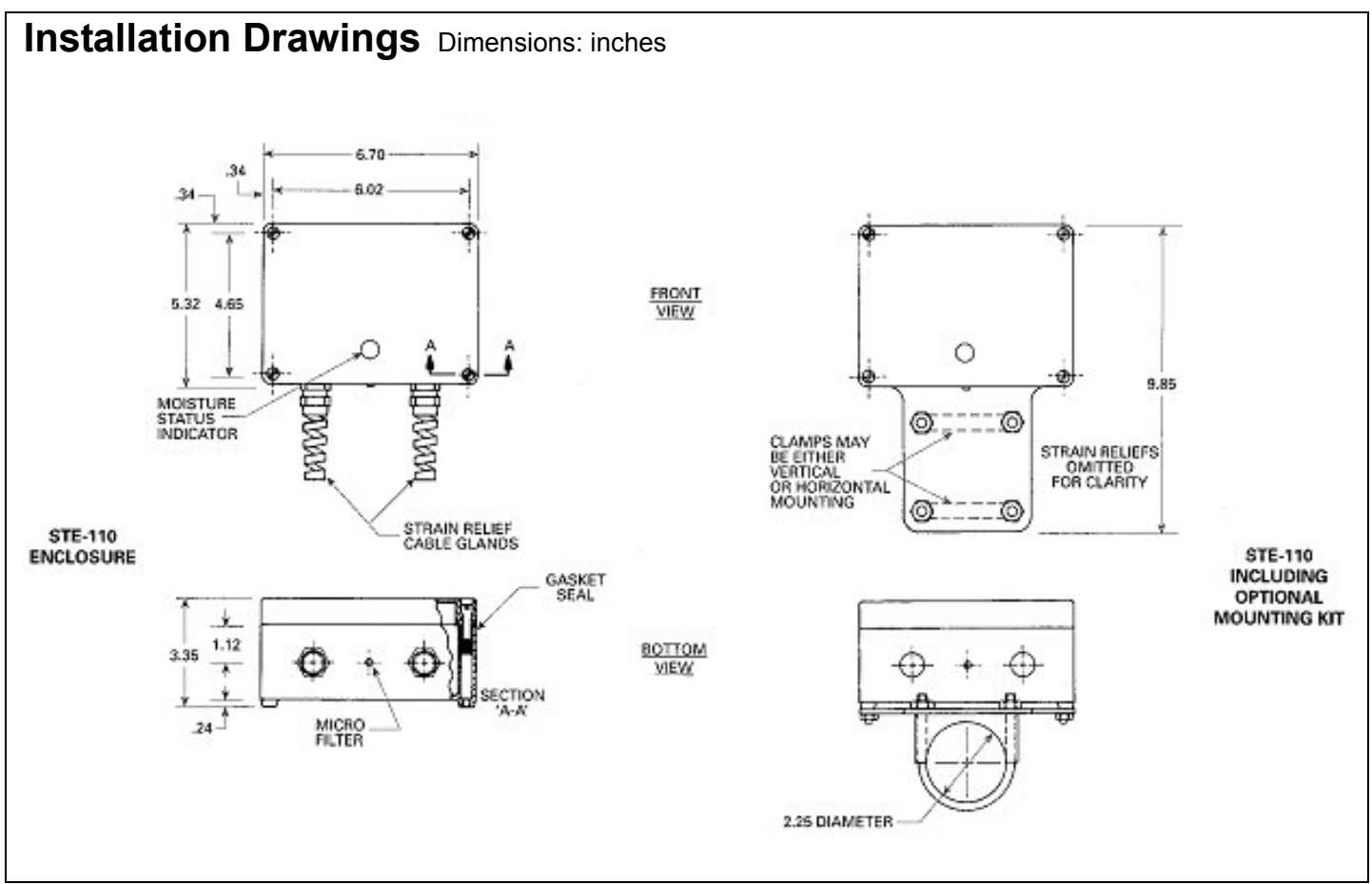

\section{Gate Position Sensor}

The position of the miter gate is also critical when evaluating the hydraulic loads as well as the stresses in the gate anchorages. Therefore, a gate position sensing system was an essential part of this project. A linear displacement transducer was chosen for this application. The position of the miter gate is derived from the linear movement of the hydraulic cylinder driving the sector gear arrangement. A Gemco Series 940 LDT transducer is mounted alongside the hydraulic cylinder as shown in Figures 35 and 36.

The transducer produces a 4-20 mA signal, which varies proportionately with the linear displacement of the cylinder to which it is rigidly attached. The PLC reads this signal and converts it to a position of the gate in degrees of travel arc from miter to recess. See the Gemco Series 940 bulletin for additional information on the transducer. The resulting gate position is displayed on the operating screen as shown in Figure 37. The miter gate graphic also rotates with the signal from the gate position transducer. 


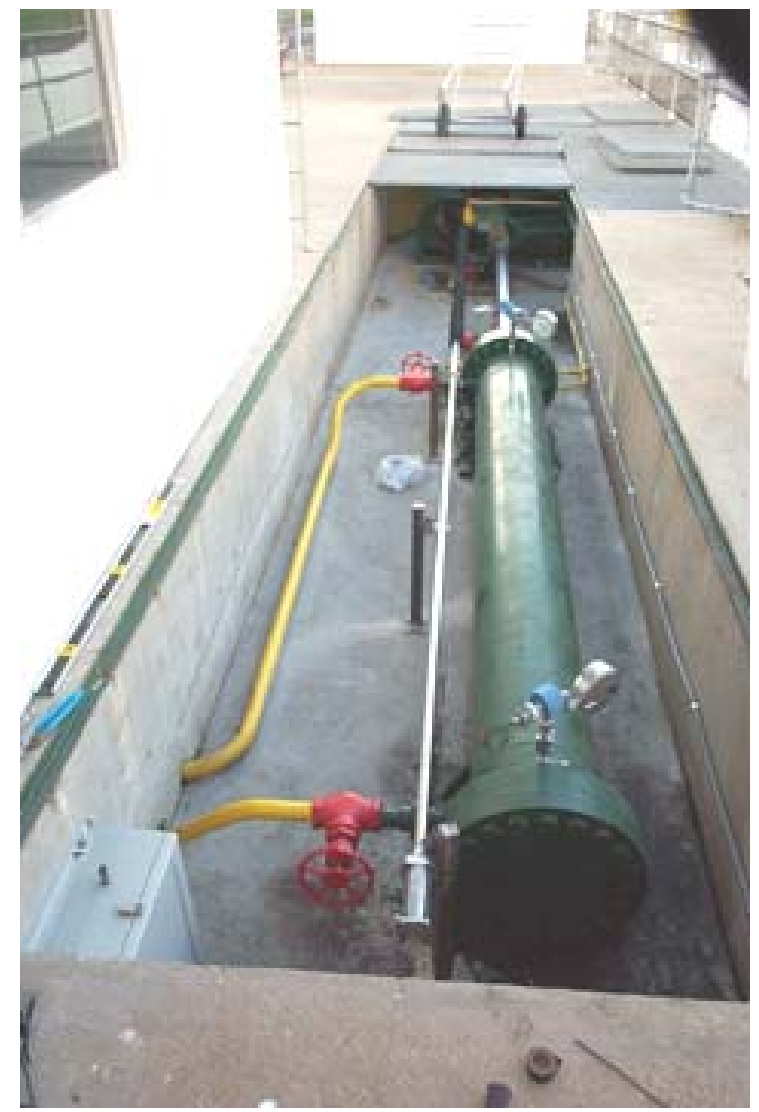

Figure 35. Linear displacement transducer.

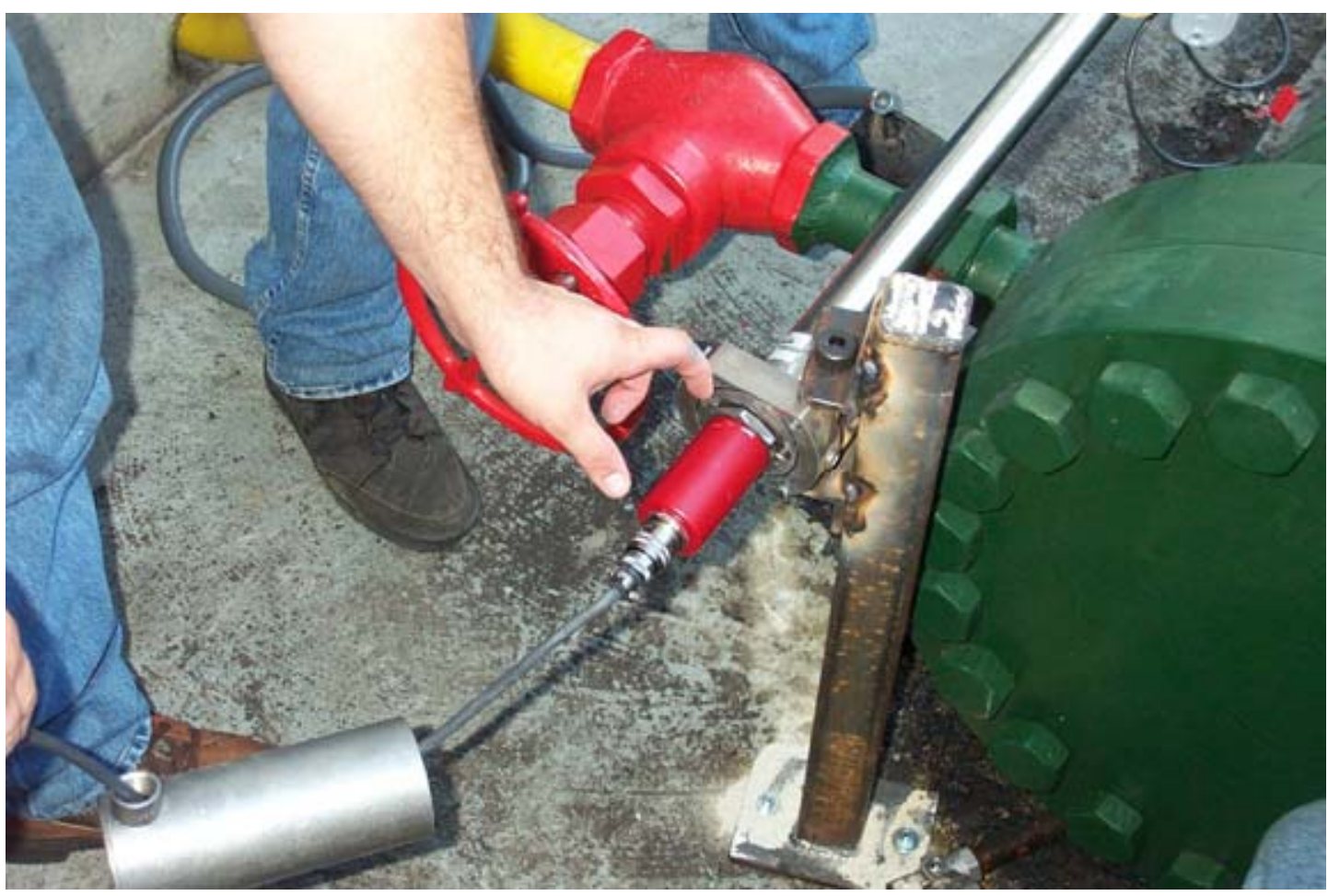

Figure 36. Close up of LDT for Miter Gate \#1 Cylinder. 


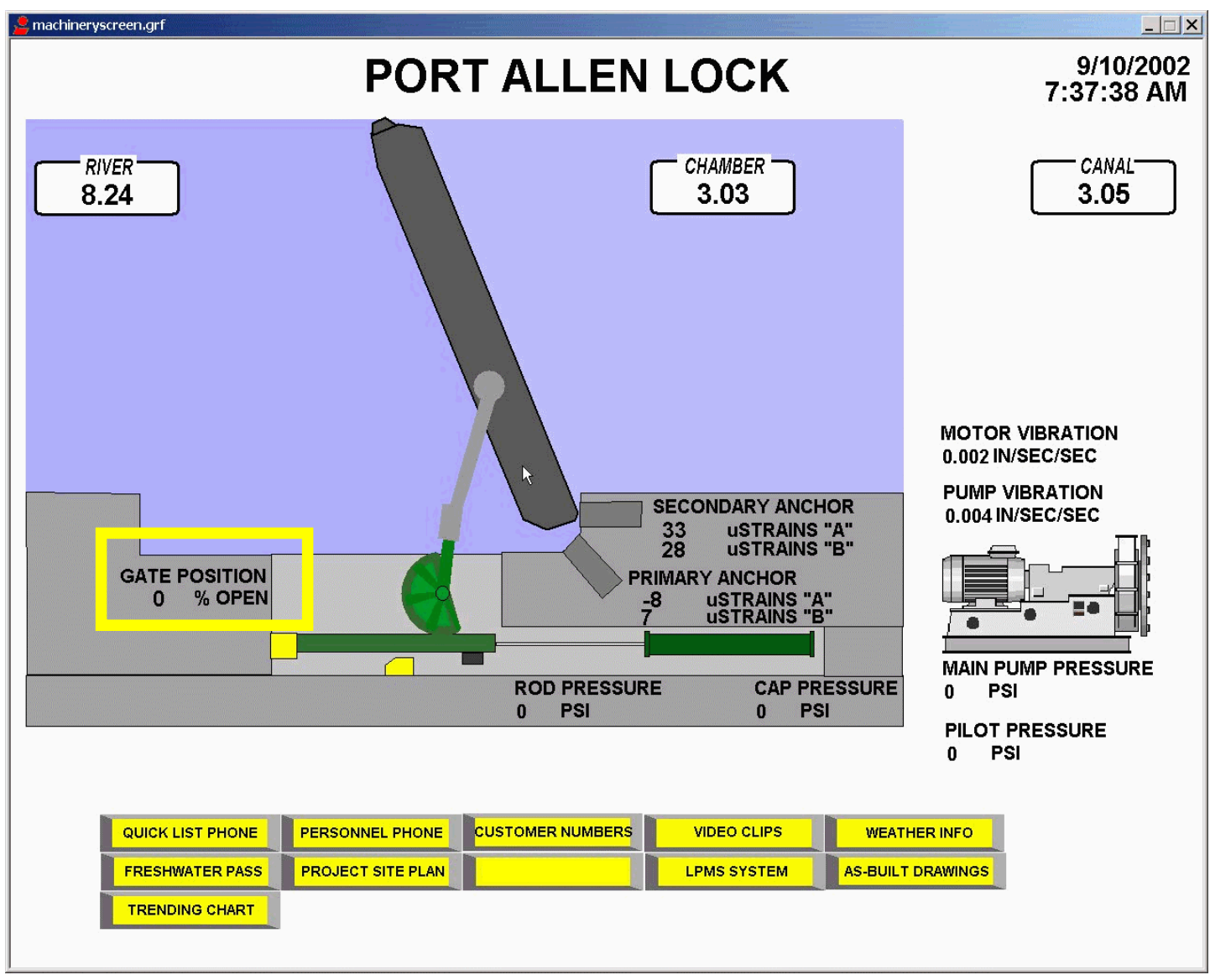

Figure 37. Port Allen operating screen showing the position of the miter gate.

\section{Programmable Logic Controller System}

The PLC system chosen for this application was the Modicon Quantum Line (Schneider Electric, Palatine, IL). This line was chosen because of its high level programming languages (compliant with the IEC 61131-3 standard), high-speed data collection, and expandability when other applications at Port Allen become funded. The St. Louis District had originally designed an entire PLC control system for Port Allen. Therefore, engineering costs were saved when it was decided to use a portion of the design for this research project. Figure 38 shows the PLC block diagram as installed for this project. The network is complete back to the temporary office of the lockmaster, location of the New Orleans District widearea network (WAN) hub. 


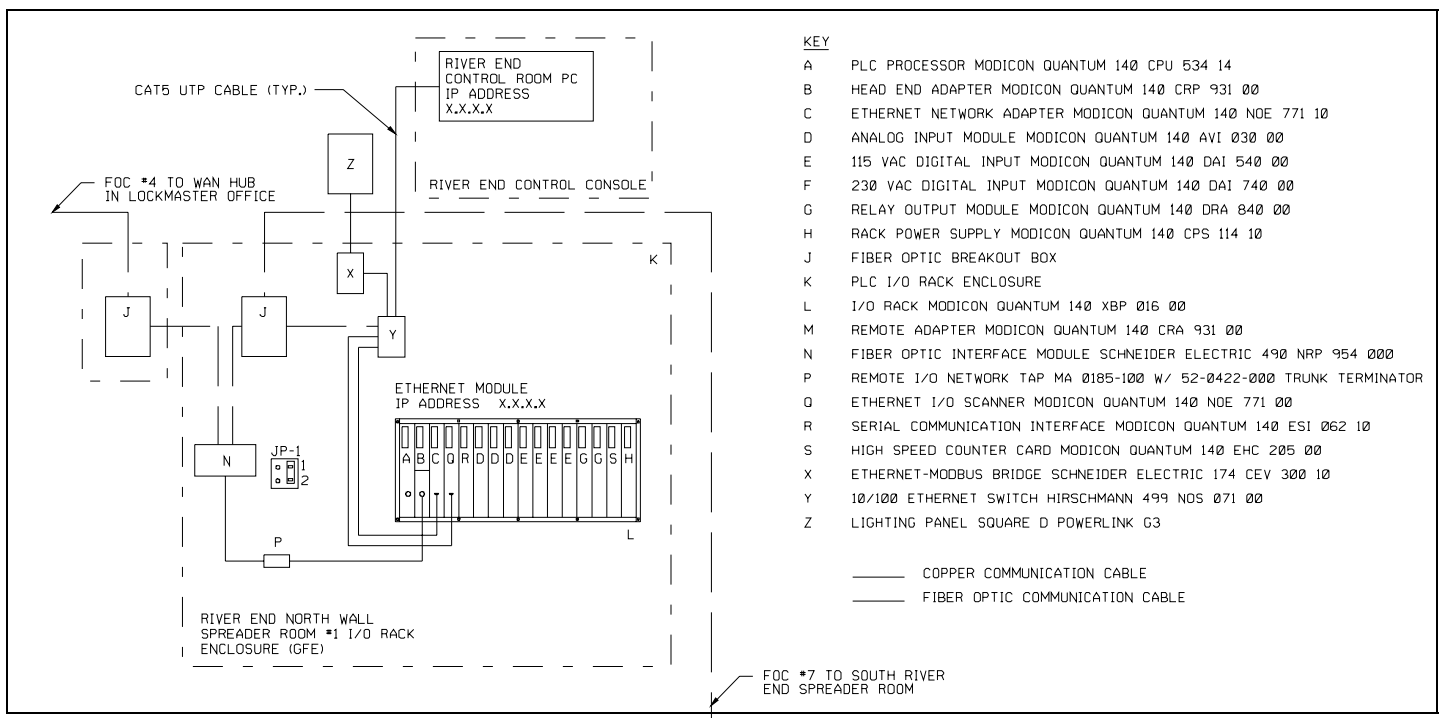

Figure 38. PLC block diagram designed for Port Allen.

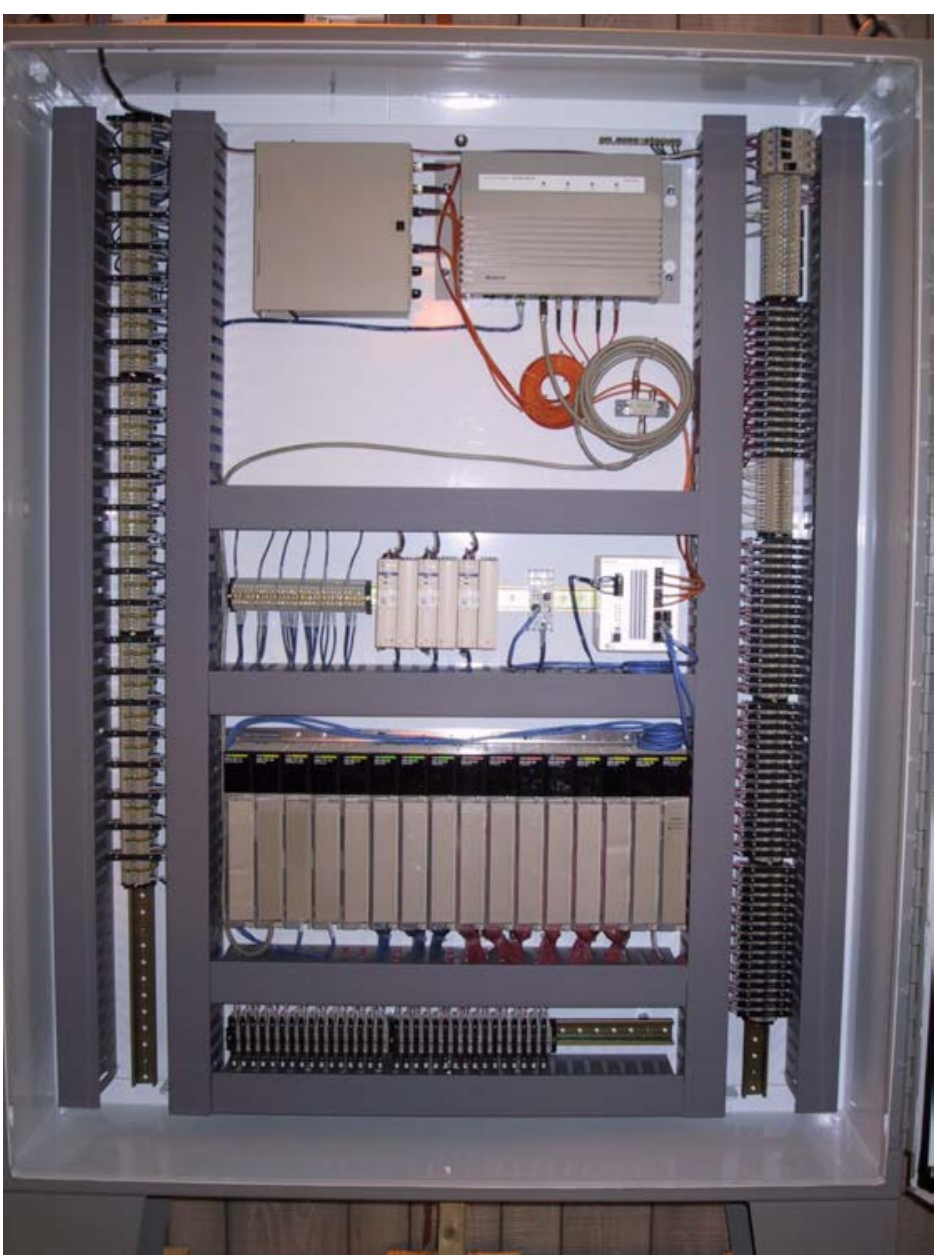

Figure 39. PLC enclosure in spreader room \#1 showing the $\mathrm{I} / \mathrm{O}$ rack. 


\section{Processor}

The processor used in this research project was a Modicon Quantum Q534-14A, the largest and best processor that Modicon made at the time it was specified. It is sized to eventually have control and instrumentation for the whole project.

\section{I/O Rack and Cards}

This project uses several different I/O cards to interface with the various signals that are generated by the transducer devices discussed previously. The cards include analog input (pressure transducers, water level transducer, vibration sensor, and gate position sensor), a high-speed counter card (strain gauges), a serial input card (weather station data collection platform), a web server Ethernet card, and a power supply. Digital I/O cards are also included in the rack for future use. See Figures 40 and 38 for a picture of the cards and a diagram delineating the model numbers.

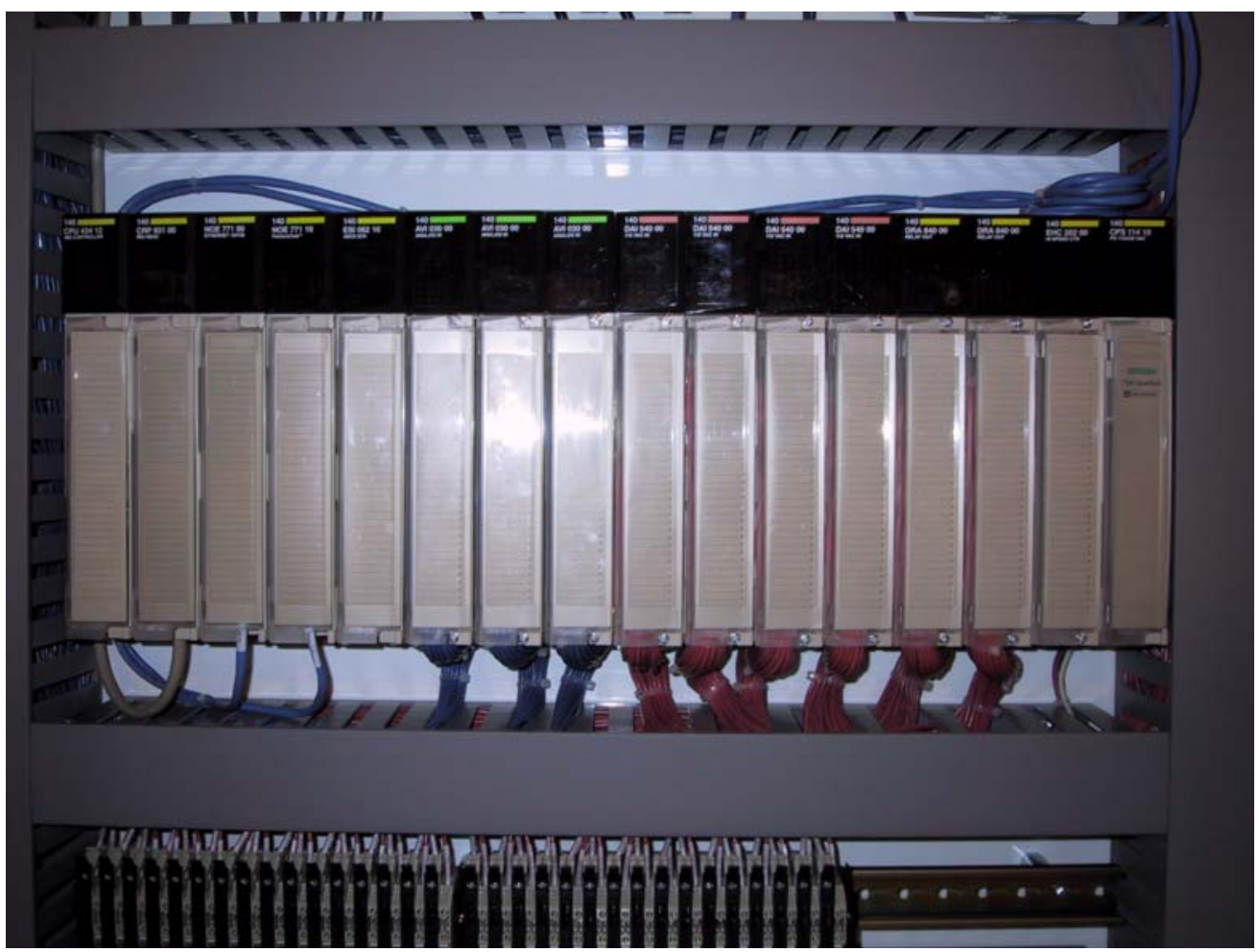

Figure 40. PLC rack showing the processor.

\section{HMI Software}

The purpose of the HMI software is to provide a high speed graphical interface for the onsite operators (as well as remote monitoring) and a robust data trend- 
ing mechanism to observe long-term changes in the operating signature of the equipment being monitored. Recall the discussion of alarms in Chapter 2. Both static and dynamic alarms are included with this project. The trending is needed to provide dynamic alarms, which are indications of long-term gradual changes in a signature curve of operation.

\section{Real-Time Monitoring}

Throughout this report are screen captures of the machinery monitoring screen on the computer interface at Port Allen Lock no. 1 control house. The screens are also available through remote monitoring. The HMI package that was used to create these screens is the iFix Dynamics ${ }^{\circledR}$ V2.6 (Intellution, Foxborough, MA). For monitoring purposes, the software simply allows the creation of graphical symbols, such as gate operating machinery, and the assignment of "tags" linked to the PLC database, which allows the real-time animation of the graphics. The screen capture in Figure 41 shows a chart that can be called up to provide either real-time graphical data or, through the use of a scroll bar, trended data over a period of time. Using an HMI package like this can allow maintenance crews to observe the various monitored parameters such as anchor strain, hydraulic pressure, and water levels, that took place during an incident prior to their shifts. An operator reports a load noise with the gate and, while there are no visual signs of problems, this feature could show what might have happened to the gate. All data are date and time stamped. 


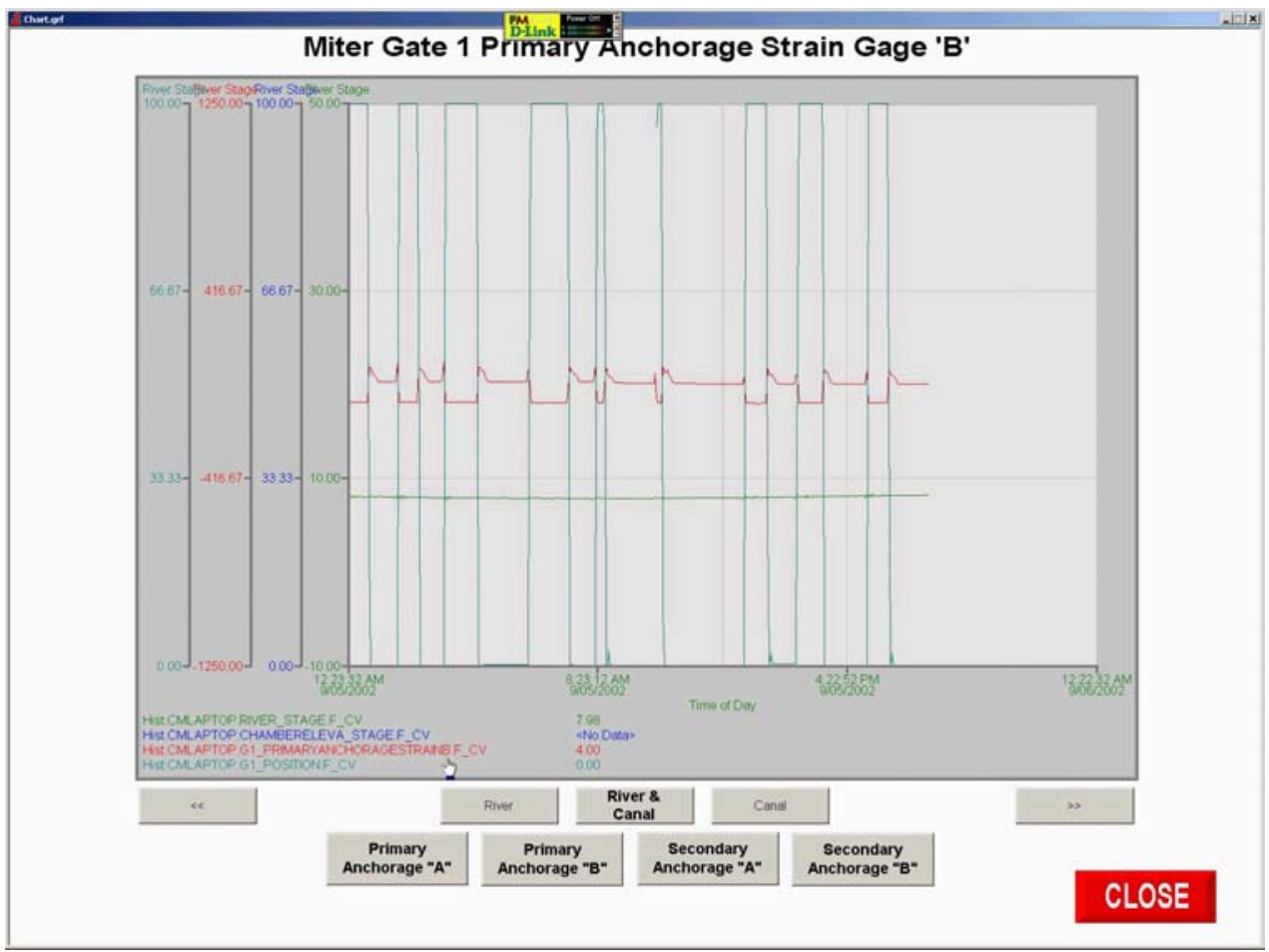

Figure 41. Screen capture of a chart showing various monitored parameters.

\section{Trending of Data}

The HMI package, Intellution's $i F i x^{\circledR}$, also has a powerful data trending package called iHistorian ${ }^{\circledR}$. This package allows the assignments of various database parameters, such as strain gauge data, to trending blocks that will record the data values on a predetermined time basis and store this information for analysis. There are other software packages, called relational databases, which will automatically analyze the data collected by iHistorian ${ }^{\circledR}$ for specific trends. For this project, only collection of the data to be used for manual analysis was done. All data are date and time stamped and can be stored in an Excel ${ }^{\circledR}$ spreadsheet for analysis. 


\section{Conclusions and Recommendations}

\section{Conclusions}

\section{Port Allen Pilot Project}

The project at Port Allen is ongoing and will continue to provide results for some time to come. At present there are no unusual operating conditions to report for the operating machinery that is being monitored for this project. That does not mean that the operating signature curves have not changed from the original baseline. From here on, the operating conditions will be compared to those in place at the time of this project, which has achieved the following goals:

- It was shown that a PLC control system can be used for high-speed collection of the data from instrumentation transducers used to monitor the condition of lock equipment. It was also shown that the funds used to provide such a condition monitoring system can overlap significantly with those used to upgrade the control system of a lock and dam. Thus one project can actually help justify the other instead of competing for funds. The Port Allen project used plans and specifications from a previous design intended to automate the lock. The engineering and material costs were therefore shared, and an overall savings will be shown when the other project is funded.

- This project showed the accuracy and real-time qualities of the data collected by the PLC system. The data were given a cursory exam by a structural engineer to ensure relevance. The changing of the strain gauges relative to the gate position is what would be expected given the type of anchorage and framing of the gate.

- The data collected can be used onsite for short-term purposes (i.e., static warnings, or stored and trended for long-term prediction of maintenance based on the changes to operating machinery conditions).

- The data can be exported in spreadsheet database form for use with other programs such as Microsoft ${ }^{\circledR}$ Excel. Structured Query Language (SQL) 
Server and $\mathrm{OPC}^{*}$ data collection platforms are also compatible with this type of data acquisition, making it flexible enough to use for virtually any application.

- The project demonstrated on a small scale that the possibility of future cost savings may be attainable from such instrumentation if applied on a global scale.

\section{Applicability of Predictive Maintenance}

While this project only slightly tapped into the possibilities of predictive maintenance at the lock and at other projects, it is believed that it did show that a good predictive maintenance program can realize O\&M savings. Total savings will depend on how well and how widely the program is used. Failures of numerous gates at major locks have been caused by abnormal operating conditions that a program such as this could have prevented. The cost for a single gate failure on a major lock could offset the cost of installing monitoring instruments on all of the machinery on the project. Some Program Managers seem to accept a $\$ 10$ million repair and an unexpected 30-day failure resulting from a gate that fails under abnormal operating conditions such as siltation. These same managers, however, balk at the cost of a predictive maintenance program that uses condition monitoring.

\section{Recommendations}

\section{Port Allen Pilot Project}

To really show the true value and savings attainable by a project like this, the scope needs to be expanded to include the entire project. At the same time, the original automation and PLC control system need to be put in place to demonstrate the savings available when combining the technologies and using the same hardware and engineering. It is recommended that further work in this area include the installation of cameras and other sensors to really show what benefits a total system can provide. Port Allen Lock, because of the current research project, is recommended for further research and as a demonstration area for an "ideal" system.

\footnotetext{
* Object Linking and Embedding for Process Control
} 


\section{Predictive Maintenance Research}

This project was really scoped as a condition monitoring project. Predictive maintenance is a higher order concept that uses the results of a good condition monitoring program. Research needs to be done in various engineering fields (i.e., structural, electrical, and mechanical) to determine how best to use these data to predict maintenance and how to automate the process to produce the most cost-effective results. 


\section{References}

Cato, William and R. Keith Mobley, 1999, Computer Managed Maintenance Systems, Southwest Missouri State University, Duane G. Meyer Library, Cape Girardeau, Missouri.

Douglas, John, 1995, "The Maintenance Revolution," Electric Power Research Institute (EPRI) Journal, Vol 20:3, 1 May 1995.

International Electrotechnical Commission (IEC), 2003, "Programmable controllers - Part 3: Programming languages," IEC 61131-3, http://www.iec.ch/.

Kumar, Ashok and Henry Cardenas, 2000, Predictive Maintenance, U.S. Army Construction Engineering Research Laboratory, Presentation from 2000 Conference Field Advisory User Group, Sheffield, Alabama.

Mobley, R. Keith, 1990, Introduction to Predictive Maintenance, Southeast Missouri State University, Kent Library, Cape Girardeau, Missouri.

National Fire Protection Association (NFPA) 70, National Electric Code, 1999.

Parks, Roy and Terry Wireman, 1997, Maintaining and Troubleshooting Electrical Equipment, Central Missouri State University, James C. Kirkpatrick Library, Warrensburg.

Patterson, Carols G., 2000, E-Maintenance - Advanced Preventive Maintenance using Electronic Technology, Panama Canal Authority.

Schimpf, Andy and Mike Sommars, 2000, Predictive Maintenance, US Army Corps of Engineers, St. Louis District, Presentation from 2000 Conference Field Advisory User Group, Sheffield, Alabama.

U.S. Army Corps of Engineers, St. Louis District, 2000, Operations \& Maintenance Manual, Melvin Price Locks and Dams.

U.S. Army Corps of Engineers, St. Louis District, 1998, Trip Report, European Initiatives in Lock Automation and Remote Control.

Warren, V., 1996, Does Predictive Maintenance Save Money?, Iris Power Engineering, Etobicoke, Ontario, Canada.

Wireman, Terry, 1990, World Class Maintenance Management, Southwest Missouri State University, Duane G. Meyer Library, Cape Girardeau, Missouri.

Wireman, Terry, 1994, Computerized Maintenance Management Systems, Southeast Missouri State University, Kent Library, Cape Girardeau, Missouri. 


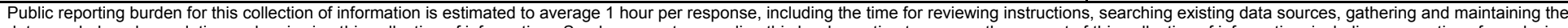

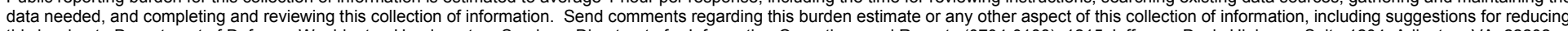

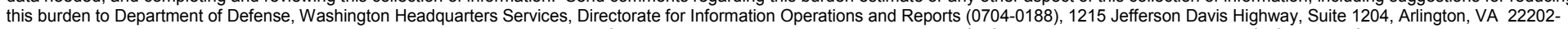

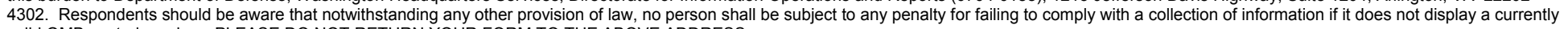
valid OMB control number. PLEASE DO NOT RETURN YOUR FORM TO THE ABOVE ADDRESS.
1. REPORT DATE (DD-MM-YYYY)
2. REPORT TYPE
3. DATES COVERED (From - To)

08-2003

4. TITLE AND SUBTITLE

Condition Monitoring Technology for Civil Works Lock Operating Machinery

Final

5a. CONTRACT NUMBER

5b. GRANT NUMBER

5c. PROGRAM ELEMENT NUMBER

6. AUTHOR(S)

Andrew Schimpf, L.D. Stephenson, and Ashok Kumar

\section{5d. PROJECT NUMBER \\ $\mathrm{CW}$}

5e. TASK NUMBER

5f. WORK UNIT NUMBER

33125

8. PERFORMING ORGANIZATION REPORT NUMBER

ERDC/CERL TR-03-19

Construction Engineering Research Laboratory (CERL)

PO Box 9005

Champaign, IL 61826-9005

\section{SPONSORING / MONITORING AGENCY NAME(S) AND ADDRESS(ES)}

U.S. Army Corps of Engineers

441 G Street, NW

Washington, DC 20314-1000

\section{DISTRIBUTION / AVAILABILITY STATEMENT}

Approved for public release; distribution is unlimited.

\section{SUPPLEMENTARY NOTES}

Copies are available from the National Technical Information Service, 5285 Port Royal Road, Springfield, VA 22161.

\section{ABSTRACT}

This pilot project successfully demonstrated condition monitoring and predictive maintenance at Port Allen Lock by installation of programmable logic controllers (PLCs) and field sensors for lock operating machinery and structural components at one of the lock's gate leafs. The need to continue such research as a more complete condition monitoring program at Port Allen Lock, and then as a part of an overall computerized control system has also been demonstrated. This study achieved the following goals:

1. It was shown that a PLC control system can be used for high-speed collection of the data from instrumentation transducers used to monitor the condition of lock equipment. It was also shown that the funds used to provide such a condition monitoring system can overlap significantly with those used to upgrade the control system of a lock and dam. Thus, one project can actually help justify the other instead of competing for the same funds.

2. This project showed the accuracy and real-time qualities of the data collected by the PLC system.

3. The data collected can be used onsite for short-term purposes such as static warnings as well as being stored and trended for long-term prediction of maintenance based on the changes to operating machinery conditions.

4. The data can be exported in spreadsheet database form for use with other programs such as Microsoft ${ }^{\circledR}$ Excel. SQL Server and OPC data collection platforms are also compatible with this type of data acquisition making it flexible enough to use for virtually any application.

The project demonstrated on a small scale that the possibility of future cost savings might be attainable from such instrumentation if applied on a global scale.

\section{SUBJECT TERMS}

civil works, maintenance and repair, condition assessment, programmable logic controllers (PLCs), locks and dams, predictive maintenance, Port Allen Lock, LA, data collection

\begin{tabular}{|c|c|c|c|c|c|}
\hline \multicolumn{3}{|c|}{ 16. SECURITY CLASSIFICATION OF: } & \multirow{2}{*}{$\begin{array}{l}\text { 17. LIMITATION } \\
\text { OF ABSTRACT } \\
\text { SAR }\end{array}$} & \multirow{2}{*}{$\begin{array}{l}\text { 18. NUMBER } \\
\text { OF PAGES } \\
70\end{array}$} & $\begin{array}{c}\text { 19a. NAME OF RESPONSIBLE PERSON } \\
\text { Ashok Kumar }\end{array}$ \\
\hline $\begin{array}{l}\text { a. REPORT } \\
\text { Unclassified }\end{array}$ & $\begin{array}{l}\text { b. ABSTRACT } \\
\text { Unclassified }\end{array}$ & $\begin{array}{l}\text { c. THIS PAGE } \\
\text { Unclassified }\end{array}$ & & & $\begin{array}{l}\text { 19b. TELEPHONE NUMBER (in- } \\
\text { clude area code) } \\
(217) 373-7235\end{array}$ \\
\hline
\end{tabular}

